\title{
Impacts of non-renewable resource extraction on shrubland songbird nest success and abundance
}

\author{
Ryan Douglas Davis \\ West Virginia University
}

Follow this and additional works at: https://researchrepository.wvu.edu/etd

\section{Recommended Citation}

Davis, Ryan Douglas, "Impacts of non-renewable resource extraction on shrubland songbird nest success and abundance" (2014). Graduate Theses, Dissertations, and Problem Reports. 296.

https://researchrepository.wvu.edu/etd/296

This Thesis is protected by copyright and/or related rights. It has been brought to you by the The Research Repository @ WVU with permission from the rights-holder(s). You are free to use this Thesis in any way that is permitted by the copyright and related rights legislation that applies to your use. For other uses you must obtain permission from the rights-holder(s) directly, unless additional rights are indicated by a Creative Commons license in the record and/ or on the work itself. This Thesis has been accepted for inclusion in WVU Graduate Theses, Dissertations, and Problem Reports collection by an authorized administrator of The Research Repository @ WVU. For more information, please contact researchrepository@mail.wvu.edu. 
Impacts of Non-renewable Resource Extraction on Shrubland Songbird Nest Success and Abundance

Ryan Douglas Davis

Thesis submitted to the Davis College of Agriculture, Natural Resources, and Design at West Virginia University in partial fulfillment of the requirements for the degree of

Master of Science

in

Wildlife and Fisheries Resources

Petra Bohall Wood, Ph. D, Chair

James T. Anderson, Ph. D

George T. Merovich, Ph. D

Division of Forestry and Natural Resources

Morgantown, West Virginia

2014

Keywords: early-successional songbirds, unconventional natural gas development, surface mines, Blue-winged Warbler, Appalachian region 


\section{ABSTRACT \\ Impacts of Non-renewable Resource Extraction on Shrubland Songbird Nest Success and Abundance}

\section{Ryan Douglas Davis}

Shrubland songbirds are a highly imperiled guild across much of North America due to wide-scale land use changes and resulting loss of shrubland habitat. Land management practices which produce early-successional habitat, namely field abandonment and clearcut timber harvests, have become increasingly uncommon in the eastern United States, and natural maintenance processes such as fires and floods are often suppressed. The Appalachian region is rich in natural resources; it has historically seen high amounts of surface mining for coal and is currently experiencing prolific development of shale gas. Both of these practices alter local habitats and the landscape, and it is essential to understand their impacts on shrubland songbirds in order to inform conservation efforts for this declining guild. Research for this thesis was composed of three studies during the breeding seasons of 2012-2013 on four shrubland sites in southwestern Pennsylvania and the northern panhandle of West Virginia. This work aimed to fill knowledge gaps in shrubland songbird ecology and responses to extractive land uses.

In my second chapter I focus on habitat selection patterns and nesting ecology of one species, the Blue-winged Warbler (Vermivora cyanoptera). This species has not been studied much outside of its antagonistic relationship to the closely related and highly imperiled Goldenwinged Warbler (Vermivora chrysoptera). A quantitative habitat selection study for the species has never been done, although knowing habitat requirements is key to effective conservation measures. I found significant differences in vegetative structure between territories and random plots using non-parametric MANOVA, indicating strong patterns of territory selection. Bluewinged Warblers placed territories in later stages of succession relative to the sites as a whole, having more woody structure, taller vegetation, more shrub, sapling, and canopy cover, and were closer to forest edge than random points.

My third chapter is a study on the impact of unconventional shale gas development on shrubland songbird nest success, abundance, and community composition. The practice of 
unconventional gas development is new to the eastern United States and has become controversial due to concern over environmental impacts, but few studies have been done on the potential effects to terrestrial biota, especially in the east. My objective was to fill a specific research gap, the impacts of development on shrubland songbirds in an already-fragmented landscape context, because this is where both shale gas development and shrubland songbirds are more likely to occur. During the 2013 breeding season, I determined the effects of gas development presence at different spatial scales on shrubland songbird nest success and community dynamics and quantified noise and light emissions from developed pads.

There were no differences in noise or light emissions between impacted and nonimpacted shrublands, or at a developed site with increasing distance from the wellpad. The presence of gas wells and related infrastructure were important influences on Field Sparrow (Spizella pusilla) nest success; survival was reduced close to the wellpad and increased near pipelines and roads. However, nest survival was higher site-wide for the Field Sparrow and other early successional species on the impacted site than on non-impacted shrublands in the region. Nest predators were important in explaining nest survival variation at the site-level. Within the developed site, nest abandonment was a more likely force near wells and a paved road, while predation better explained variation in survival by distance to the pipeline and unpaved access road. Avian communities significantly differed between impacted and non-impacted sites but the differences were not extractable from vegetative differences. Shannon's diversity and species richness did not differ between impacted and non-impacted sites and had no significant trend with increasing distance from the developed well.

Although unconventional gas extraction is new to the region, surface mining has historically been a common practice in Appalachia. Once mining has ceased, these areas stay in early succession conditions for extended durations due to poor topsoil quality, providing habitat for early-successional species which endures on the landscape much longer than habitats in abandoned fields or recent clearcuts. Reclamation of surface mines to a vegetated state is mandated by federal law, but questions have been raised on the habitat quality of the resulting areas. Many studies have assessed the use of former surface mines by various species and the success of grassland-nesting songbirds in these habitats, but none have quantitatively compared nest survival and avian community composition between former surface mines and non-mined 
shrublands. In my fourth chapter, I determined the utility of former surface mines as breeding habitat for shrubland songbirds. I performed site-level comparisons of community composition, species abundances, and nest survival of three focal species to determine if these metrics differed between former surface mines and non-mined shrublands and also between a reclaimed and a non-reclaimed former surface mine.

Whether a site was mined or not was an important factor influencing nest success, as was whether a mined site was reclaimed or not. Daily survival rates of nests for all three species were higher on mined sites and higher on the reclaimed former surface mine. Avian communities did not differ between mined and non-mined sites. Community composition on the reclaimed and non-reclaimed former surface mine sites differed, but most species were detected on both. Vegetative conditions on mined sites were broader and encompassed the range of structure at non-mined sites, providing similar habitat for species found at unmined shrublands, plus more. All sites significantly differed in vegetative characteristics. Higher nest survival on mined sites may result from the higher vegetative heterogeneity there. The reclaimed site may have had higher nest survival due to lower rodent and corvid nest predator abundances.

This research informs conservation efforts of the declining early-successional songbird guild and answers questions about the impacts of common energy extraction practices on these species. Blue-winged Warblers select conditions of later succession for nesting, which demonstrates that the early-successional sere should not be treated as a homogeneous management unit which spans only a few years after disturbance, but maintained over a range of ages on the landscape. Unconventional gas development in an already-fragmented landscape context may not degrade shrubland songbird habitat as much as it does interior forests, but does impact nest success and results in the displacement of large amounts of habitat. Former surface mines provide productive, lasting habitats for breeding shrubland songbirds that accommodate the early-successional songbird guild comparably to unmined shrublands. Shrubland songbirds can coexist with the ever-expanding extraction of fossil fuels from Appalachia if their habitat requirements are met. These species rely upon ephemeral conditions, and the key to retaining them remains management of the landscape in a dynamic fashion to provide ample habitat. 


\section{ACKNOWLEDGEMENTS}

First and foremost I thank my graduate adviser Dr. Petra Bohall Wood, for her enormous role in making this project a reality. I also thank my graduate committee, Dr. Jim Anderson and Dr. George Merovich, for their input, edits, and insight. My graduate colleagues at West Virginia University were always helpful and supportive, and I especially thank Jim Sheehan and Kyle Aldinger for their assistance in analysis and study design. These studies would not have been possible without the hard work of my field technicians and volunteers: R. Blake Hepner, Corey Johnston, Jeremy Mizel, Ian Dudley, Ashley Chattle, Anna Livingston, and Dan Sherlock.

Funding was provided by the US Department of Energy National Energy Technology Laboratory. I thank the West Virginia Cooperative Fish and Wildlife Research Unit (especially Becky Nestor, administrator extraordinaire) and West Virginia University for support, and the West Virginia Division of Natural Resources for support and cooperation. These studies were completed following approved IACUC protocols from West Virginia University (10-0201, 130102). 


\section{TABLE OF CONTENTS}

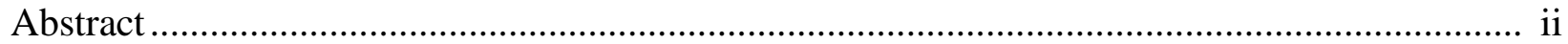

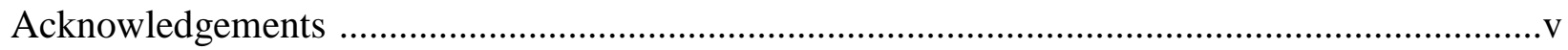

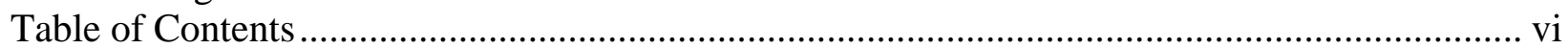

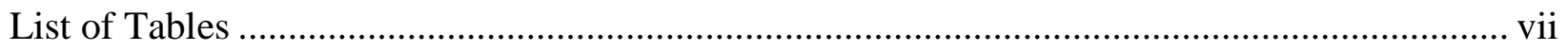

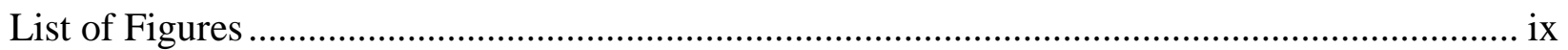

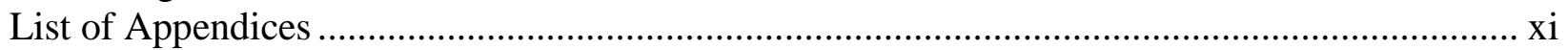

\section{Chapter 1: LITERATURE REVIEW}

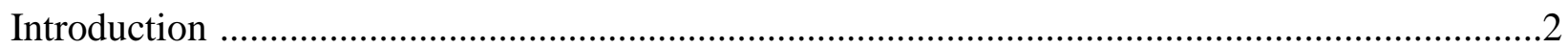

The Condition of Shrubland Birds in the Northeastern United States .........................................4

Blue-winged Warbler Habitat Selection .............................................................................

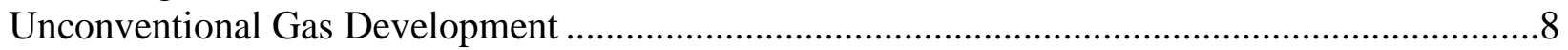

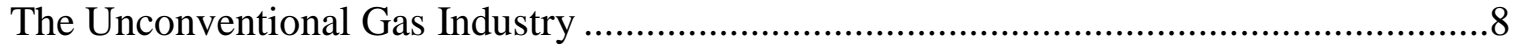

Landscape-scale Impacts of Unconventional Gas Development ..................................9

Local-scale Impacts of Unconventional Gas Development...........................................10

Former Surface Mines as Shrubland Songbird Breeding Habitat............................................12

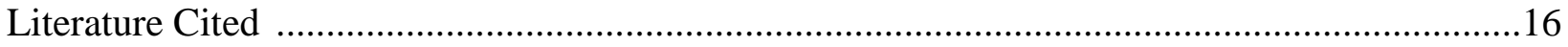

\section{Chapter 2: Nesting ECOlogy ANd Habitat Characteristics OF THE BLUE-Winged WARBLER, VERMIVORA CYANOPTERA}

Abstract .26

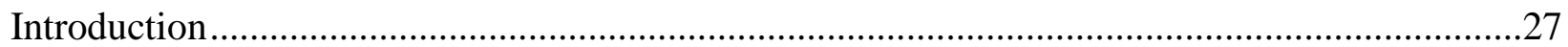

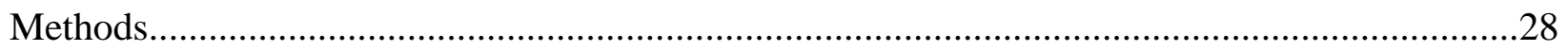

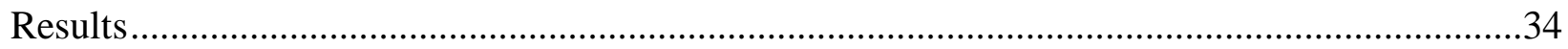

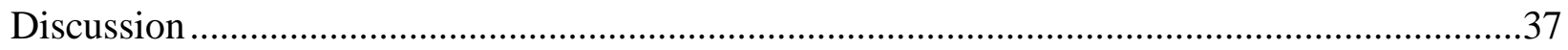

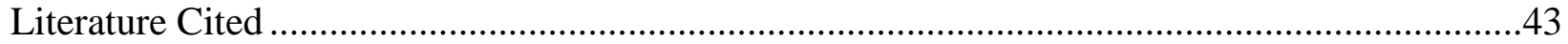

\section{Chapter 3: IMPACTS OF UNCONVENTIONAL GAS DEVELOPMENT ON EARLY-SUCCESSIONAL SONGBIRDS}

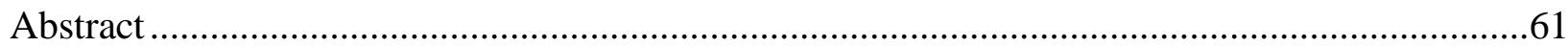

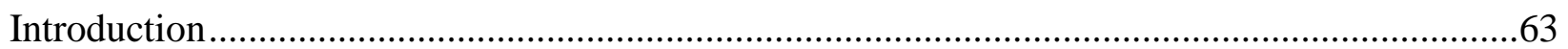

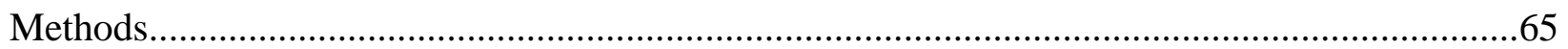

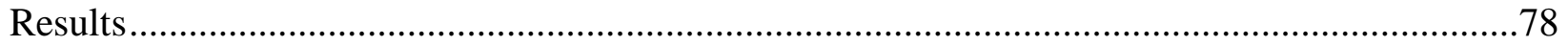

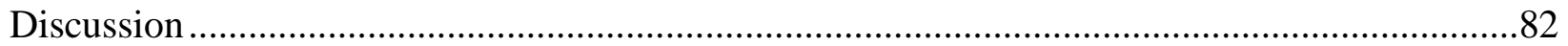

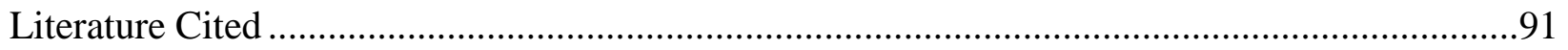




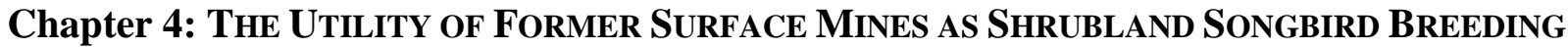 HABITAT}

Abstract ctom

\section{Chapter 2:}

\section{LIST OF TABLES}

Table 1. ANOVA results for a test of means on 22 vegetation variables by plot type (territory $\mathrm{v}$ non-territory) and site. Variables that differed between territories and random plots at $\alpha=0.0023$ are bolded for added emphasis

Table 2. ANOVA results for a test of means on 29 vegetation variables by plot type (territory $\mathrm{v}$ nest) and site. Variables that differed between nests and territories at $\alpha=0.05$ are bolded for added emphasis

Table 3. ANOVA test results for differences in means on 38 vegetation variables between successful (S) and failed (F) Blue-winged Warbler nests. None were significant, possibly due to low sample size

\section{Chapter 3:}

Table 1. Nest metrics for all species. Number of eggs/nest is the average number of eggs from all nests. Number of fledglings/nest is the average number of nestlings at the last check before fledging from all successful nests. CCWMA (Cross Creek Wildlife Management Area) was gasimpacted, HSP (Hillman State Park) and HWMA (Hillcrest Wildlife Management Area) were not. FISP $=$ Field Sparrow, BWWA= Blue-Winged Warbler, and EATO=Eastern Towhee. FISPs did not significantly differ in number of eggs $(\mathrm{F}=2.65, \mathrm{df}=3 / 75, \mathrm{P}=0.08)$ or fledglings per nest $(\mathrm{F}=0.82, \mathrm{df}=3 / 21, \mathrm{P}=0.46)$ across sites.

Table 2. Candidate models of nest survival for site-level comparisons. Models with $\Delta \mathrm{AICc}<2$ are considered to be highly supported and are bolded for emphasis. Species monitored in the shrubland guild are the Field Sparrow, Blue-winged Warbler, and Eastern Towhee.....

Table 3. Predators detected by site. CCWMA (Cross Creek Wildlife Management Area) was gasimpacted. HSP (Hillman State Park) and HWMA (Hillcrest Wildlife Management Area) were not

Table 4. Candidate models of nest survival for determining site-level mechanisms of failure. Models with $\triangle \mathrm{AICc}<2$ are considered to be highly supported and are bolded for emphasis. Species monitored are the Field Sparrow, Blue-winged Warbler, and Eastern Towhee 
Table 5. Candidate models of Field Sparrow nest survival at the gas-impacted Cross Creek Wildlife Management Area. Models with $\triangle \mathrm{AICc}<2$ are considered to be highly supported and are bolded for emphasis 101

Table 6. Candidate models of Field Sparrow nest survival at the gas-impacted Cross Creek Wildlife Management Area, incorporating effects of gas development and predation risk. Models with $\triangle$ AICc $<2$ are considered to be highly supported

\section{Chapter 4:}

Table 1. Nest metrics for all species. Number of eggs/nest is the average number of eggs from all nests. Number of fledglings/nest is the average number of nestlings from all nests that survived to the nestling stage. CCWMA (Cross Creek Wildlife Management Area) and HSP (Hillman State Park) were former surface mines. HWMA (Hillcrest Wildlife Management Area) and PRIV (Private land) were unmined shrublands. FISP = Field Sparrow, BWWA = Blue-Winged Warbler, and EATO = Eastern Towhee. Yearly total breeding season survival was derived from the model of nest survival by species and year. Survival for each site and year was derived from the model of nest survival by species, year, and site. F and $\mathrm{P}$ values are from anova models comparing among sites and accounting for year.....

Table 2. Model candidates for nest survival. Models with $\Delta \mathrm{AICc}<2$ are considered supported and are bolded for emphasis

Table 3. Predators detected by site during the 2013 breeding season. CCWMA (Cross Creek Wildlife Management Area) and HSP (Hillman State Park) were former surface mines. HWMA (Hillcrest Wildlife Management Area) was not mined

Table 4. Mean abundance comparisons for the 20 early-successional species detected over all sites. Species with significantly different abundances at $\alpha=0.0025$ are bolded for emphasis. CCWMA (Cross Creek Wildlife Management Area) was reclaimed and HSP (Hillman State Park) was not. HWMA = Hillcrest Wildlife Management Area, PRIV = Private land .

Table 5. Post-testing Kruskal-Wallis results for species found to have significantly different abundances across sites (Table 4a). Significant differences at $\alpha=0.01$ are bolded for emphasis. CCWMA (Cross Creek Wildlife Management Area) was reclaimed and HSP (Hillman State Park) was not. HWMA = Hillcrest Wildlife Management Area, PRIV = Private land. $\mathrm{df}=1$ for all tests

Table 6. Kruskal-Wallis Rank Sum results for a test of means on 23 vegetation variables over all sites. Variables that differed at the Bonferroni-adjusted $\alpha$ of 0.002 are bolded for added emphasis. CCWMA (Cross Creek Wildlife Management Area) was reclaimed and HSP (Hillman State Park) was not. HWMA = Hillcrest Wildlife Management Area, PRIV = Private land .... 143

Table 7. Post-testing Kruskal-Wallis results for vegetation variables found to have significantly different means across sites (Table 5a). Significant differences at $\alpha=0.0029$ are bolded for emphasis. CCWMA (Cross Creek Wildlife Management Area) was reclaimed and HSP (Hillman State Park) was not. HWMA = Hillcrest Wildlife Management Area, PRIV = Private land. $\mathrm{df}=1$ for all tests 


\section{Chapter 2:}

\section{LIST OF FIGURES}

Figure 1. Means and standard errors (error bars) for the 10 significantly different vegetation variables at $\alpha=0.0023$ between territory and random plots.

Figure 2. The Nonmetric Multi-Dimensional Scaling ordination of vegetation plots, overlaid with surface gradients for 10 significantly differing variables between territories and random plots at $\alpha=0.0023$. Black squares represent plots at Blue-winged Warbler territories while gray triangles represent randomly placed plots

Figure 3. The Nonmetric Multi-Dimensional Scaling ordination of vegetation plots, overlaid with surface gradients for the 3 significantly differing variables between nests and randomly placed plots within territories at $\alpha=0.05$. Gray squares represent plots at Blue-winged Warbler nests while black triangles represent randomly placed plots within territories

Figure 4. Means and standard errors (error bars) of the 3 significantly different vegetation characteristics at $\alpha=0.05$ for nest and within-territory random plots.

Figure 5. Mean and standard error (error bars) for Blue-winged Warbler nest productivity and success data for each year with sites combined. DSR=Daily Survival Rate and BSP=Breeding Season Probability of Survival.

Figure 6. Means and standard errors (error bars) for vegetation characteristics of successful (S) and failed $(\mathrm{F})$ nests

\section{Chapter 3:}

Figure 1. An aerial photograph of Cross Creek Wildlife Management Area (CCWMA), including both wells, the eight point count stations, and added approximations of infrastructure which has been added since the aerial was taken (2008).....

Figure 2. Site-wide comparison of mean and SE lux and $\mathrm{dB}$ values. There were no significant differences for either at $\alpha=0.05$. CCWMA (Cross Creek Wildlife Management Area) was gasimpacted, HSP (Hillman State Park) and HWMA (Hillcrest Wildlife Management Area) were not

Figure 3. Comparisons of daily survival rate (DSR) for Field Sparrows (FISP) and three species in the shrubland guild (Blue-winged Warbler, Eastern Towhee, Field Sparrow), derived from Program MARK models of nest survival by presence of gas development

Figure 4. Mean and SE of A) Shannon's diversity and B) species richness by site; and trends in C) Shannon's diversity and D) species richness at CCWMA (Cross Creek Wildlife Management Area) with increasing distance from the north gas well. CCWMA was gas-impacted, HSP (Hillman State Park) and HWMA (Hillcrest Wildlife Management Area) were not 105

Figure 5. NMDS ordination of avian communities from point counts, with (A) overlays of highly correlated vegetative variables and (B) bird species displayed. Species are displayed with the standardized alpha code of The Institute for Bird Populations, available online at: http://www.birdpop.org/Download Documents/Alpha_codes_eng.pdf .. 
Figure 6. Mean lux values and mean decibels recorded at each CCWMA (Cross Creek Wildlife Management Area) point, which were arrayed in increasing distances from the north gas well. There were no significant differences in either at $\alpha=0.05$

Figure 7. Minimum, mean, and maximum dB values for sampling periods at Cross Creek Wildlife Management Area, representing noise site-wide. Minimum and mean levels had significant differences by date $(\min \mathrm{F}=5.75, \mathrm{df}=1 / 44, \mathrm{P}=0.021 ;$ mean $\mathrm{F}=10.39, \mathrm{df}=1 / 44, \mathrm{P}$ $=0.002)$ but not by distance to the north wellpad $(\min \mathrm{F}=2.02, \mathrm{df}=1 / 44, \mathrm{P}=0.16$; mean $\mathrm{F}=$ 0.02 , df $=1 / 44, \mathrm{P}=0.89$ )

Figure 8. The Nonmetric Multi-Dimensional Scaling ordination of vegetation plots, overlaid with a surface gradient for distance from the north gas well and vectors representing variables which contribute most to the ordination. The 10 most highly correlated variables are shown 108

Figure 9. The predicted nest survival curves of Field Sparrows at the gas-impacted site for variables in the top four models, holding all other variables in each model constant: (A) distance to nearest well, (B) distance to the paved road, (C) distance to the pipeline, and (D) distance to the unpaved road.....

\section{Chapter 4:}

Figure 1. A comparison of daily survival rates (DSR) of all species between mined and nonmined sites, derived from the highest-ranked model which included site type; nest survival dependent on species and type. FISP= Field Sparrow, BWWA= Blue-Winged Warbler, and EATO=Eastern Towhee

Figure 2. Mean and standard error of Shannon's diversity and species richness by site and year. CCWMA (Cross Creek Wildlife Management Area) and HSP (Hillman State Park) were former surface mines. HWMA (Hillcrest Wildlife Management Area) and PRIV (Private land) were unmined shrublands

Figure 3. NMDS results of the point count data. CCWMA (Cross Creek Wildlife Management Area) and HSP (Hillman State Park) were former surface mines. HWMA (Hillcrest Wildlife Management Area) and PRIV (Private land) were unmined shrublands

Figure 4. NMDS results of vegetation plot data. CCWMA (Cross Creek Wildlife Management Area) and HSP (Hillman State Park) were former surface mines. HWMA (Hillcrest Wildlife Management Area) and PRIV (Private land) were unmined shrublands

Figure 5. A comparison of daily survival rates (DSR) of all species between the two mined sites, CCWMA (Cross Creek Wildlife Management Area) which was reclaimed and HSP (Hillman State Park) which was not reclaimed. The estimates are derived from the highest-ranked model which included site (nest survival dependent on species and site; Table 2). FISP= Field Sparrow, BWWA= Blue-Winged Warbler, and EATO=Eastern Towhee .

Figure 6. The Nonmetric Multi-Dimensional Scaling ordination of avian communities at point counts for the two mined sites, correlated with surface gradients for the significantly differing 
vegetation variables at $\alpha=0.0029$. HSP (Hillman State Park) was not reclaimed, and CCWMA

(Cross Creek Wildlife Management Area) was ................................................................ 150

Figure 7. Means and standard errors (error bars) for the significantly different vegetation variables at $\alpha=0.0029$ between the two mined sites, one of which was reclaimed and the other was not

\section{LIST OF APPPENDICES}

Appendix A. Materials cited in text

Table A1. Transformations used in ANOVAs for all variables in Blue-winged Warbler analyses

Table A2. Average nesting period length for Blue-winged Warblers at our sites, used to calculate daily survival rates and probabilities of success with the Mayfield product method, and total exposure days per period per year

Table A3. Nesting cycle data for Blue-winged Warblers across all sites; eight nests in 2012 (four failed, four successful) and six nests in 2013 (four failed, two successful).....

Table A4. The Structure loadings of the CANDISC function used to reduce and describe the north-south vegetative gradient at Cross Creek Wildlife Management Area. Structure loadings are the correlations of each variable to the resulting discriminant function

Figure A1. Study sites for both years. In 2012 research was only conducted on Hillman State Park (HSP) and private lands (PRIV). In 2013 research was only conducted on HSP, Hillcrest Wildlife Management Area, and Cross Creek Wildlife Management Area. CCWMA and HSP are former surface mines, HWMA and PRIV are shrublands which were never mined.

Figure A2. Site maps. (A) Cross Creek Wildlife Management Area (CCWMA) including both wells, the eight point count stations, and added approximations of infrastructure which has been added since the aerial was taken (2008); (B) Private Land (PRIV) including the eight point count stations (imagery from 2006); (C) Hillman State Park (HSP) including the eight point count stations (imagery from 2006); (D) Hillcrest Wildlife Management Area (HWMA) including the eight point count stations (imagery from 2005). 156

Figure A3. Site photographs. (A) Cross Creek Wildlife Management Area in early May 2013, (B) Hillman State Park in late May 2012, (C) Hillman State Park in late June 2013, (D) Hillcrest Wildlife Management Area in early May 2013, (E) Private land site in late May 2012 .......... 158

Figure A4. Mean temperatures for April and May in Northwestern WV from 1895-2013. Image is from the NOAA National Climatic Data Center, Asheville NC, web site at http://www.ncdc.noaa.gov/cag/time-series/us ....

Figure A5. The scores (top) and structure of the discriminant function which re-expresses vegetative variables at Cross Creek wildlife Management Area based on distance to the northern 
gas well. Scores are the values that each vegetation plot is reassigned in the new function, and structure shows the relative importance of each variable in determining the function

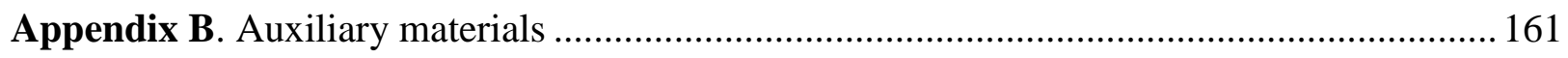

Table B1. All species detected in point counts at all sites over both years ........................... 161

Table B2. Relative abundances (mean detections per point) of species from maximum point counts. All flyovers, raptors, waterbirds, transitory migrants, and detections $>75 \mathrm{~m}$ from the observer were removed. For species codes see Table B1 


\section{CHAPTER 1}

LITERATURE REVIEW 


\section{INTRODUCTION}

Shrubland songbirds are a highly imperiled guild across much of North America due to wide-scale land use changes and resulting diminished habitat (Dettmers 2003). Shrublands can be naturally maintained in early succession by fires and floods, both of which are now typically suppressed. They are also created by humans, but through practices which have become increasingly uncommon in the eastern United States: land abandonment and clearcut timber harvests. Early seral stages of forest succession (including grasslands, shrublands, and young regenerating forests) are the most ephemeral, which compounds the plight of species which are highly specialized to these systems (DeGraaf and Yamasaki 2003). Because this habitat is rare

and ephemeral, activities which negatively impact early successional songbird populations could be detrimental across their ranges.

The Blue-winged Warbler (Vermivora pinus) is one early successional songbird species that is declining across large parts of its range (Sauer et al. 2014), but is typically only studied in the context of its often antagonistic relationship with the closely related and highly imperiled Golden-winged Warbler (Vermivora chrysoptera). The Golden-winged Warbler has habitat requirements which are similar but narrower than those of its sister species. It is faced with precipitous population losses because of diminishing habitat and genetic introgression and eventual replacement by the Blue-winged Warbler where populations meet (Buehler et al. 2007). Many studies have been conducted on Golden-winged Warbler habitat selection and population dynamics when sympatric with Blue-winged Warblers (Confer et al. 2003, Confer and Knapp 1981). We have an opportunity to add unique insight to this knowledge base by studying patterns of Blue-winged Warbler nest site selection in the absence of Golden-winged Warblers, using identical protocols as those used for the imperiled species. Few studies have focused on Blue- 
winged Warbler ecology post-extirpation of Golden-winged Warblers, but the former is declining as well and could benefit from informed habitat management. Research into Bluewinged Warbler nest site selection may also help clarify interaction dynamics with the Goldenwinged Warbler, insight which could be useful in management of the more deeply imperiled species. Additionally, habitat beneficial to breeding Blue-winged Warblers will likely also be selected by other early successional species which are currently declining, and managing for it could thus benefit the entire vulnerable guild.

Succession does not progress as quickly on poor soils, and thus land uses which remove the topsoil will harbor early successional species for longer periods of time after abandonment. This often holds true for former surface mines, which are re-vegetated at varying rates based on reclamation practices, but hold high potential as habitat for early successional species (Buehler and Percy 2012). Grassland and shrubland songbirds are known to occur on former minelands, and while the utility of these areas as breeding habitat is well-documented for the grassland guild (Bajema et al. 2001, Ammer 2003, Wray et al. 1982), there have been no studies focusing on shrubland songbird nest success there. Due to the depletion of early successional habitat discussed above, it is essential to know if shrubland songbird nest success on former mines is comparable to old-field sites, as the large amount of area which is surface mined could be reclaimed as a lifeline to this imperiled guild.

While surface mining has been common in the mid-Atlantic and northeastern United States for many years, unconventional natural gas extraction is a very new practice to the area and thus presents many questions on potential impacts which have yet to be answered. Extraction of gas from the Marcellus shale formation has increased dramatically in recent years due to technological advancements, namely hydraulic fracturing ("fracking") and horizontal drilling, 
which enable companies to reach these previously untapped deposits (GWPC and ALL Consulting 2009). These new techniques leave a much larger surface footprint than conventional oil and gas infrastructure does, and there is growing concern over the potential environmental impacts of hydraulic fracturing methods (Johnson 2010). Avian concerns mostly relate to habitat fragmentation and loss due to the large area of land that is converted from forest to well pads, gas lines, and roads. There has been an upswing in research being conducted on the various impacts of Marcellus shale gas extraction and development commensurate with growing implementation of the practice (Johnson 2010), but most examines the changes in avian communities on forested landscapes, although development frequently occurs in non-forest habitat (Drohan et al. 2012). Little research on the subject has been conducted in eastern forests, and no studies have assessed the local-scale impacts of development in an already highlyfragmented landscape context.

\section{THE CONDITION OF SHRUBLAND BIRDS IN THE NORTHEASTERN UNITED STATES}

Early-successional habitat, which includes recently-disturbed forest, naturally maintained shrublands, and old-field succession, is very valuable yet currently declining in the northeastern United States. It spans from the first growing season following a disturbance to young forests (stands where most trees are less than $12.7 \mathrm{~cm}$ in diameter, Trani et al. 2001). The shrubland stage falls between the grassland period, which has little woody vegetation, and young forest period, which is dominated by saplings. Naturally-maintained shrublands in floodplains have been largely replaced by human development and ephemeral anthropogenic shrublands have diminished due to decreasing field abandonment and clearcut harvests, and this lack of habitat heavily limits current populations of avian early-successional specialists (Dettmers 2003). Due to 
historically high abundances, early-successional species were considered to be generalists and frequently ignored in management plans in favor of managing for mature-forest-dependent species. Modern ecologists recognize that early-successional species do indeed require management, as their populations are rapidly declining where specialists of mature forests are generally increasing (DeGraaf and Yamasaki 2003). The only avian suite more imperiled is grassland birds. Since the initial BBS surveys in $1966,45 \%$ of shrubland bird species have declined across their ranges while only $2 \%$ have increased, and $25 \%$ have decreased by more than half. The most uncommon shrubland species have some of the lowest abundances in the United States, and $45 \%$ are under consideration for requiring conservation responsibility in the Northeast (Sauer et al. 2014). Early seral stages of forest succession (including grasslands, shrublands, and young regenerating forests) are the most fleeting, which compounds the plight of species which are highly specialized to these systems (DeGraaf and Yamasaki 2003); the habitat is rare and also ephemeral, becoming unsuitable for early-successional species not long after being created.

\section{BLUE-WINGED WARBLER HABITAT SELECTION}

The Blue-winged Warbler (BWWA) is one example of an early-successional forest songbird which is declining across much of the eastern United States (Sauer et al. 2014). It is a species of interest because of its close phylogenetic relationship to and interesting interactions with the highly imperiled Golden-winged Warbler (GWWA) (Hunter et al. 2001), but outside of those scopes little research has been done on the BWWA itself, especially in relation to habitat selection mechanisms. While gathering data on BWWA natural history could potentially provide 
additional insight towards GWWA conservation efforts, it too is a declining early-successional neotropical migrant and should be studied further in its own right.

As previously mentioned, much of the research conducted on BWWAs has been in studies focusing on GWWA conservation efforts because a major threat to GWWA populations is hybridization and genetic introgression with closely related BWWA (Buehler et al. 2007, Confer et al. 2003, Vallender et al. 2009). GWWA and BWWA populations are thought to have been largely sympatric until the industrial revolution swept the United States mid-19 ${ }^{\text {th }}$ century, when farmers abandoned land en masse and thus created large amounts of habitat for both species (Gill 1980). While GWWAs select habitat in the earliest stages of succession and can rarely persist beyond 30 years after disturbance, BWWAs begin colonizing habitats slightly later but select a much broader range of succession habitats and can persist twice as long after disturbance (Confer and Knapp 1981). The nature of succession is such that species adapted to earlier seres are replaced by more generalist species or those adapted to later seres, but the GWWA/BWWA case is exceptional in that the species hybridize when sympatric (Hunter et al. 2001). Genetic introgression rates can vary, and complete BWWA replacement of GWWAs typically takes 20 to 50 years but has been documented to happen in 4 to 5 (Gill 2004). Sympatric populations have been documented to exist for over a century (Confer et al. 1998), likely due to bottomland sites providing BWWA-free refuges which function as GWWA sources (Confer et al. 2010).

Allopatric populations of GWWAs do exist in areas where BWWAs are currently excluded and seem to be "safe" from likely BWWA colonization, namely high elevations in the southern Appalachians and the northernmost reaches of the GWWA range (Buehler et al. 2007). However, a recent Vallender et al. (2009) study using mitochondrial DNA found only one 
population (in Manitoba) of genetically "pure" GWWAs, where there had been no BWWA introgression, making the plight of the Golden-winged Warbler even more dire.

Studies on sympatric populations of the two species have helped clarify the ecological basis for BWWA replacement of GWWAs. A Confer and Knapp (1981) study revealed the more generalist habitat requirements of the BWWA, but noted that GWWA declines are steeper than the habitat loss rate, implicating that there may be more factors which contribute to waning GWWA populations in the sympatric zone other than simple replacement as succession proceeds. Indeed, a Confer et al. (2003) study confirmed diminishing GWWA nest success with increasing tree cover, but also showed a negative correlation between GWWA nest success and BWWA proximity and higher BHCO depredation in earlier-succession areas, where BWWAs are less likely to nest. Thus GWWAs face lower nest success on both ends of the succession timeline, due first to BHCOs and then BWWAs.

While allopatric zones of GWWA populations are small, a large effort in conservation of the species aims to maintain these areas in suitable habitat for the species (Buehler et al. 2007). After extirpation GWWAs will rarely recolonize an area, even if quality habitat exists (Confer et al. 2003). Many studies are underway in these areas which aim to assist in management decisions for the species, and we aim to generate potentially useful additional insight by examining BWWA territory and nest site selection in the absence of GWWAs.

BWWA breeding-season habitat has been described as a dense matrix of herbaceous, shrub, and sapling growth near forest edges where woody vegetation dominates (Askins et al. 2007, Confer and Knapp 1981, Confer et al. 2003, Gill et al. 2001). However, a detailed quantitative analysis of BWWA habitat selection, where vegetative composition at territories and nests are compared to available habitat site-wide, has yet to be conducted. Developing a better 
understanding of BWWA ecology in allopatric areas is important for conservation of the declining BWWA and would also aid in GWWA management and inform attempts to provide habitat for the entire suite of shrubland songbirds.

\section{UNCONVENTIONAL GAS DEVELOPMENT}

\section{THE UNCONVENTIONAL GAS INDUSTRY}

Oil and gas extraction have been a component of land use in the eastern United States since the early 1800s, and shale gas has comprised a small volume of extracted material throughout this history. Technological advances in the 1980s have allowed companies to access far more resources that were once unreachable with conventional methods. The modern, "unconventional" well uses hydraulic fracturing and horizontal drilling techniques, resulting in a much more thorough extraction of natural gas. Hydraulic fracturing entails using a highpressured slurry of water, sand, and chemicals to fracture the shale layer beneath the Earth's surface and release the natural gas locked therein, and horizontal drilling extends the horizontal reach of each well (GWPC and ALL Consulting 2009). These methods combined have dramatically increased the volumes of unconventional gas which can be extracted and have brought large-scale commercial shale gas development to the northeastern United States.

The largest shale gas basin in the United States, in square mileage of the basin and estimated recoverable gas volume, is the Marcellus play, which lies beneath 6 eastern states but is predominantly extracted in New York, Pennsylvania, Ohio, and West Virginia. Production here has expanded rapidly since unconventional methods were first applied in Pennsylvania in 2005 (GWPC and ALL Consulting 2009). This area closely overlaps with the northern two thirds of the Appalachian Mountain Bird Conservation Region, which is a very important region for 
breeding, migrating, and wintering eastern landbirds (AMBCRP 2005). Within the past decade shale gas development in this region has gone from practically non-existent to very prolific (PADEP 2011), which has raised concern amongst the public and scientific community over the long-term impacts of this increasingly pervasive land use.

\section{LANDSCAPE-SCALE IMPACTS OF UNCONVENTIONAL GAS DEVELOPMENT}

Much of the concern regarding avian species and unconventional gas development revolves around landscape-scale habitat fragmentation from the wellpads and related infrastructure. Marcellus development has a large footprint; an average of 8.8 acres of land is altered (3.1ac for the pad, 5.7ac for infrastructure such as roads and gasline right-of-ways) per wellpad. If development occurs in core forest, 21.2 acres of edge-related forest degradation can occur for each pad (Johnson 2010). Projections by Johnson (2010) estimate that by the year 2030 6,000-15,000 new pads may be developed in Pennsylvania alone, meaning that $34,000-82,000$ acres of forest could be cleared and 85,000-190,000 acres of interior forest could be lost. By these accounts $40 \%$ of contiguous forest patches larger than 5,000 acres and $20 \%$ of those larger than 1,000 acres will be perforated by Marcellus shale development in Pennsylvania (Johnson 2010). Others predict even more extensive development, with 40,000 new wells by 2030 (U.S. Department of Energy 2010). As of 2011, 38-54\% of development in Pennsylvania occurred in forest while 45-62\% has occurred on formerly agricultural land (Drohan et al. 2012). Although most shale gas development occurs on non-forested land, no studies have addressed eastern songbird responses to unconventional shale gas development in heavily fragmented landscape contexts where shrubland habitats are most likely to occur. The suite of songbirds requiring shrublands are declining (Dettmers 2003), but it is not known how these habitats are being 
impacted. Further, if already-fragmented habitats can tolerate additional anthropogenic development, the industry could potentially reduce negative impacts to forest birds by choosing fragmented landscapes more frequently for development.

Many studies have addressed the possible effects of unconventional gas development on human health (Colborn et al., 2011), air and water quality (Colborn et al., 2012, Jackson et al., 2013), hydrology (Soeder and Kappel 2009), and aquatic life (Weltman-Fahs and Taylor 2013), but research into impacts on terrestrial biota has just begun.

\section{LOCAL-SCALE IMPACTS OF UNCONVENTIONAL GAS DEVELOPMENT}

The accumulated impact of unconventional shale gas development on the landscape is a primary concern, and while local-scale impacts on wildlife immediately surrounding these developments are expected, little research has examined these events in the eastern United States. The changes in vegetative structure due to the installation of abrupt edges around the pad, roads, and pipelines may impact avian community composition. Studies on the avian responses to gaswell-impacted environments have indicated significant effects on communities, with individual species often responding in different ways. Some sensitive species such as the Greater Sage-Grouse (Centrocercus urophasianus) avoided gas development-impacted areas (Holloran 2005) likely due to acoustic masking of lekking vocalizations (Blickley and Patricelli 2012). Other species, such as Chestnut-collared Longspurs (Calcarius ornatus), had no response to gaswell-dominated landscapes, while Savannah Sparrows (Passerculus sandwichensis) were attracted to impacted areas (Hamilton et al. 2011).

The presence of humans and the accompanying increased noise levels have been implicated for many of the shifts of species towards and away from natural gas developments. 
Roads themselves can alter avian behavior (Stolen 2003) and can lead to avoidance (Ingelfinger and Anderson 2004, Benitez-Lopez et al. 2010), but the most impacts have been seen around compressor stations. These noisy infrastructures change avian occupancy, nest success, and community dynamics in intricate ways; lower species richness occurs because many species show avoidance behaviors but others can apparently tolerate the perturbation and show increased nest success (Francis et al. 2009, Francis et al. 2011) due to predator avoidance of compressor stations (Francis et al. 2012a). Cascading ecological impacts have been found to ensue; less pinion pine regeneration occurs around compressor stations in New Mexico due to Western Scrub-Jay (Aphelocoma californica) avoidance (Francis et al. 2012b). In boreal forests compressor stations created sink populations of ground-nesting Ovenbirds (Seiurus aurocapilla) (Habib et al. 2007) and had lower density and occupancy of birds compared to quiet wellpads (Bayne et al. 2008).

Compressor stations are extremely loud and are constantly producing noise, thus have a clear impact on the surrounding avian community. Thorough research has also been conducted on non-constant anthropogenic noise impacts, but the trend is much more nebulous. Birds are particularly sensitive to noise and acoustic interference because auditory communication is central to their ecology, behavior, and breeding (Slaabbekoorn and Ripmeester 2008). Anthropogenic habitat features can alter the acoustic properties of ecosystems (Kight et al. 2012), and urban birds modulate their songs in response (Wood and Yezerinac 2006). This vocal plasticity may allow some species to thrive in human settings and others without it to be excluded (Luther and Baptista 2010). Non-urban avian species have varying degrees of habituation to anthropogenic noise; Golden-cheeked Warblers (Setophaga chrysoparia) in Texas readily habituated to road construction noise (Lackey et al. 2012), while Conomy et al. (1998) 
found American Black Ducks (Anas rubripes) to habituate to aircraft noise and presence but Wood Ducks (Aix sponsa) to not adjust. Constant, chronic noise sources are less tolerable to wildlife than brief, punctuated ones (Barber et al., 2010), but direct impacts of non-constant noise on individuals seem to vary on a case-by-case basis. Increased depredation due to decreased attention stemming from background noise has been posited (Chan and Blumstein 2011), and Bisson et al. (2009) found that while heart rates of wild, free-roaming songbirds increase initially when exposed to anthropogenic noise, their mean energy expenditures were not altered.

Artificial lighting during well development also could have local-scale impacts on avian communities. Street lights can alter forest bird breeding behaviors such as singing times, egg laying, and extra-pair copulation (Kempenaers et al. 2010), but had only a small impact on marsh-nesting bird nest density (de Molenaar et al. 2006).

It is important to note that anthropogenic infrastructure such as power line right-of-ways and conventional oil pads have been found to accommodate certain songbird communities, especially ones which require canopy gaps (Thomas 2011) or early-successional vegetation (Confer and Pascoe 2003, King and Byers 2002). The net impacts of shale gas development on birds at a local scale have yet to be determined in eastern forests, and our research aims to clarify the nature of this relationship.

\section{FORMER SURFACE MINES AS SHRUBLAND SONGBIRD BREEDING HABITAT}

Former surface mines cover a large area of the United States and thus hold potential to stand in for breeding habitat of early successional species (Buehler and Percy 2012) which is otherwise rapidly diminishing (Dettmers 2003). The utility of a site for wildlife depends heavily 
on the vegetative composition, which is strongly influenced by properties of the growing substrate. The practices of mining companies once finished with a surface mine will thus strongly influence the land's utility to wildlife, so these actions are important to consider when examining population metrics on these areas. Before the passage of the 1977 Surface Mining Control and Reclamation Act (SMCRA), former mines were typically left barren. They would proceed through succession naturally and tended to follow a distinct pattern of vegetation patch establishment, patch growth, and then the coalescence of patches into a fully vegetated site (Game et al. 1982). While this process proceeds more slowly than secondary succession such as clearcut regeneration or old-field succession, Rodrigue et al. (2002) determined that these unreclaimed minelands can be planted with hardy trees and develop timber output comparable to that of non-mined forests within 60 years. The purpose of SMCRA lies largely in watershed and human health protection, and requires that mining companies must meet reclamation standards before redeeming a monetary bond. Reclamation must restore "approximate original contour", prevent or treat hydrologic detriment and environmental toxicity, and revegetate the site such that it can progress towards a future intended land use (Office of Surface Mining Reclamation and Enforcement 2010).

Many studies have found post-SMCRA surface mines to have reduced utility for certain wildlife species and have implicated the reclamation standards themselves for the shortcoming. "Smoothing" the former mineland in order to meet the contour requirement frequently results in grading and soil compaction (Daniels and Zipper 1997) and the burial of weathered, more fertile surface materials and replacement by low-quality unweathered materials as surface substrate (Leedy et al. 1981), which can make re-establishing vegetation difficult (US Forest Service 1982). Release of a mining company's bond is granted after successful reclamation 5 years after 
beginning the process, and this short-term goal to re-vegetate the site is often met by establishing aggressive non-native plants which hamper long-term vegetative community health (Holl 2002, Holl and Cairns 1994).

Reclaimed minelands often do not progress fully to forests but stay instead in early successional seres due to poor soil quality and aggressive herbaceous groundcover (Franklin et al. 2012, Zipper et al. 2011). While this may be a detriment to species which use later successional forests, it may provide quality habitat for early successional specialists, from elk (Schneider et al. 2006) to grassland birds (Stauffer et al. 2011) to herpetofauna (Walton 2012) . Indeed, Bulluck and Buehler (2006) found reclaimed surface mine sites to hold more avian diversity than clearcuts and utility right-of-ways, the other predominant anthropogenic earlysuccessional habitats in the southern Appalachians. Many studies have assessed grassland songbird populations and nest success on reclaimed minelands. Bajema et al. (2001) found large Midwestern reclaimed surface mines to support high Henslow's Sparrow (Ammodramus henslowii) populations and concluded that they formed an important component of the species' breeding range habitat. In West Virginia, Wray et al. (1982) assessed nest success and productivity levels for Grasshopper Sparrows (Ammodramus savannarum), Savannah Sparrows (Passerculus sandwichensis), Vesper Sparrows (Pooecetes gramineus), and Field Sparrows (Spizella pusilla) and found the sites to have very low productivity for all species, suggesting that the areas are likely population sinks for these species, while Ammer (2003) reported Grasshopper Sparrow nest success rates that were commensurate with those reported on other grassland habitats. Shrubland songbird nest success on former surface mines has been measured (Ingold and Dooley 2013), but there have been no studies that compare abundance or nest success on former surface mines to levels on non-mined shrublands. Reclaimed minelands 
remain in shrub/scrub habitat for a much longer period than they do in grassland, and thus the potential for breeding habitat of shrubland songbirds on these areas is even greater and needs to be examined. 


\section{LITERATURE CITED}

Ammer, F. K. 2003. Population level dynamics of Grasshopper Sparrow populations breeding on reclaimed mountaintop mines in West Virginia. Ph.D. dissertation. West Virginia University, Morgantown.

Askins, R. A., B. Zuckerberg, and L. Novak. 2007. Do the size and landscape context of forest openings influence the abundance and breeding success of shrubland songbirds in southern New England? Forest Ecology and Management 250:137-147.

Bajema, R. A., T. L. DeVault, P. E. Scott, and S. Lima. 2001. Reclaimed coal mine grasslands and their significance for Henslow's Sparrows in the American Midwest. The Auk 188:422-431.

Barber, J. R., K. R. Crooks, and K. M. Fristrup. 2010. The costs of chronic noise exposure for terrestrial organisms. Trends in Ecology and Evolution 25:180-189.

Bayne, E. M., L. Habib, and S. Boutin. 2008. Impacts of chronic anthropogenic noise from energy-sector activity on abundance of songbirds in the boreal forest. Conservation Biology 22:1186-1193.

Benitez-Lopez, A., R. Alkemade, and P. A. Verweij. 2010. The impacts of roads and other infrastructure on mammal and bird populations: a meta-analysis. Biological Conservation 143:1307-1316.

Bisson, I., L. K. Butler, T. J. Hayden, L. M. Romero, and M. C. Wikelski. 2009. No energetic cost of anthropogenic disturbance in a songbird. Proceedings of the Royal Society Biological Sciences 276:961-969. 
Blickley, J. L. and G. L. Patricelli. 2012. Potential acoustic masking of Greater Sage-grouse (Centrocercus urophasianus) display components by chronic industrial noise. Ornithological Monographs 74:23-35.

Buehler, D. A., A. M. Roth, R. Vallender, T. C. Will, J. L. Confer, R. A. Canterbury, S. B. Swarthout, K. V. Rosenberg, and L. P. Bulluck. 2007. Status and conservation priorities of Golden-winged Warbler (Vermivora chrysoptera) in North America. The Auk 124: $1439-1445$.

Buehler, D. A. and K. Percy. 2012. Coal mining and wildlife in the eastern United States: a literature review. University of Tennessee. Available online at: http://www.appalachianwildlife.com/Coal\%20Mining\%20and\%20Wildlife\%20in\%20the \%20Eastern\%20United\%20States-final\%20draft.pdf .

Bulluck, L. P. and D. A. Buehler. 2006. Avian use of early successional habitats: Are regenerating forests, utility right-of-ways and reclaimed surface mines the same? Forest Ecology and Management 236:76-84.

Chan, A. A. Y. H. and D. T. Blumstein. 2011. Attention, noise, and implications for wildlife conservation and management. Applied Animal Behaviour Science 131:1-7.

Colborn, T., C. Kwiatkowski, K. Shultz, and M. Bachran. 2011. Natural gas operations from a public health perspective. Human and Ecological Risk Assessment 17:1039-1056.

Colborn, T., K. Shultz, L. Herrick, and C. Kwiatkowski. 2012. An exploratory study of air quality near natural gas operations. Human and Ecological Risk Assessment 20:86-105.

Confer, J. L. and K. Knapp. 1981. Golden-winged Warblers and Blue-winged Warblers: the relative success of a habitat specialist and a generalist. The Auk 98:108-114. 
Confer, J. L. and S. M. Pascoe. 2003. Avian communities on utility rights-of-ways and other managed shrublands in the northeastern United States. Forest Ecology and Management 185:193-205.

Confer, J. L, J. L. Larkin, and P. E. Allen. 2003. Effects of vegetation, interspecific competition, and brood parasitism on Golden-winged Warbler (Vermivora chrysoptera) nesting success. The Auk 120:138-144.

Confer, J.L., J. Gebhards, and J. Yrizarry. 1998. Golden-winged and Blue-winged warblers at Sterling Forest: a unique circumstance. Kingbird 39:50-55.

Confer, J. L., K. W. Barnes, and E. C. Alvey. 2010. Golden- and Blue-Winged Warblers: Distribution, nesting success, and genetic differences in two habitats. Wilson Journal of Ornithology 122:273-278.

Conomy, J. T., J. A. Dubovsky, J. A. Collazo, and W. J. Fleming. 1998. Do Black Ducks and Wood Ducks habituate to aircraft disturbance? Journal of Wildlife Management 62:11351142.

Daniels, W. L., and C. E. Zipper. 1997. Creation and management of productive mine soils. Reclamation guidelines for surface mined land in southwest Virginia series. Powell River Project, Virginia Cooperative Extension. Pub. 460-121.

de Molenaar, J. G., M. E. Sanders, and D. A. Jonkers. 2006. Road lighting and grassland birds: local influence of road lighting on a Black-tailed Godwit population. Pages 114-136 in Ecological Consequences of Artificial Night Lighting (C. Rich and T. Longcore, Ed.). Island Press, Washington DC. 
DeGraaf, R. M., and M. Yamasaki. 2003. Options for managing early-successional forest and shrubland bird habitats in the northeastern United States. Forest Ecology and Management 185:179-191.

Dettmers, R. 2003. Status and conservation of shrubland birds in the northeastern US. Forest Ecology and Management 185:81-93.

Drohan, P. J., M. Brittingham, J. Bishop, and K. Yoder. 2012. Early trends in landcover change and forest fragmentation due to shale-gas development in Pennsylvania: a potential outcome for the northcentral Appalachians. Environmental Management 49:1061-1075.

Francis, C. D., C. P. Ortega, and A. Cruz. 2009. Noise pollution changes avian communities and species interactions. Current Biology 19:1415-1419.

Francis, C. D., C. P. Ortega, R. I. Kennedy, and P. J. Nylander. 2012a. Are nest predators absent from noisy areas or unable to locate nests? Ornithological Monographs 74:101-110.

Francis, C. D., J. Paritsis, C. P. Ortega, and A. Cruz. 2011. Landscape patterns of avian habitat use and nest success are affected by chronic gaswell compressor noise. Landscape Ecology 26:1269-1280.

Francis, C. D., N. J. Kleist, C. P. Ortega, and A. Cruz. 2012b. Noise pollution alters ecological services: enhanced pollination and disrupted seed dispersal. Proceedings of the Royal Society Biological Sciences. 279:2727-2735.

Franklin, J. A., C. E. Zipper, J. A. Burger, J. G. Skousen, and D. F. Jacobs. 2012. Influence of herbaceous ground cover on forest restoration of eastern US coal surface mines. New Forests 43:905-924.

Game, M., J. E. Carrel, and T. Hotrabhavandra. 1982. Patch dynamics of plant succession on abandoned surface coal mines: a case history approach. Journal of Ecology 70:707-720. 
Gill, F. B., R. A. Canterbury, and J. L. Confer. 2001. Blue-winged Warbler (Vermivoracyanoptera), The Birds of North America Online (A. Poole, Editor). Cornell Lab of Ornithology, Ithaca, New York, USA. http://bna.birds.cornell.edu.bnaproxy.birds. cornell.edu/bna/species/584doi:10.2173/bna.584 (accessed 5 December 2013).

Gill, F.B. 1980. Historical aspects of hybridization between Blue-winged and Golden-winged Warblers. The Auk 97:1-18.

Gill, F. B. 2004. Blue-winged Warblers (Vermivora pinus) versus Golden-winged Warblers ( $V$. chrysoptera) The Auk 121:1014-1018.

GWPC (Ground Water Protection Council) and ALL Consulting. 2009. Modern shale gas development in the United States: a primer. Report commissioned by the United States Department of Energy, Office of Fossil Energy and National Energy Technology Laboratory. Accessible online at: http://www.netl.doe.gov/technologies/oilgas/publications/epreports/shale_gas_primer_2009.pdf.

Habib, L., E. M. Bayne, and S. Boutin. 2007. Chronic industrial noise affects pairing success and age structure of ovenbirds Seiurus aurocapilla. Journal of Applied Ecology 44:176-184.

Hamilton, L. E., B. C. Dale, and C. A. Paszkowski. 2011. Effects of disturbance associated with natural gas extraction on the occurrence of three grassland songbirds. Avian Conservation and Ecology 6, article 7. [Online] Available at www.ace-eco.org/vol6/iss1/art7/.

Holl, K. D. 2002. Long-term vegetation recovery on reclaimed coal surface mines in the eastern USA. Journal of Applied Ecology 39: 960-970.

Holl, K. D. and J. Cairns Jr.. 1994. Vegetational community development on reclaimed coal surface mines in Virginia. Bulletin of the Torrey Botanical Club 121:327-337. 
Holloran, M. J. 2005. Greater Sage-Grouse (Centrocercus urophasianus) population response to natural gas field development in western Wyoming. Ph.D. dissertation, University of Wyoming, Laramie.

Hunter, W.C., D.A. Buehler, R.A. Canterbury, J.L. Confer, and P.B. Hamel. 2001. Conservation of disturbance-dependent birds in eastern North America. Wildlife Society Bulletin 29: $440-455$.

Ingelfinger, F. and S. Anderson. 2004. Passerine response to roads associated with natural gas extraction in a sagebrush steppe habitat. Western North American Naturalist 64: 385395.

Jackson, R. B., A. Vengosh, T. H. Darrah, N. R. Warner, A. Down, R. J. Poreda, S. G. Osborn, K. Zhao, and J. D. Karr. 2013. Increased stray gas abundance in a subset of drinking water wells near Marcellus shale gas extraction. Proceedings of the National Academy of Sciences of the United States of America 110:11250-11255.

Johnson, N.. 2010. Pennsylvania Energy Impacts Assesment, Report 1: Marcellus Shale Natural Gas and Wind. The Nature Conservancy. Online, available at http://www.nature.org/media/pa/tnc_energy_analysis.pdf.

Kempenaers, B., P. Borgstrom, P. Loes, E. Schlicht, and M. Valcu. 2010. Artificial night lighting affects dawn song, extra-pair siring success, and lay date in songbirds. Current Biology 20:1735-1739.

Kight, C. R., M. K. Hinders, and J. P. Swaddle. 2012. Acoustic space is affected by anthropogenic habitat features: Implication for avian vocal communication. Ornithological Monographs 74:47-62. 
King, D. I. and B. E. Byers. 2002. An evaluation of powerline rights-of-way as habitat for earlysuccessional shrubland birds. Wildlife Society Bulletin 30:868-874.

Lackey, M. A., M. L. Morrison, Z. G. Loman, B. A. Collier, and R. N. Wilkins. 2012. Experimental determination of the response of Golden-cheeked Warblers (Setophaga chrysoparia) to road construction noise. Ornithological Monographs 74:91-100.

Leedy, D. L., T. M. Franklin, W. T. Mason, J. R., and C. T. Cushwa. 1981. Coal surface mining reclamation and fish and wildlife relationships in the eastern United States. Voume II: Opportunities and approaches for fish and wildlife planning and management in coal surface mining reclamation and postmining land uses. Office of Biological Services, Fish and Wildlife Service, U.S. Department of the Interior. Washington, D.C., USA.

Luther, D. and L. Baptista. 2010. Urban noise and the cultural evolution of bird songs. Proceedings of the Royal Society Biological Sciences 277:469-473.

Office of Surface Mining Reclamation and Enforcement. 2010. Surface Mining Control and Reclamation Act of 1977 (Public Law 95-87). U.S. Department of Interior, Washington, D.C., USA. Available online at: http://www.osmre.gov/topic/SMCRA/SMCRA.shtm PADEP (Pennsylvania Department of Environmental Protection) 2011. Oil and Gas Well Drilling and Production in Pennsylvania Fact Sheet. Accessible online at: http://www.elibrary.dep.state.pa.us/dsweb/Get/Document-83620/5500-FS-DEP2018.pdf.

Rodrigue, J. A., J. A. Burger, and R. G. Oderwald. 2002. Forest productivity and commercial value of pre-law reclaimed mined land in the eastern United States. Northern Journal of Applied Forestry 19:106-114. 
Sauer, J. R., J. E. Hines, J. E. Fallon, K. L. Pardieck, D. J. Ziolkowski, Jr., and W. A. Link. 2014. The North American Breeding Bird Survey, Results and Analysis 1966 - 2012. Version 02.19.2014 USGS Patuxent Wildlife Research Center, Laurel, MD.

Slaabbekoorn, H. and E. A. P. Ripmeester. 2008. Birdsong and anthropogenic noise: implications and applications for conservation. Molecular Ecology 17:72-83.

Soeder, D. J. and W. M. Kappel. 2009. Water resources and natural gas production from the Marcellus Shale. U.S. Department of the Interior, U.S. Geological Survey, Reston, VA.

Stolen, E. D. 2003. The effects of vehicle passage on foraging behavior or wading birds. Waterbirds: The International Journal of Waterbird Biology 26:429-436.

Thomas, E. H. 2011. Effects of oil and gas development on songbird abundance in the Allegheny national forest. M.S. Thesis, Pennsylvania State University, State College.

Trani, M. K., R. T. Brooks, T. L. Schmidt, V. A., Rudis, C. M., Gabbard. 2001. Patterns and trends of early successional forests in the eastern United States. Wildlife Society Bulletin 29:413-424.

United States Department of Energy. 2010. Projecting the economic impact of Marcellus shale gas development in West Virginia: a preliminary analysis using publicly available data.

DOE/NETL-402033110. U.S. Department of Energy, National Renewable Energy

Laboratory. Available online at: http://netl.doe.gov/energy-analyses/pubs/ WVMarcellusEconomics3.pdf.

United States Forest Service. 1982. Wildlife user guide for mining and reclamation. U.S. Department of Agriculture, U.S. Forest Service, Intermountain Forest and Range Experiment Station, Ogden, Utah, USA. General Technical Report INT-126. 
Vallender, R., S. L. Van Wilgenburg, L. P. Bulluck, A. Roth, R. Canterbury, J. Larkin, R. Fowlds, and I. J. Lovette. 2009. Extensive rangewide mitochondrial introgression indicates substantial cryptic hybridization in the Golden-winged Warbler (Vermivora chrysoptera). Avian Conservation and Ecology 4:4. Available at: http://www.aceeco.org/vol4/iss2/art4/.

Weltman-Fahs, M. and J. M. Taylor. 2013. Hydraulic fracturing and brook trout habitat in the Marcellus Shale region: potential impacts and research needs. Fisheries 38:4-15.

Wood, W. E., and S. M. Yezerinac. 2006. Song Sparrow (Melospiza melodia) song varies with urban noise. The Auk 123:650-659.

Wray, T. II, K. A. Strait, and R. C. Whitmore. 1982. Reproductive success of grassland sparrows on a reclaimed surface mine in West Virginia. Auk 99:157-164.

Zipper, C. E., J. A. Burger, J. G. Skousen, P. N. Angel, C. D. Barton, V. Davis, and J. A. Franklin. 2011. Restoring forests and associated ecosystem services on Appalachian coal surface mines. Environmental Management 47:751-765. 


\section{CHAPTER 2}

Nesting ECology and Habitat Characteristics of THE BLUE-Winged

WARBLER, VERMIVORA CYANOPTERA 
ABSTRACT.--- Early successional songbirds are a highly imperiled group in need of active management across North America. Developing an understanding of each species' unique habitat selection patterns and natural history is key to effective conservation measures, but this has not yet been accomplished for the Blue-winged Warbler (Vermivora cyanoptera) outside of the context of research on the closely related and highly vulnerable Golden-winged Warbler (Vermivora chrysoptera) or descriptive studies which do not compare selected to available habitats. To fill these gaps in knowledge, we conducted a study of Blue-winged Warbler territory and nest-site selection and nesting ecology on early-successional habitats in southwestern Pennsylvania and the northern panhandle of West Virginia during the 2012 and 2013 breeding seasons. We found that vegetative structure on territories differed significantly from plots placed randomly in the available shrublands $(P=0.001)$, and means of 16 of 22 vegetative variables differed significantly at $\alpha=0.05$. Blue-winged Warblers placed territories in later stages of succession relative to the sites as a whole, having more woody structure, taller vegetation, more shrub, sapling, and canopy cover, and were closer to forest edge than random points. Vegetative characteristics did not differ significantly between nest sites and randomly placed plots within territories $(P=0.29)$, and only three of the 29 vegetative variables differed significantly at $\alpha=$ 0.05. Nests were placed in areas of taller herbaceous growth and higher levels of Rubus and sapling cover. Successful nests were closer to mature forest edges and in denser vegetation than failed nests. Mayfield probability of success was $46 \%( \pm 18 \%)$ in 2012 and $25 \%( \pm 17 \%)$ in 2013 , which are similar to rates reported in the literature. Median nesting cycle initiation occurred about a week and a half later in 2013 (20 May, as opposed to 8 May in 2012), possibly due to weather influences, and may help explain the disparity in success rates. Blue-winged Warblers selected specifically for later stages of early succession. Maintenance of early-successional habitat over a range of ages on the landscape, rather than treating the entire period as a homogenous management unit which spans only a few years after disturbance, would provide breeding habitat for BWWAs in addition to species which specialize in earlier stages of the sere.

KEY WORDS: Appalachian region, Blue-winged Warbler, Habitat Selection, Nest-site Selection, Early-successional Songbirds 


\section{INTRODUCTION}

Shrubland songbirds are a highly imperiled guild across much of North America due to wide-scale land use changes and resulting loss of early successional habitat (Dettmers 2003), the sere spanning from the first growing season following a disturbance to young forest conditions (stands where most trees are less than $12.7 \mathrm{~cm}$ in diameter, Trani et al. 2001). The shrubland stage falls between the grassland period, which has little woody vegetation, and young forest period, which is dominated by saplings. Nearly half of shrubland bird species have declined over the past 50 years, and the less common species of this suite have some of the lowest abundances in the United States (Sauer et al. 2014). Creation and maintenance of early successional habitat has accordingly become a priority (DeGraaf and Yamasaki 2003).

The Blue-winged Warbler (Vermivora cyanoptera, BWWA) is one example of an earlysuccessional songbird which is declining across much of the eastern United States (Sauer et al. 2014). It is a species of interest because of its close phylogenetic relationship to and interactions with the highly imperiled Golden-winged Warbler (Vermivora chrysoptera, GWWA) (Hunter et al. 2001). A major threat to Golden-winged Warbler populations is hybridization and genetic introgression with the closely related BWWA (Confer et al. 2003, Vallender et al. 2009). Studies in sympatric populations have revealed BWWAs to have higher breeding success in a slightly later period of early succession than the GWWA and to select a much broader range of habitats (Confer and Knapp 1981, Confer et al. 2003).

BWWA breeding-season habitat has been described as a dense matrix of herbaceous, shrub, and sapling growth near forest edges where woody vegetation dominates (Askins et al. 2007, Confer and Knapp 1981, Confer et al. 2003, Gill et al. 2001). However, a detailed quantitative analysis of BWWA habitat selection, where vegetative composition at territories and 
nests are compared to available habitat site-wide, has yet to be conducted. Developing a better understanding of BWWA ecology in allopatric areas is important for conservation of the declining BWWA and would also aid in GWWA management and inform attempts to provide habitat for the entire suite of shrubland songbirds.

We aim to 1) describe territory selection patterns of BWWAs by comparing vegetative characteristics within territories to those available across our shrubland sites, 2) describe patterns of nest site selection within territories, and 3) investigate BWWA nesting ecology by measuring productivity metrics. Fulfilling these objectives will provide valuable information to managers attempting to increase habitat for BWWAs and may yield insights into management for earlysuccessional songbirds at large.

\section{METHODS}

STUDY AREA

The study was conducted on shrubland sites in southwestern Pennsylvania and the northern panhandle of West Virginia (Appendix Fig. A1), a largely agricultural and developed landscape in the Appalachian Mountains Bird Conservation Region (AMBCRP 2005) with low elevation (average $\sim 325 \mathrm{~m}$ ) and rolling topography. We sampled two sites in 2012 in PA, one on 118 ha of private land which was historically managed for grazing and is currently a mix of mature forest and early succession (PRIV), and one on 237 ha of a former surface mine which was abandoned without reclamation in the late 1960s and is now also partially in early succession and partly in forest (Hillman State Park, HSP). In 2013, we sampled at HSP and an additional site in WV, 158 ha of shrubland on a former surface mine that was reclaimed in the late 1980s primarily with autumn olive (Eleagnus umbellata) and tall fescue (Festuca arundinacea) (Cross Creek Wildlife Management Area, CCWMA) (Appendix Fig. A2). 
The shrubland areas of PRIV, HSP, and CCWMA consisted predominantly of exotic woody shrubs, mainly bush honeysuckle (Lonicera spp.) and autumn olive, which occurred in clusters in open areas of grass and forbs. While PRIV was dominated by invasive vegetation, it also had some native woody shrubs, namely hawthorn (Crataegus spp.), and moderate amounts of Rubus and regenerating hardwood trees (Appendix Fig. A3).

\section{FIELD METHODS}

Nest Monitoring.--- Blue-winged Warbler nests were searched for and monitored from early May to mid-June. We followed the protocols of Martin and Geupel (1993) and Martin et al. (1997) to minimize risk of increasing depredation or abandonment. Nest searching was opportunistic throughout shrublands on the study areas and based on pair behavior; observers watched adults of the focal species which exhibited signs of breeding such as aggression or carrying nest material until the nest was found. Once found, the contents of each nest were checked every other day. We anticipated projected fledge dates based on nestling development and considered a nest successful if at least one fledgling was visually confirmed after this date. Failures were recorded to have occurred on the day between the last two nest checks.

Territory Delineation.--- Territories were delineated for each Blue-winged Warbler pair by conducting 30-min burst sampling (Barg et al. 2005), which was successfully used by Bulluck and Buehler (2008) to map territories of Golden-winged Warblers. Individual males were observed for 30 minutes between dawn and 1000 and UTM locations of males were marked every three minutes, yielding a minimum of 10 locations possible per day. Frequently used perches that were missed during the burst sampling were also recorded. Each territory was mapped at least five times during the territorial period (1 May to 15 June) at different times in the morning to account for daily variation in use, and were not mapped twice within the same 
week in order to account for variation across the breeding season. This continued until at least 50 locations were gathered. Territories were delineated for all pairs with a nest, which was confirmed to belong to a BWWA only if the female was observed on it. We created minimum convex polygons using the Geospatial Modelling Environment platform (Beyer 2012) in ArcGIS 10.1 (ESRI 2012) from the burst-sampling points to generate a polygon of the BWWA territory. We then generated a random point within each polygon at which to sample vegetation.

Vegetation Sampling.--- We measured a variety of vegetative characteristics to assess as possible components of habitat selection, following a sampling protocol adapted largely from the Golden-winged Warbler Working Group (Bulluck and Buehler 2008) with additional measurements from James and Shugart (1970) and Martin et al. (1997). Vegetation sampling began after the BWWA nesting period ended to avoid disturbing active nests. Territory plots were centered at confirmed nests and at the randomly generated point within each territory. Random plots were randomly generated points placed to cover all available shrubland areas which were searched for nests. We used the Geospatial Modelling Environment platform (Beyer 2012) in ArcGIS 10.1 (ESRI 2012) to generate a 1-ha grid over the searched shrubland area and generated one random sampling point within each cell.

From the center of each plot, we measured distance to nearest habitat edge (the three types being forest, shrubland, or field/developed) using a rangefinder and the litter depth in each cardinal direction at $1 \mathrm{~m}$ from plot center, and visually estimated the percentage of canopy closure (including only trees with diameter at breast height $(\mathrm{DBH})>10 \mathrm{~cm})$ directly above plot center. We visually estimated the ground cover within $1 \mathrm{~m}$ of each plot center, to the $1 \%$ level, as the percentage of the ground covered by each of the following categories which sum to $100 \%$ : 
litter (leaves or dead grass), grass, bare (ie rock, pavement), forbs, woody (live stems), vines, and Rubus.

Within the $11.3 \mathrm{~m}$ radius of all plot centers, we recorded the DBH and species of each canopy tree which had a DBH $>10.0 \mathrm{~cm}$, the number of snags (standing dead trees with DBH $>10 \mathrm{~cm}$ ), and the height of the herbaceous (grass and forb), shrub-Rubus, and sapling layers by measuring an individual plant which was representative of the estimated average height of that layer. We measured plot composition, the percentage of the plot surface where a plant is present in each vegetation category (grass, forb, vine, Rubus, shrub, sapling, or canopy), by recording the number of times that each was encountered at marked $1.1 \mathrm{~m}$ intervals radiating from plot center in each cardinal direction. Percentages in these categories do not sum to 100 because they are recorded separately for each category.

Within $5 \mathrm{~m}$ of each plot center, we tallied species and number of individuals $>1 \mathrm{~m}$ tall of shrubs and saplings. We used two categories for shrubs, those 1-2 $\mathrm{m}$ tall and those $>2 \mathrm{~m}$ tall, because shrub height can be linked to stage of succession. Understory species richness was the sum of the number of unique species for each of the three categories.

We measured vertical vegetation density in each cardinal direction at $10 \mathrm{~m}$ from each plot center with a cover-board that was $2 \mathrm{~m}$ tall and $0.4 \mathrm{~m}$ wide, divided into twenty $0.2 \times 0.2 \mathrm{~m}$ squares. Number of squares at least $50 \%$ obscured by vegetation were tallied. We averaged the four values to calculate vegetation density for the plot.

At nest plots, we recorded the height of the nest, substrate (defined as the plant which supports or provides the main structure for the nest) height and species, all plant species responsible for concealing the nest, the percentage of the nest concealed by vegetation from above and at each cardinal direction (estimated $1 \mathrm{~m}$ away from the nest at nest-level), and the 
following metrics of the nearest shrub (the shrub with the closest stem): species, height, number of stems at $10 \mathrm{~cm}$ above the ground, width (at the maximum and perpendicular to the maximum), distance from nest to the shrub's nearest stem, and distance from nest to the shrub's nearest branch.

\section{STATISTICAL ANALYSES}

Territory Selection.--- To compare overall vegetative composition between territory and random vegetation plots, we used non-parametric MANOVAs (function adonis in the vegan library, Oksanen et al. 2012, R Development Core Team 2013). This is a Multivariate Analysis of Variance, which partitions the sums of squares of the groups in a distance matrix (Bray-Curtis coefficient) between plot types for the 22 variables that are relevant at the territory scale (Table 1), and statistically tests for differences using permutations (999).

We applied a non-metric multidimensional scaling (NMDS) ordination (function metaMDS in the vegan library, Oksanen et al. 2012, R Development Core Team 2013) to the Bray-Curtis distance matrix of the 22 vegetation variables to graphically interpret the relationships between vegetative features and territory selection. NMDS is a non-parametric, unconstrained ordination technique which represents a full dataset in a newly defined dimensional space while attempting to preserve the distances between each observation from a dissimilarity matrix (Faith et al. 1987). It places each sample point in a multidimensional space using ranked distances such that stress, a measure of the disparity between the original distance matrix and the distance in the newly ordinated space, is minimized (Clarke and Green 1988). We used a square root transformation and Wisconsin double standardization, and ran the ordination with multiple random starts to increase the chances of stability. Gradients in habitat variables identified as significant by ANOVAs (see below) were correlated to the ordination to examine 
relations for each variable (function ordisurf in the vegan library, Oksanen et al. 2012, R Development Core Team 2013).

We used a blocked ANOVA to test if plot type (territory $\mathrm{v}$ random) differed for each vegetative variable after controlling for variation due to site. Statistical significance was designated a priori to be $\alpha=0.05$, which became $\alpha=0.0023$ after applying a Bonferroni adjustment (0.05/22). Before completing the ANOVAs, normality assumptions for the variables were confirmed using histograms, quantile-quantile plots, and the Shapiro-Wilk Test (Royston 1995) and homoscedasticity assumptions were confirmed using the Fligner-Killeen Test (Conover et al. 1981). Variables which did not meet assumptions were transformed with square root, log, or arcsin functions until they did or were corrected as much as possible (all transformations used are listed in Appendix Table 1).

Nest Site Selection.--- We used the same statistical methods described for territory selection to examine nest site selection within each territory. For this analysis, we compared 29 variables (Table 2) between nests and random plots within each territory, which provides a more meaningful comparison than between nests and random plots within all available habitat (Jones and Robertson 2001). The seven variables added to the analysis described ground cover within 1 $\mathrm{m}$ of the nest, which is of interest in examining nest site selection, but was not when analyzing larger-scale territory selection. Statistical significance at $\alpha=0.05$ was adjusted with the Bonferroni method to become $\alpha=0.0015(0.05 / 29)$.

Nesting Ecology.--- We calculated the daily survival rate (DSR) using the modified Mayfield Method, which is superior to using the raw ratios of successful to failed nests because it neutralizes the bias introduced when nests are found at different points in the nesting cycle (Mayfield 1975, Johnson 1979). DSR is the inverse of the ratio of failed nests to total exposure 
days: $\mathrm{DSR}=1$-(total number of failed nests/total number of exposure days). We calculated breeding season probability of success (BSP) by raising DSR to the 24.6 power. This was the average number of days for the nesting cycle to be completed at our sites, from the laying of the first egg to fledging (Appendix Table A2). We tested for annual differences in Mayfield rates with program CONTRAST (Hines and Sauer 1989) and number of eggs, nestlings, and fledglings with ANOVAs.

We compared vegetation characteristics between successful and failed nests with the same methods as we did with territory and nest-site selection, but with successful and failed nests as the two categories being compared. We combined data from both years and all sites to increase sample size. Variables pertaining only to nest plots were added to the 29 territory variables, bringing the total to 38 (Table 3). All analyses were performed in the R Language and Environment for Statistical Computing (program R) (R Development Core Team 2013).

\section{RESULTS}

We monitored 14 nests, eight in 2012 and six in 2013. Three were on CCWMA, six on HSP, and 4 on PRIV. One pair at CCWMA had two nesting attempts. We sampled vegetation on territories delineated for 13 of the 14 nests.

Territory Selection.--- Vegetative structure differed between territory $(n=26)$ and random $(n=228)$ plots, indicating that BWWAs were displaying patterns of habitat selection (Adonis test $P=0.001)$. Sixteen of the 22 variables had significantly different means between territory and random plots after accounting for variability among sites at $\alpha=0.05$, and 10 were significant at the Bonferroni-adjusted $\alpha=0.0023$ (Table 1, Fig. 1). 
The NMDS produced an accurate ordination of the vegetative data (stress $=12 \%$ ) in two dimensions (Clarke and Green 1988). NMDS graphs of vegetation plots show clear discrimination of territories from random plots in vegetative structure for the 10 significant variables; BWWAs used a smaller range of values than available at all random plots (Fig. 2). Territories had more abundant and species-rich shrubs and saplings and had higher percentages of cover by vines, Rubus, and saplings (Table 1, Fig. 1). Territories were about $50 \%$ closer to forest edge on average, and had taller herbaceous and sapling layers. Overall, BWWAs selected territories in later stages of succession that had more woody structure, taller vegetation, and were closer to forest cover.

Nest Site Selection.--- We collected vegetation data for 13 of the 14 nests monitored. One pair was monitored during two separate nesting attempts and thus had four vegetation plots conducted within its territory, one random within-territory plot and one nest plot for each nesting attempt. Vegetative community structure between nests $(n=13)$ and random points within territories $(n=13)$ did not differ (Adonis test $P=0.286)$. The NMDS ordination was determined in two dimensions and had a stress of $19 \%$. Nests did not clearly separate from territories in ordination space (Fig. 3).

Only three of the 29 variables differed significantly in means at $\alpha=0.05$ between nest and territory plots after accounting for site-level variation, and no differences were significant at the Bonferroni-adjusted $\alpha$ of 0.0015 (Table 2). Graphs of these three variables show large apparent magnitude differences which suggest that differences were not type I errors; height of the herbaceous layer and the percentage of Rubus and sapling cover were significantly higher on nest plots (Fig. 4). While the patterns are weaker than those for territory selection, this finding 
suggests that nest sites were placed in dense microhabitats with taller grasses and forbs and higher amounts of Rubus and sapling stems.

Nesting Ecology.--- Twenty fledglings were produced from eight nests in 2012 and seven from six nests in 2013. Eight of the 14 nests failed; two during egg laying, three during incubation, and three during the nestling stage. Brown-headed Cowbird (Molothrus ater, BHCO) parasitism occurred twice, both in 2012; one nest was abandoned and classified as a failed nest and the other nest was successful and fledged BWWAs and a BHCO. In both years, failed nests were started later than successful ones, and in 2013 the median nesting cycle initiation occurred about a week and a half later (20 May, as opposed to 8 May in 2012) (Appendix Table 3).

Nest survival (BSP) did not differ by year $\left(\chi^{2}=2.33\right.$, df $\left.=1, P=0.51\right)$. Number of eggs per nest $(F=0.003$, df $=1 / 13, P=0.96)$ and number of fledglings per successful nest $(F=0.96$, df $=1 / 6, P=0.38$ ) also did not differ by year. However, overall BSP in 2013 was about half of the 2012 rate, which is likely biologically significant (Fig. 5).

BWWA nests were placed close to the ground (mean nest height $=0.1 \mathrm{~m} \pm 0.02 \mathrm{SE}$ ) in substrates which averaged about $1 \mathrm{~m}$ tall $( \pm 0.1 \mathrm{SE})$ and included Rubus, multiflora rose (Rosa multiflora), hawthorn, ash saplings (Fraxinus spp.), elm saplings (Ulmus spp.), and grass-forb clusters. Nests were placed in areas with high amounts of herbaceous cover (mean $=55.2 \% \pm$ 12.9 SE) and moderate amounts of woody (mean $=15.8 \% \pm 4.7 \mathrm{SE})$ and Rubus $($ mean $=15.3 \% \pm$ 6.5 SE) cover (Table 2).

Vegetative characteristics at successful $(n=6)$ and failed $(n=7)$ nests did not significantly differ (Adonis test $P=0.22$ ). ANOVA test results on all 38 variables showed no significant differences between successful and failed nests (Table 3). Although not statistically 
different, some variables that had an appreciable magnitude difference are of note (Table 3, Fig. 6). Failed nests had less Rubus cover, less canopy cover, and less vegetative density compared to successful nests and had more sapling and shrub stems. Failed nests were on average twice as far from forest edge as successful nests and were placed closer to the nearest shrub, but had shorter nearest shrub heights. Eighty-six percent of failed nests and 33\% of successful nests were built in woody substrates. None of the failed nests were built in grass or forb substrates, while $50 \%$ of successful nests were in grass and $17 \%$ in forbs.

\section{DISCUSSION}

We found that there were clear patterns of habitat selection for territories, but not for nest sites within territories. BWWAs placed territories in areas of later succession relative to the range of available shrubland habitat and tended to place nests in pockets of more dense low vegetation within territories. Nests in 2013 were less successful and productive than in 2012, and nesting cycles started later. There were no significant vegetation differences between failed and successful nests, but magnitude trends indicate that failed nests may have been more exposed.

Territory Selection.--- Territory selection patterns were very clear; BWWAs established territories in areas with vegetative characteristics that differed from the shrubland sites at large. Territories were placed in a limited range of all available habitat (Fig. 2) and this segregation was closely tied to gradients in vegetative structure and composition. Territory plots had more young forest features such as sapling and canopy growth and taller, denser woody vegetation, all hallmarks of the closing end of the early-successional sere. The presence of later-succession conditions in territories disproportionate to the distribution of these features at randomly placed plots demonstrates that BWWAs specialize in early successional habitats that have progressed through the first few years after disturbance. Our results aligned with other descriptive studies 
(Askins et al. 2007, Confer and Knapp 1981, Confer et al. 2003, Gill et al. 2001), which reported BWWAs to select habitat in dense mosaics of woody and herbaceous vegetation and defended territories in older, more sapling-dominated areas. However, BWWA territories on reclaimed surface mines in Kentucky had appreciably lower percentages of grass, shrub, and forb cover and shorter shrubs than those in our study (Patton et al. 2010), and moderately higher measurements of distance to forest edge and percentage of canopy cover. These differences may be due simply to site-level habitat availability differences or represent geographic disparities in habitat selection; the Patton et al. (2010) sites were at higher elevations $~ 400 \mathrm{~km}$ south of ours and the birds there may have slightly different habitat requirements.

Variables with which territories did not differ from random plots can also help elucidate microhabitat components important in territory selection. Means were not significantly different for plot composition of grass or percentage of shrubs that were non-native species, indicating that these variables were less important to BWWAs in selecting territories. Shrub layer height was not significantly different between territory and random plots while areas of taller sapling and herbaceous layers were selected for, which further supports that BWWAs select for more tree-dominated, later-succession habitats. While mean canopy closure was higher in territories (by $11.3 \%$ ), this difference was not statistically significant; BWWAs selected habitat in shrubland areas that were progressing into young forests, but with few canopy trees. BWWAs are noted to use a broader range of successional conditions relative to GWWAs, and Confer and Knapp (1981) suggested BWWAs to be generalists in the early successional guild which are tied more to forest edges than to young forest conditions in shrublands. This conclusion may be influenced by the perspective of comparing BWWA and GWWA habitat selection; however, we found BWWAs to use only a restricted range of all available habitats. The BWWAs in our study 
did exhibit affinities for areas closer to forest edge, but it may be that these zones are simply where the later-succession conditions are more likely to occur; edges are presumably seeded by mature trees at faster rates than shrubland interiors and were likely disturbed with less intensity, allowing faster regeneration of saplings and woody structure.

Nest Site Selection.--- We found little clear segregation in vegetative characteristics between nest and territory plots, which suggests that nest placement specificity may be less constrained within the territories that BWWAs have already selected. While the results of the pairwise tests on means of variables between nest and random within-territory plots were much weaker than those conducted between territory and random site-wide plots, the significant differences in three of the variables do identify patterns of within-territory nest site selection (Fig. 4). While territories were placed in more tree-dominated, later-succession areas of shrubland, nests were placed in microhabitats with disproportionately high amounts of Rubus and sapling cover and taller herbaceous layers. Some other variables that did not differ significantly did have high magnitudes of differences, which may indicate some trends in nest site selection; nest plots were in pockets of conditions within territories that were denser and related to stages of later succession. These nest-site selection patterns corroborate those detailed in descriptive studies which report nest-site vegetation as dense, shrub- and sapling-dominated areas near to or within the forest-field ecotone (Gill et al. 2001).

It is possible that BWWA territory selection for later-successional areas of shrublands was driven by the quality of these areas for use as nest sites. It may be that these pockets of denser vegetation function as protection from nest depredation, which has been suggested in other studies (Thompson 2007). Other studies have also found little segregation between songbird nest sites and territory plots, suggesting that territories may represent a bounded 
collection of potential nest sites rather than areas of optimal conditions for all habitat requirements. Habitat selection of some species is driven by nesting sites rather than foraging potential (Steele 1993), and selecting territories which hold multiple suitable nest sites may increase a male's likelihood of females pairing with them (Jones and Robertson 2001). Multiple potential nest sites within a territory may increase fecundity by decreasing predator efficiency in locating nests (Martin and Roper 1988) or providing substrates for re-nesting (Jones and Robertson 2001).

Nesting Ecology.--- The nest success rates in this study (24\% and $46 \%$ ) fall within the broad range reported by other studies of BWWAs (21-77\%; Askins et al. 2007, Confer et al. 2010, Slay 2010) and are slightly lower than those reported for GWWAs in our region (Klaus and Buehler 2001, Bulluck and Buehler 2008), but higher than those found for other shrubland songbird species at our sites during the study (RDD, unpubl. data). Drawing conclusions about nest survival and success rates is difficult due to the low sample size of nests, but rates were appreciably lower in 2013 (Fig. 5). Although all nests were initiated within the typical date range reported in the literature (Gill et al. 2001), we found pronounced temporal differences between the two years (Appendix Table 3). The nesting cycle dates in 2013 were a week or two later than those in 2012, and it is unlikely that this is due to observer bias because we began monitoring with standardized procedures on the same date both years. Because successful nests tended to start earlier than failed nests for both years, the later start dates in 2013 may have contributed to the lower productivity during the second year of the study. This makes sense ecologically; Neotropical migrant individuals which arrive earlier on breeding grounds are noted to have better chances to produce more offspring (Norris et al. 2004). Weather variation has been found to explain high amounts of variation in songbird fecundity (Chase et al. 2005), and this may have 
contributed to the disparity between years. The spring of 2012 was the sixth warmest and the $31^{\text {st }}$ driest since 1901, while 2013 was only slightly warmer and wetter than the average (National Oceanic and Atmospheric Administration National Climatic Data Center 2013, Appendix Fig. 4), and this may have influenced BWWA nesting attempts more than other factors such as habitat relationships, or perhaps contributed to later arrival and thus lower success. Annual nest success in 2013 (24\%) was about half that of the warmer $2012(46 \%)$.

The GWWA's range is steadily shifting northward and increasingly restricted to higher elevations in the central and southern Appalachians (Buehler et al. 2007, Confer et al. 2011), where BWWAs were largely absent (Hunter et al. 2001) until recent years (West Virginia Division of Natural Resources 2009). If our result of higher BWWA nest survival in a warmer season reflects a pattern of higher BWWA productivity in warmer conditions, climate change could accelerate their range expansion into higher elevations. Additionally, Bulluck et al. (2013) compared GWWA demographic rates between populations in Ontario and Tennessee and found some evidence for decreasing nest survival with increasing temperatures in the southern population but not the northern one. This could also hasten the replacement of GWWA by BWWA in the Appalachians as climate change continues.

Conclusions.---Many members of the shrubland songbird guild are declining across their ranges and require active management. Providing breeding habitat for early successional songbirds may be accomplished by periodically initiating stand disturbance through fire, mowing, or overstory removal timber harvests (Dettmers 2003, DeGraaf and Yamasaki 2003). Our study has demonstrated the partitioning of habitat even within a given successional sere; Blue-winged Warblers are specialized to establish territories in habitats which are in the later stages of young forest succession. Because all members of the early successional songbird guild 
similarly select habitats of different ages and compositions, it would be wise to plan habitat management for varying levels of succession such that the landscape holds the full spectrum of stand ages and conditions. Within-stand variation would also likely offer habitat to a higher number of species; gradual "feathered" edges for example could provide varied habitat conditions within a management unit and would provide nesting substrate for Blue-winged Warblers and other shrubland songbirds. 


\section{LITERATURE CITED}

Askins, R. A., B. Zuckerberg, and L. Novak. 2007. Do the size and landscape context of forest openings influence the abundance and breeding success of shrubland songbirds in southern New England? Forest Ecology and Management 250:137-147.

AMBCRP (Appalachian Mountains Bird Conservation Region Partnership). 2005. Appalachian Mountains Bird Conservation Initiative Concept Plan. Can be accessed online at: http://www.acjv.org/documents/bcr28_concept_plan.pdf.

Barg, J. J., J. Jones, and R. J. Robertson. 2005. Describing breeding territories of migratory passerines: suggestions for sampling, choice of estimator, and delineation of core areas. Journal of Animal Ecology 74:139-149.

Beyer, H. L. 2012. Geospatial Modeling Environment. Version 0.7.2.1. Spatial Ecology LLC. Toronto, Ontario, Canada.

Buehler, D. A., A. M. Roth, R. Vallender, T. C. Will, J. L. Confer, R. A. Canterbury, S. B. Swarthout, K. V. Rosenberg, and L. P. Bulluck. 2007. Status and conservation priorities of Golden-winged Warbler (Vermivora chrysoptera) in North America. The Auk 124:1439-1445.

Bulluck, L. P., and D. A. Buehler. 2008. Factors influencing Golden-winged Warbler (Vermivora chrysoptera) nest-site selection and nest survival in the Cumberland Mountains of Tennessee. Auk 125:551-559.

Bulluck, L., D. Buehler, R. Vallender, and R. J. Robertson. 2013. Demographic comparison of Golden-winged Warbler (Vermivora chrysoptera) populations in northern and southern extremes of their breeding range. The Wilson Journal of Ornithology 125:479-490. 
Chase, M. K., N. Nur, and G. R. Geupel. 2005. Effects of weather and population density on reproductive success and population dynamics in a Song Sparrow (Melospiza melodia) population: a long-term study. Auk 122:571-592.

Clarke, K. R., and R. H. Green. 1988. Statistical design and analysis for a "biological effects" study. Marine Ecology Progress Series 46:213-226.

Confer, J. L., K. W. Barnes, and E. C. Alvey. 2010. Golden- and Blue-Winged Warblers: Distribution, nesting success, and genetic differences in two habitats. Wilson Journal of Ornithology 122:273-278.

Confer, J. L., P. Hartman, and A. Roth. 2011. Golden-winged Warbler (Vermivora chrysoptera). The Birds of North America Online (A. Poole, Editor). Cornell Lab of Ornithology, Ithaca, New York, USA. http://bna.birds.cornell.edu.bnaproxy.birds.cornell.edu/bna/ species/020 (accessed 5 December 2013).

Confer, J. L. and K. Knapp. 1981. Golden-winged Warblers and Blue-winged Warblers: the relative success of a habitat specialist and a generalist. Auk 98:108-114.

Confer, J. L., J. L. Larkin, and P.E. Allen. 2003. Effects of vegetation, interspecific competition, and brood parasitism on Golden-winged Warbler (Vermivora chrysoptera) nesting success. Auk 120:138-144.

Conover, W. J., M. E. Johnson, and M. M. Johnson. 1981. A comparative study of tests for homogeneity of variances, with applications to the outer continental shelf bidding data. Technometrics 23:351-361.

DeGraaf, R. M., and M. Yamasaki. 2003. Options for managing early-successional forest and shrubland bird habitats in the northeastern United States. Forest Ecology and Management 185:179-191. 
Dettmers, R. 2003. Status and conservation of shrubland birds in the northeastern US. Forest Ecology and Management 185:81-93.

ESRI. 2012. ArcGIS Desktop: Release 10.1. Environmental Systems Research Institute, Redlands, California, USA.

Faith, D. P., P. R. Minchin, and L. Belbin. 1987. Compositional dissimilarity as a robust measure of ecological distance. Vegetatio 69:57-68.

Gill, F. B., R. A. Canterbury, and J. L. Confer. 2001. Blue-winged Warbler (Vermivoracyanoptera), The Birds of North America Online (A. Poole, Editor). Cornell Lab of Ornithology, Ithaca, New York, USA. http://bna.birds.cornell.edu.bnaproxy.birds. cornell.edu/bna/species/584doi:10.2173/bna.584 (accessed 5 December 2013).

Hines, J. E. and J. R. Sauer. 1989. Program CONTRAST - a general program for the analysis of several survival or recovery rate estimates. Fish and Wildlife Technical Report 24:1-7. Patuxent Wildlife Research Center, Laurel, Maryland, USA.

Hunter, W. C., D. A. Buehler, R. A. Canterbury, J. L. Confer, and P. B. Hamel. 2001. Conservation of disturbance-dependent birds in eastern North America. Wildlife Society Bulletin 29:440-455.

James, F. C. and H. H. Shugart Jr.. 1970. A quantitative method of habitat description. Audubon Field Notes 24:727-736.

Johnson, D. H. 1979. Estimating nest success: the Mayfield method and an alternative. Auk 96:651-661.

Jones, J. and R. J. Robertson. 2001. Territory and nest-site selection of Cerulean Warblers in eastern Ontario. Auk 118:727-735. 
Klaus, N. A. and D. A. Buehler. 2001. Golden-winged Warbler breeding habitat characteristics and nest success in clearcuts in the southern Appalacian Mountains. Wilson Bulletin 113:297-301.

Martin, T. E., C. J. Conway, W. M. Hochachaka, P. Allen, and W. Jenkins. 1997. BBIRD field protocols. U.S.G.S. Biological Resources Division, Montana Cooperative Wildlife Research Unit, University of Montana, Missoula, Montana, USA.

Martin, T. and G. Geupel. 1993. Nest-monitoring plots: methods for locating nests and monitoring success. Journal of Field Ornithology 64:507-519.

Martin, T. E. and J. J. Roper. 1988. Nest predation and nest-site selection of a western population of the Hermit Thrush. Condor 90:51-57.

Mayfield, H. F. 1975. Suggestions for calculating nest success. The Wilson Bulletin 87:456-466.

Norris, D. R., P. P. Marra, T. K. Kyser, T. W. Sherry, and L. M. Ratcliffe. 2004. Tropical winter habitat limits reproductive success on the temperate breeding grounds in a migratory bird. Proceedings of the Royal Society of London Biology 271:59-64.

National Oceanic and Atmospheric Administration National Climatic Data Center. 2013. Climate Monitoring, Climate at a Glance. National Oceanic and Atmospheric Administration National Climatic Data Center, Asheville, North Carolina, USA. http://www.ncdc.noaa. gov/cag/time-series/us (accessed 13 November 2013).

Oksanen, J., F. G. Blanchet, R. Kindt, P. Legendre, P. R. Minchin, R. B. O'Hara, G. L. Simpson, P. Solymos, M. H. Stevens, and H. Wagner. 2012. Vegan: Community Ecology Package. R package version 2.0-5. http://CRAN.R-project.org/package=vegan.

Patton, L. L., D. S. Maehr, J. E. Duchamp, S. Fei, J. W. Gassett, and J. L. Larkin. 2010. Do the Golden-winged Warbler and Blue-winged Warbler exhibit species-specific differences in 
their breeding habitat use? Avian Conservation and Ecology 5:2. http://www.aceeco.org/vol5/iss2/art2/.

R Development Core Team. 2013. R: A language and environment for statistical computing. R Foundation for Statistical Computing, Vienna, Austria.

Royston, P. 1995. Remark AS R94: A remark on Algorithm AS 181: The W test for normality. Applied Statistics 44:547-551.

Sauer, J. R., J. E. Hines, J. E. Fallon, K. L. Pardieck, D. J. Ziolkowski, Jr., and W. A. Link. 2014. The North American Breeding Bird Survey, Results and Analysis 1966 - 2012. Version 02.19.2014 USGS Patuxent Wildlife Research Center, Laurel, MD.

Slay, C. M. 2010. An evaluation of reproductive success, adult survivorship and habitat use of shrubland birds on conservation-managed fields in western Connecticut. Dissertation. University of Arkansas, Fayetteville, USA.

Steele, B. B. 1993. Selection of foraging and nesting sites by Black-throated Blue Warblers: their relative influence on habitat choice. Condor 95:568-579.

Thompson, F. R. III. 2007. Factors affecting nest predation on forest songbirds in North America. Ibis 149:98-109.

Trani, M. K., R. T. Brooks, T. L. Schmidt, V. A., Rudis, C. M., Gabbard. 2001. Patterns and trends of early successional forests in the eastern United States. Wildlife Society Bulletin 29:413-424.

Vallender, R., S. L. Van Wilgenburg, L. P. Bulluck, A. Roth, R. Canterbury, J. Larkin, R. M. Fowlds, and I. J. Lovette. 2009. Extensive rangewide mitochondrial introgression indicates substantial cryptic hybridization in the Golden-winged Warbler (Vermivora 
chrysoptera). Avian Conservation and Ecology 4:4. http://www.aceeco.org/vol4/iss2/art4/

West Virginia Division of Natural Resources. 2009. WV Breeding Bird Atlas II: 2009-2014. South Charleston, West Virginia, USA. http://bird.atlasing.org/Atlas/WV/ Main?viewResults=1 (accessed 12 December 2013). 
Table 1. ANOVA results for a test of means on 22 vegetation variables by plot type (territory v non-territory) and site. Variables that differed between territories and random plots at $\alpha=0.0023$ are bolded for added emphasis.

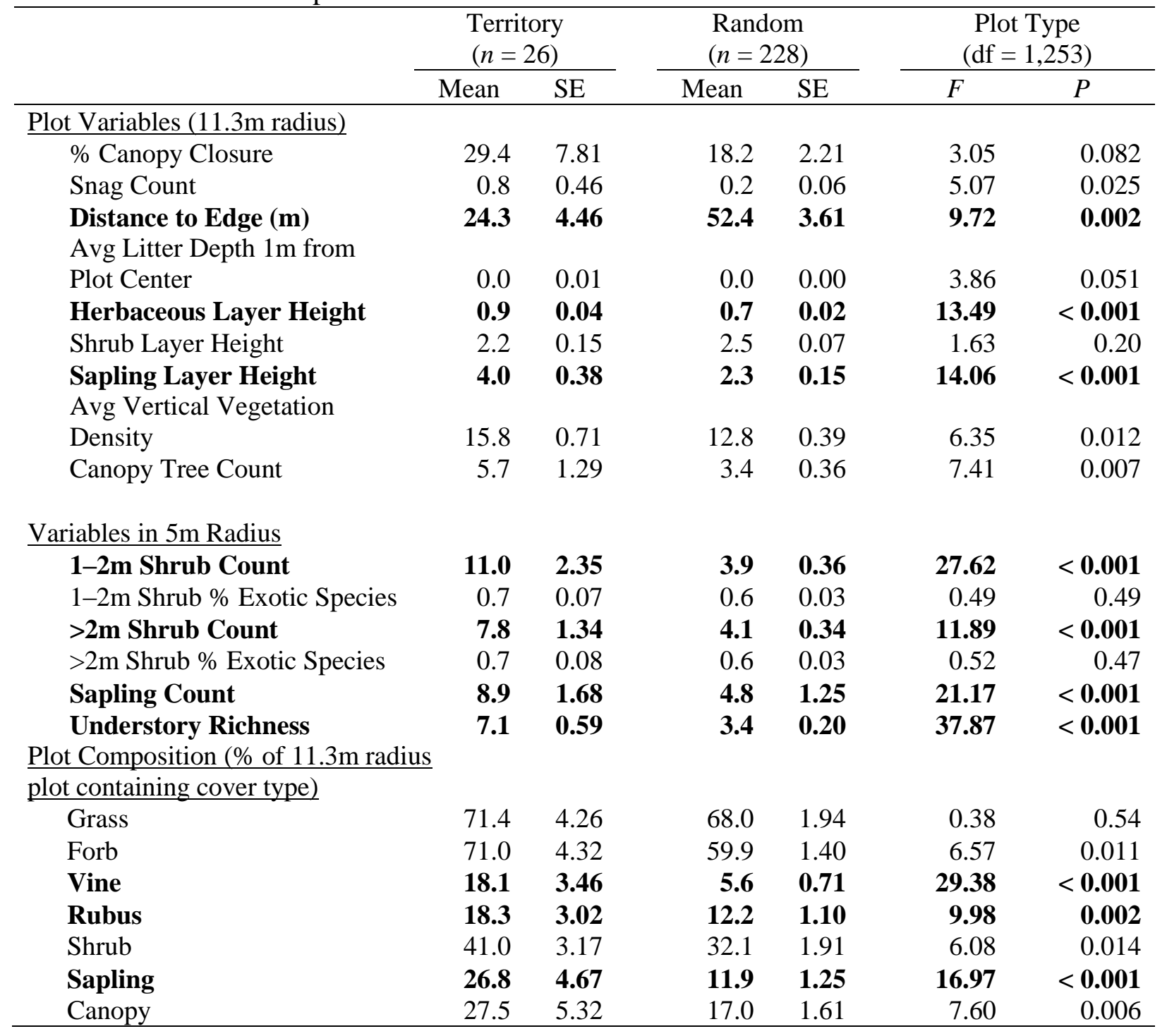


Table 2. ANOVA results for a test of means on 29 vegetation variables by plot type (territory v nest) and site. Variables that differed between nests and territories at $\alpha=0.05$ are bolded for added emphasis.

\begin{tabular}{|c|c|c|c|c|c|c|}
\hline & \multicolumn{2}{|c|}{$\begin{array}{c}\text { Nest } \\
(n=13)\end{array}$} & \multicolumn{2}{|c|}{$\begin{array}{l}\text { Territory } \\
(n=13)\end{array}$} & \multicolumn{2}{|c|}{$\begin{array}{l}\text { Plot Type } \\
(\mathrm{df}=1,25)\end{array}$} \\
\hline & Mean & SE & Mean & SE & $F$ & $P$ \\
\hline \multicolumn{7}{|l|}{ Ground Cover $(\%, 1 \mathrm{~m}$ from Plot } \\
\hline \multicolumn{7}{|l|}{ Center) } \\
\hline Litter & 0.3 & 0.31 & 0.2 & 0.23 & 0.04 & 0.85 \\
\hline Grass & 15.8 & 4.64 & 29.3 & 7.06 & 2.63 & 0.12 \\
\hline Bare Ground & 0.0 & 0.00 & 0.8 & 0.77 & 1.02 & 0.33 \\
\hline Forb & 39.4 & 8.28 & 38.3 & 7.12 & 0.10 & 0.75 \\
\hline Woody & 15.8 & 4.66 & 17.3 & 4.82 & 0.00 & 0.98 \\
\hline Vine & 1.8 & 0.60 & 5.8 & 2.63 & 0.25 & 0.62 \\
\hline Rubus & 15.3 & 6.54 & 7.8 & 3.63 & 0.44 & 0.52 \\
\hline \multicolumn{7}{|l|}{ Plot Variables (11.3m radius) } \\
\hline \% Canopy Closure & 29.8 & 9.73 & 29.0 & 12.63 & 0.39 & 0.54 \\
\hline Snag Count & 0.6 & 0.40 & 1.0 & 0.85 & 0.00 & 0.99 \\
\hline $\begin{array}{l}\text { Distance to Edge (m) } \\
\text { Avg Litter Depth } 1 \mathrm{~m} \text { from Plot }\end{array}$ & 23.4 & 7.35 & 25.1 & 5.37 & 0.16 & 0.70 \\
\hline Center & 0.0 & 0.01 & 0.0 & 0.01 & 0.48 & 0.50 \\
\hline Herbaceous Layer Height & 1.0 & 0.05 & 0.8 & 0.06 & 6.99 & 0.015 \\
\hline Shrub Layer Height & 2.2 & 0.22 & 2.3 & 0.21 & 0.01 & 0.92 \\
\hline $\begin{array}{l}\text { Sapling Layer Height } \\
\text { Avg Vertical }\end{array}$ & 4.7 & 0.45 & 3.3 & 0.58 & 3.67 & 0.069 \\
\hline VegetationDensity & 17.0 & 0.67 & 14.6 & 1.19 & 3.23 & 0.087 \\
\hline Canopy Tree Count & 5.8 & 1.86 & 5.5 & 1.87 & 0.01 & 0.91 \\
\hline \multicolumn{7}{|l|}{ Variables in $5 \mathrm{~m}$ Radius } \\
\hline $1-2 \mathrm{~m}$ Shrub Count & 10.3 & 3.06 & 11.6 & 3.69 & 0.03 & 0.86 \\
\hline 1-2m Shrub \% Exotic Species & 0.7 & 0.11 & 0.7 & 0.08 & 0.27 & 0.61 \\
\hline$>2 \mathrm{~m}$ Shrub Count & 8.2 & 2.13 & 7.5 & 1.70 & 0.00 & 0.97 \\
\hline$>2 \mathrm{~m}$ Shrub \% Exotic Species & 0.6 & 0.12 & 0.7 & 0.11 & 0.36 & 0.55 \\
\hline Sapling Count & 10.8 & 2.43 & 7.0 & 2.30 & 1.99 & 0.17 \\
\hline Understory Richness & 7.2 & 0.84 & 6.9 & 0.86 & 0.07 & 0.79 \\
\hline \multicolumn{7}{|l|}{$\frac{\text { Plot Composition ( } \% \text { of } 11.3 \mathrm{~m}}{\text { radius plot containing cover type) }}$} \\
\hline Grass & 73.5 & 4.37 & 69.4 & 7.47 & 0.25 & 0.63 \\
\hline Forb & 74.2 & 4.40 & 67.7 & 7.52 & 1.00 & 0.33 \\
\hline Vine & 15.2 & 3.51 & 21.0 & 6.03 & 0.22 & 0.64 \\
\hline Rubus & 24.0 & 5.03 & 12.5 & 2.70 & 4.61 & 0.044 \\
\hline Shrub & 39.6 & 3.51 & 42.3 & 5.40 & 0.18 & 0.68 \\
\hline Sapling & 34.6 & 6.83 & 19.0 & 5.85 & 4.35 & 0.049 \\
\hline Canopy & 34.0 & 8.21 & 21.0 & 6.60 & 1.73 & 0.20 \\
\hline
\end{tabular}


Table 3. ANOVA test results for differences in means on 38 vegetation variables between successful (S) and failed (F) Blue-winged Warbler nests. None were significant, possibly due to low sample size.

\begin{tabular}{|c|c|c|c|c|c|c|}
\hline & \multicolumn{2}{|c|}{$\mathrm{F}(n=7)$} & \multicolumn{2}{|c|}{$\mathrm{S}(n=6)$} & \multirow[b]{2}{*}{$F$} & \multirow[b]{2}{*}{$P$} \\
\hline & Mean & SE & Mean & SE & & \\
\hline \multicolumn{7}{|l|}{ Nest-Only Vegetation } \\
\hline Nest Ht. to rim (m) & 0.1 & 0.02 & 0.1 & 0.02 & 0.03 & 0.87 \\
\hline Substrate Ht. (m) & 1.1 & 0.09 & 1.0 & 0.11 & 0.40 & 0.54 \\
\hline Shrub Ht. (m) & 1.8 & 0.23 & 2.6 & 0.48 & 2.79 & 0.12 \\
\hline Max Shrub Width (m) & 1.8 & 0.37 & 2.4 & 0.62 & 0.89 & 0.36 \\
\hline Width Perpendicular to Max (m) & 1.4 & 0.35 & 1.9 & 0.52 & 0.81 & 0.39 \\
\hline Distance - Nest to Shrub Stem (m) & 1.1 & 0.15 & 2.4 & 0.80 & 1.84 & 0.20 \\
\hline Distance - Nest to Nearest Branch (m) & 0.7 & 0.18 & 1.3 & 0.48 & 0.59 & 0.46 \\
\hline \# of Stems @ 10cm Height & 2.1 & 0.77 & 4.0 & 1.10 & 2.01 & 0.18 \\
\hline Avg \% Nest Concealment & 89.3 & 4.35 & 94.1 & 3.04 & 0.77 & 0.40 \\
\hline \multicolumn{7}{|l|}{ Ground Cover $(\%, 1 \mathrm{~m}$ from Plot } \\
\hline \multicolumn{7}{|l|}{ Center) } \\
\hline Litter & 0.6 & 0.57 & 0.0 & 0.00 & 0.85 & 0.38 \\
\hline Grass & 18.7 & 8.02 & 12.5 & 4.23 & 0.38 & 0.55 \\
\hline Bare Ground & 0.0 & 0.00 & 0.0 & 0.00 & $\mathrm{n} / \mathrm{a}$ & $\mathrm{n} / \mathrm{a}$ \\
\hline Forb & 43.6 & 12.09 & 34.5 & 11.95 & 0.28 & 0.61 \\
\hline Woody & 18.6 & 8.07 & 12.5 & 4.23 & 0.20 & 0.67 \\
\hline Vine & 2.4 & 0.84 & 1.2 & 0.83 & 1.12 & 0.31 \\
\hline Rubus & 4.7 & 2.67 & 27.7 & 12.47 & 1.67 & 0.22 \\
\hline \multicolumn{7}{|l|}{ Variables in 5m Radius } \\
\hline 1-2m Shrub Count & 14.6 & 5.20 & 5.3 & 1.31 & 2.85 & 0.12 \\
\hline $1-2 \mathrm{~m}$ Shrub \% Exotic Species & 0.7 & 0.15 & 0.7 & 0.18 & 0.00 & 0.98 \\
\hline$>2 \mathrm{~m}$ Shrub Count & 10.4 & 3.29 & 5.5 & 2.42 & 1.37 & 0.27 \\
\hline$>2 \mathrm{~m}$ Shrub \% Exotic Species & 0.6 & 0.18 & 0.6 & 0.19 & 0.04 & 0.84 \\
\hline Sapling Count & 12.9 & 3.49 & 8.5 & 3.40 & 0.78 & 0.39 \\
\hline Understory Richness & 7.29 & 0.64 & 7.17 & 1.76 & 0.00 & 0.95 \\
\hline \multicolumn{7}{|l|}{ Plot Variables (11.3m radius) } \\
\hline \% Canopy Closure & 32.1 & 14.39 & 27.0 & 14.14 & 0.06 & 0.81 \\
\hline Snag Count & 0.9 & 0.70 & 0.3 & 0.33 & 0.40 & 0.54 \\
\hline Distance to Edge (m) & 30.3 & 13.18 & 15.4 & 3.66 & 0.18 & 0.68 \\
\hline Avg Litter Depth 1m from Plot & & & & & & \\
\hline Center & 0.0 & 0.01 & 0.0 & 0.01 & 0.25 & 0.63 \\
\hline Herbaceous Layer Height & 1.0 & 0.06 & 1.1 & 0.08 & 0.71 & 0.42 \\
\hline Shrub Layer Height & 2.1 & 0.38 & 2.3 & 0.23 & 0.14 & 0.71 \\
\hline Sapling Layer Height & 4.7 & 0.40 & 4.7 & 0.91 & 0.00 & 0.98 \\
\hline Avg Vertical Vegetation Density & 16.1 & 1.07 & 18.0 & 0.57 & 2.19 & 0.17 \\
\hline Canopy Tree Count & 4.9 & 1.78 & 6.8 & 3.63 & 0.08 & 0.78 \\
\hline \multicolumn{7}{|l|}{ Plot Composition (\% of $11.3 \mathrm{~m}$ radius } \\
\hline Grass & 77.5 & 3.62 & 68.8 & 8.53 & 1.00 & 0.34 \\
\hline
\end{tabular}


Forb

Vine

Rubus

Shrub

Sapling

Canopy

\begin{tabular}{rrrrrr}
73.9 & 7.77 & 74.6 & 4.00 & 0.01 & 0.94 \\
18.9 & 5.87 & 10.8 & 2.93 & 1.36 & 0.27 \\
17.1 & 7.27 & 32.1 & 5.79 & 2.46 & 0.15 \\
42.9 & 6.04 & 35.8 & 2.79 & 0.99 & 0.34 \\
42.9 & 9.81 & 25.0 & 8.56 & 1.82 & 0.21 \\
26.8 & 6.74 & 42.5 & 16.12 & 0.90 & 0.36 \\
\hline
\end{tabular}



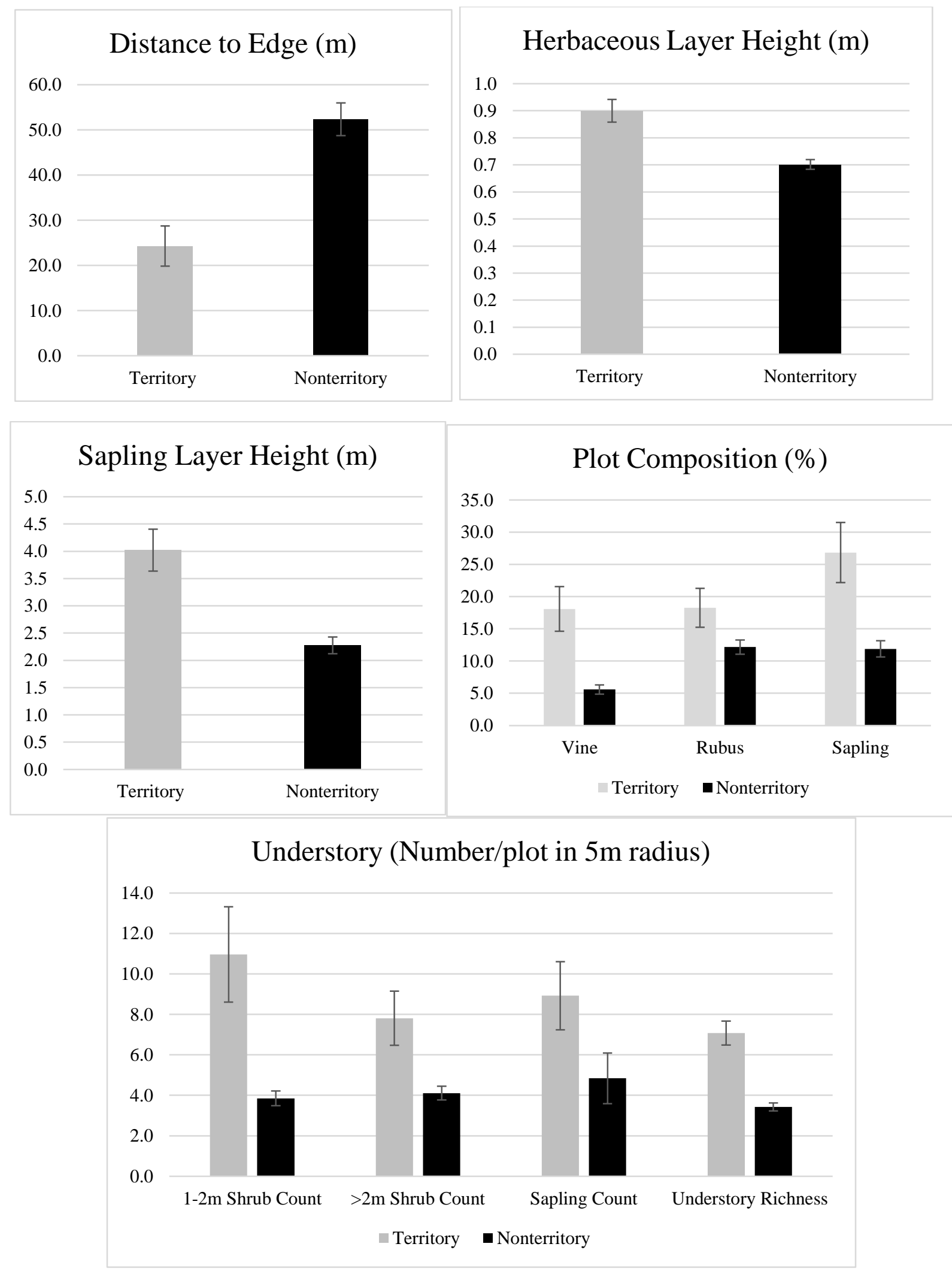

Figure 1. Means and standard errors (error bars) for the 10 significantly different vegetation variables at $\alpha=0.0023$ between territory and random plots. 

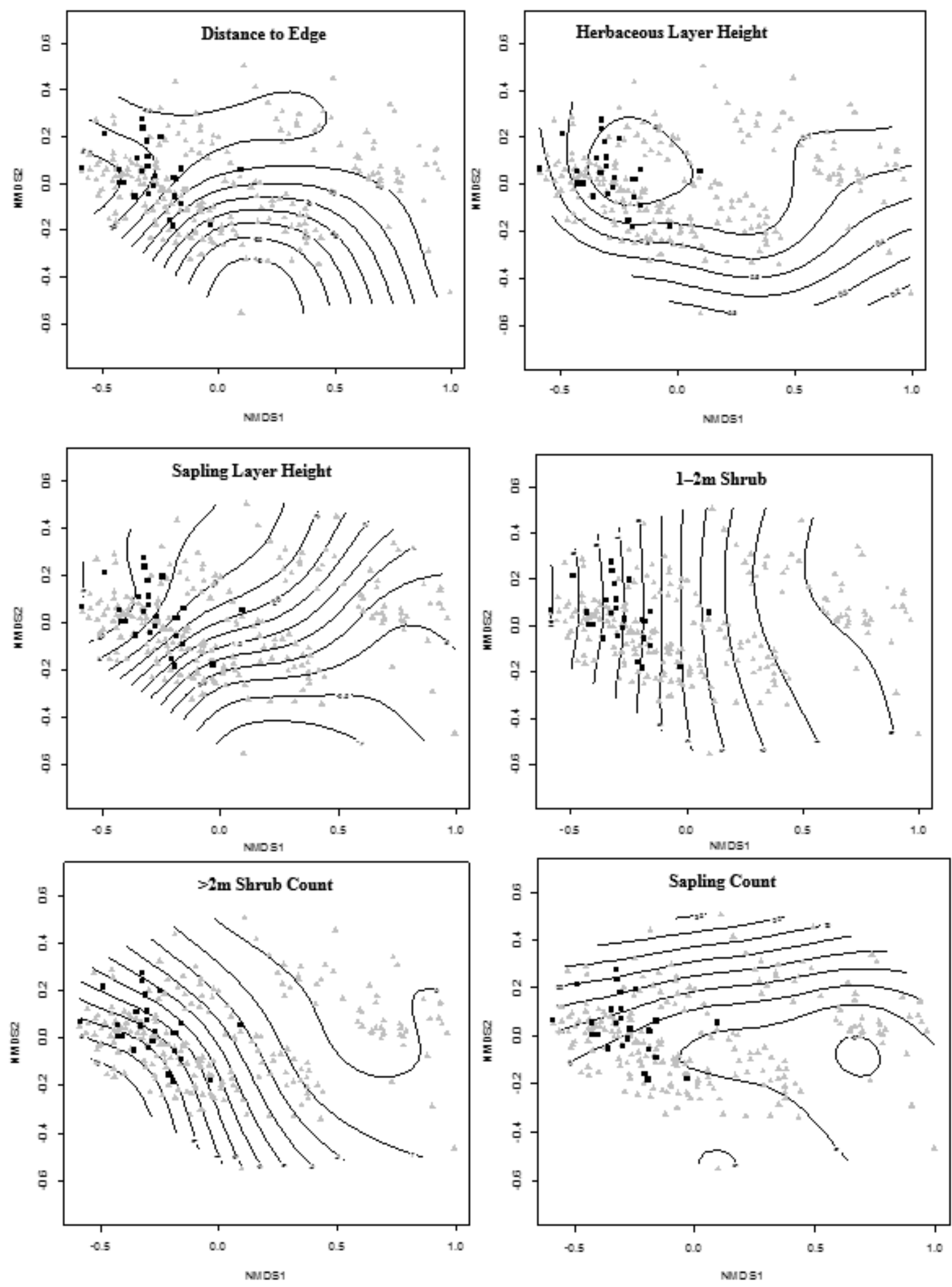

Figure 2 

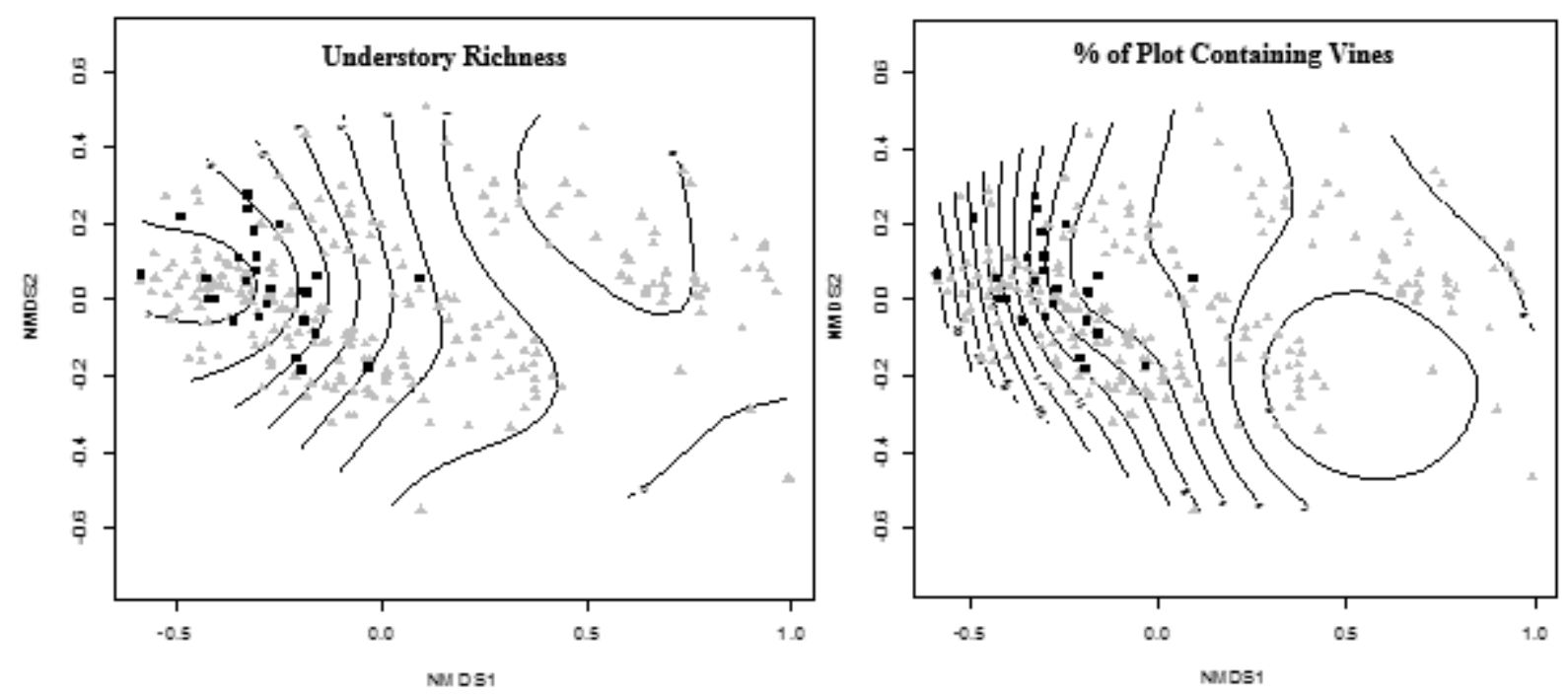

Figure 2. The Nonmetric Multi-Dimensional Scaling ordination of vegetation plots, overlaid with surface gradients for 10 significantly differing variables between territories and random plots at $\alpha=0.0023$. Black squares represent plots at Blue-winged Warbler territories while gray triangles represent randomly placed plots. Territories were placed in a small range of all available habitat. 

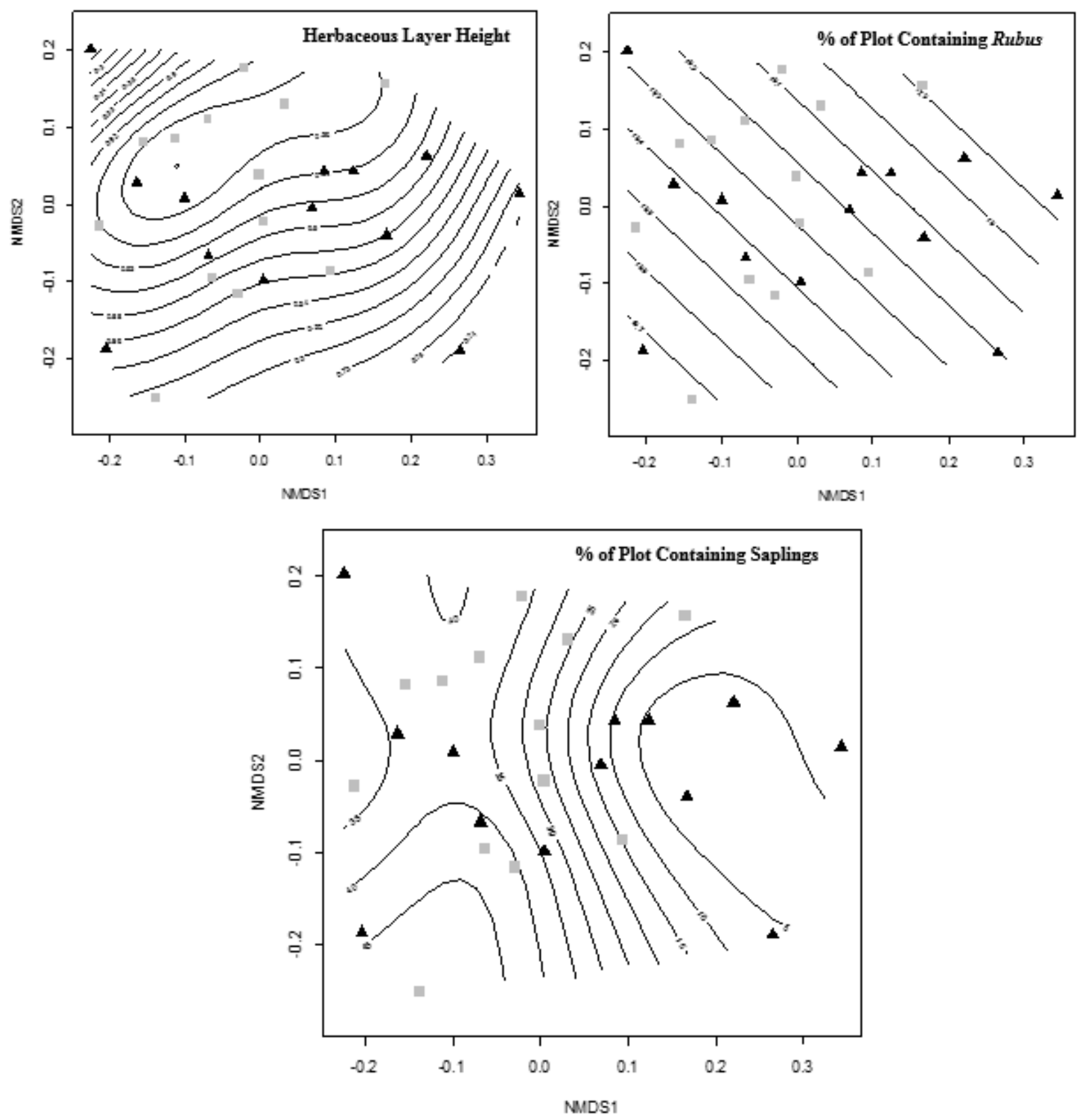

Figure 3. The Nonmetric Multi-Dimensional Scaling ordination of vegetation plots, overlaid with surface gradients for the 3 significantly differing variables between nests and randomly placed plots within territories at $\alpha=0.05$. Gray squares represent plots at Blue-winged Warbler nests while black triangles represent randomly placed plots within territories. Nests were placed in most available vegetation within territories. 

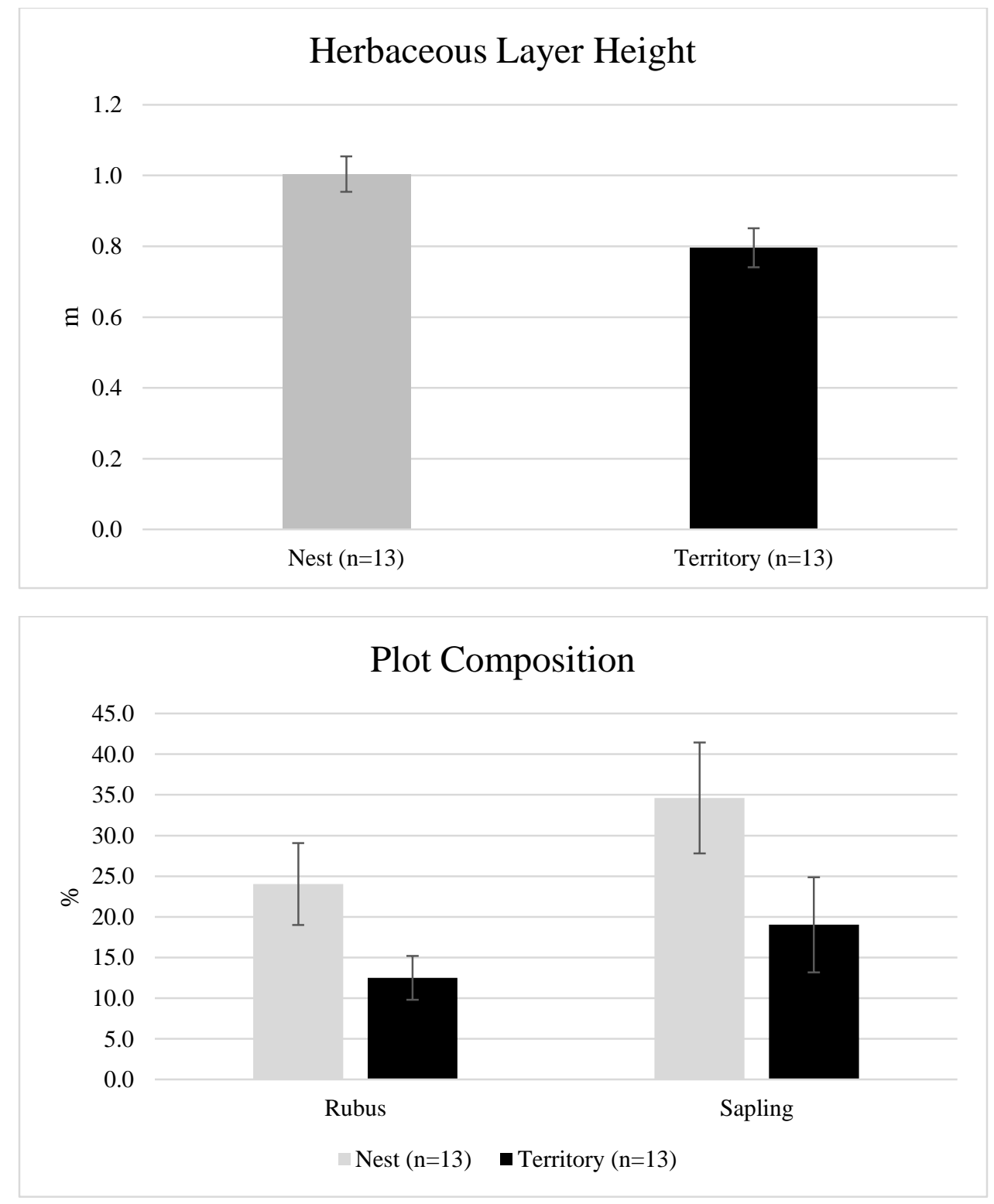

Figure 4. Means and standard errors (error bars) of the 3 significantly different vegetation characteristics at $\alpha=0.05$ for nest and within-territory random plots. 


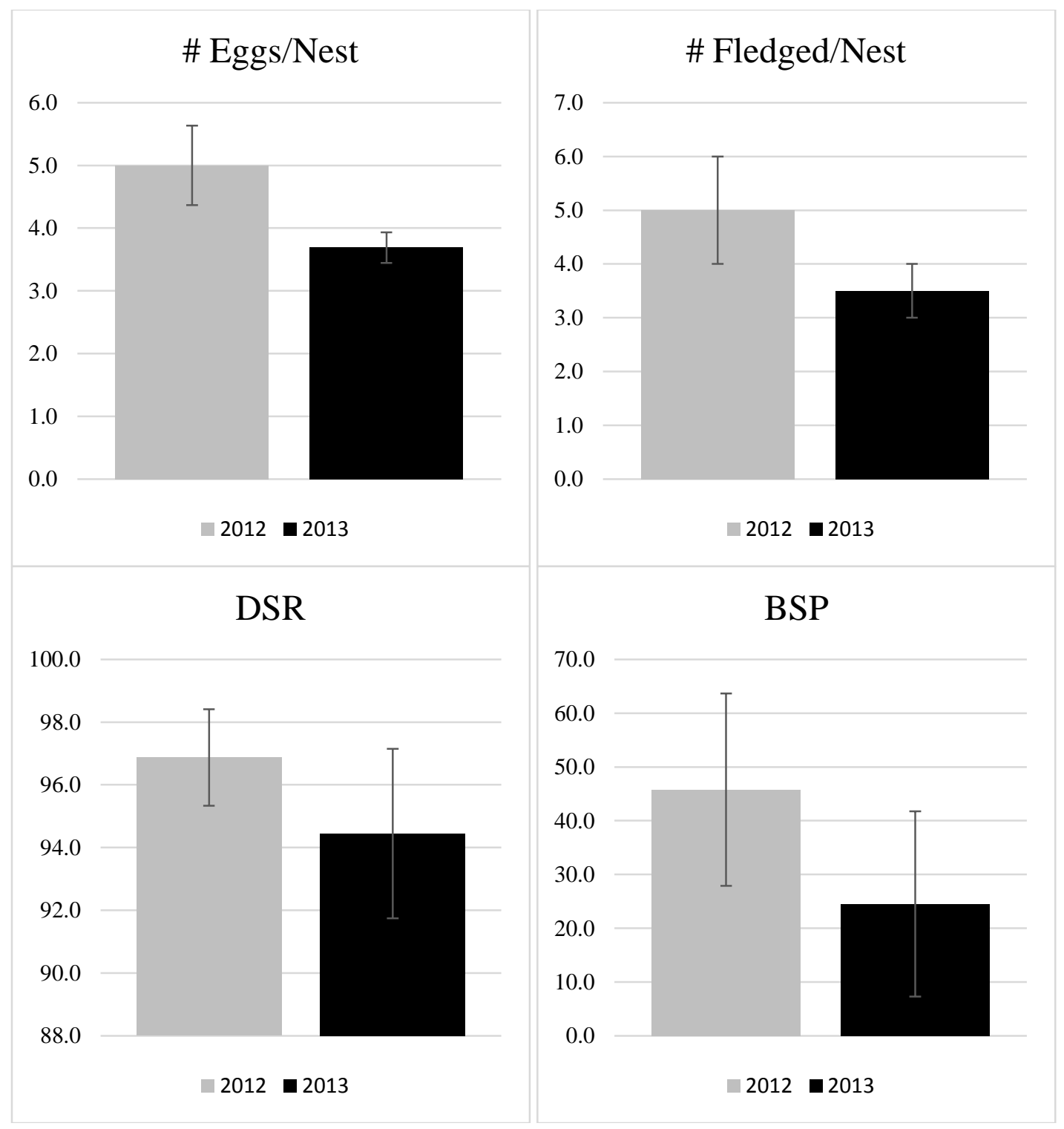

Figure 5. Mean and standard error (error bars) for Blue-winged Warbler nest productivity and success data for each year with sites combined. DSR=Daily Survival Rate and BSP=Breeding Season Probability of Survival. 


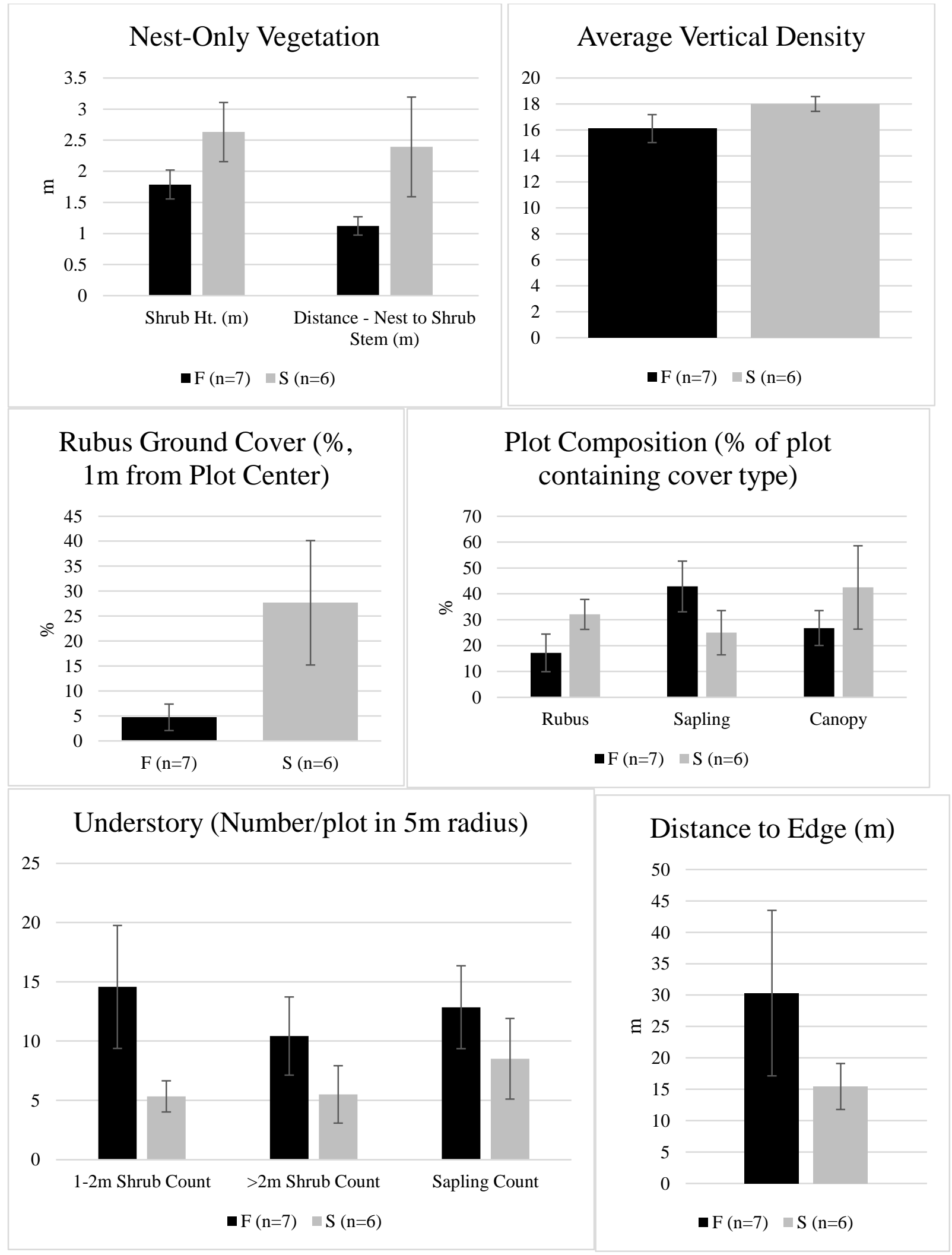

Figure 6. Means and standard errors (error bars) for vegetation characteristics of successful (S) and failed $(\mathrm{F})$ nests. 


\section{CHAPTER 3}

IMPACTS OF UNCONVENTIONAL GAS DEVELOPMENT ON EARLY-SUCCESSIONAL SONGBIRDS 
ABSTRACT.---Recent proliferation of unconventional natural gas extraction has occurred due to technological advancements which make previously unattainable resources available, and there is growing concern about the environmental impacts. Many studies have addressed the impacts of unconventional gas development on human health, hydrology, and aquatic life, but research into terrestrial wildlife has been less complete, especially in the midAtlantic and northeastern United States where extraction from the Marcellus-Utica Shale formation has increased dramatically. Most studies on the impacts to birds has related to noise from compressor stations and to habitat fragmentation and perforation in contiguous forests. Few studies have examined effects of already-developed wellpads which are quieter and more common than compressor stations, or examined effects in agricultural landscapes where the majority of development occurs. Early-successional songbirds comprise a precipitously declining guild which relies on habitat most likely to occur in human-dominated landscapes, but no studies in the eastern U.S. have determined the impact of unconventional gas development on these communities. To address these gaps in research, we determined the effects of gas development presence on shrubland songbird nest success and community dynamics at different spatial scales during the 2013 breeding season. We also quantified noise and light emissions from developed pads, which has been suggested as an influence on wildlife but not previously studied. There were no differences in noise $(\mathrm{P}=0.21)$ or light $(\mathrm{P}=0.29)$ emissions between impacted and nonimpacted shrublands, or at a developed site with increasing distance to the wellpad (noise $\mathrm{P}=$ 0.69 and light $\mathrm{P}=0.91)$. The presence of gas wells and related infrastructure were important influences on Field Sparrow (Spizella pusilla) nest success; survival was reduced close to the wellpad but increased around pipelines and roads. However, nest survival was higher site-wide for the Field Sparrow and other early successional species on the impacted site than on nonimpacted shrublands in the region. Nest predators were important in explaining variation in nest survival at the site-level. Within the developed site, nest abandonment was a more likely force around wells and the paved external road, while predation better explained variation in survival by distance to the pipeline and unpaved access road. Avian communities significantly differed between impacted and non-impacted sites $(\mathrm{P}=0.01)$ but the differences were not extractable from vegetative differences. Shannon's diversity $(\mathrm{P}=0.39, \mathrm{~F}=0.98, \mathrm{df}=2 / 21)$ and species richness $(\mathrm{P}=0.39, \mathrm{~F}=0.97, \mathrm{df}=2 / 21)$ did not differ between impacted and non-impacted sites and had no significant trend with increasing distance from the developed well (Shannon's 
diversity $\mathrm{F}=1.99, \mathrm{P}=0.21, \mathrm{df}=1 / 6$, and species richness $\mathrm{F}=1.12, \mathrm{P}=0.33 \mathrm{df}=1 / 6)$. Unconventional gas development in an already-fragmented landscape context may not degrade shrubland songbird habitat, but large amounts of shrubland habitat are still displaced when wells are developed and habitat loss is a pressing issue for shrubland species.

KEY WORDS: Shale gas development, Appalachian region, Early-successional songbirds, noise and light pollution 


\section{INTRODUCTION}

Unconventional natural gas extraction has emerged as a burgeoning energy development technique on a national scale. Extraction of gas from the Marcellus-Utica Shale formation has increased dramatically in recent years due to technological advancements, namely hydraulic fracturing ("fracking") and horizontal drilling, which enable extraction of these previously untapped deposits (GWPC and ALL Consulting 2009). Use of this method began in 2005 in the mid-Atlantic and northeastern United States (GWPC and ALL Consulting 2009), and has since become a prolific land use (PADEP 2011). The Marcellus-Utica Shale is the largest shale gas basin in the United States in area and estimated recoverable gas volume; it underlies a majority of New York, Pennsylvania, West Virginia, and Ohio (GWPC and ALL Consulting 2009). This area closely overlaps the northern two thirds of the Appalachian Mountain Bird Conservation Region, which is an important region for breeding, migrating, and wintering eastern landbirds (AMBCRP 2005).

The new "unconventional" techniques typically leave a larger surface footprint than conventional oil and gas infrastructure (8.8 ha compared to 1 ha, Drohan et al., 2012), and there is growing concern over the potential environmental impacts of hydraulic fracturing methods (Johnson 2010, Sutherland et al., 2011). Many studies have addressed the possible effects of unconventional gas development on human health (Colborn et al., 2011), air and water quality (Colborn et al., 2012, Jackson et al., 2013), hydrology (Soeder and Kappel 2009), and aquatic life (Weltman-Fahs and Taylor 2013), but research into impacts on terrestrial biota is limited.

Avian concerns mostly relate to habitat fragmentation, loss, and degradation due to the large area of land that is converted from forest to wellpads, gas lines, and roads and the subsequent human activity in these areas. Noise and light pollution are commonly suggested as 
potential threats to terrestrial wildlife (Francis et al., 2009, Kiviat 2013), but studies of light effects from gas development have not been conducted and research on noise influence have focused on compressor stations (Bayne et al., 2008, Francis et al., 2011, Francis et al., 2012, Habib et al., 2007) and not on other unconventional gas infrastructure such as existing wellpads. Compressors occur only at a limited number of sites, but wellpads will be present on the landscape at every well for the entire duration of the 40-50 years of production before reclamation (Mitchell and Casman 2011).

Because the practice is so new in the eastern United States, most research regarding avian communities has taken place in the west (Blickley and Patricelli 2012, Hamilton et al., 2011, Holloran 2005). More research is being conducted on the various impacts of Marcellus and Utica Shale gas extraction and development commensurate with the growing implementation of the practice (Johnson 2010). However, most research examines the changes in avian communities on forested landscapes (e.g., Thomas 2011), although development more frequently (43-69\%, depending on the region) occurs in non-forest habitat (Drohan et al., 2012). Little research on the subject has been conducted in eastern forests, and no studies have assessed the impacts of shale gas development in an already highly-fragmented landscape context such as what occurs in agricultural landscapes.

Fragmented, agriculturally-dominated landscapes are rarely considered important for biodiversity, but these areas are where increasingly rare early-successional habitat is most likely to occur. Early-successional habitat comprises the sere spanning from the first growing season following a disturbance to young forest conditions (stands where most trees are less than $12.7 \mathrm{~cm}$ in diameter, Trani et al. 2001). The shrubland stage falls between the grassland period, which has little woody vegetation, and young forest period, which is dominated by saplings. Land 
management practices which produce early-successional habitat, namely field abandonment and clearcut timber harvests, have become increasingly uncommon in the eastern United States and natural maintenance processes such as fires and floods are often suppressed. Due to wide-scale habitat reductions, shrubland songbirds are a highly imperiled guild across much of the northeastern United States (Dettmers 2003). Creation and maintenance of early successional habitat has accordingly become a priority to counter the rapid declines (DeGraaf and Yamasaki 2003). Whereas concern over threats from unconventional gas development to interior forest species has been raised (Kiviat 2013, Johnson 2010), the impacts to shrubland songbirds in already-fragmented landscapes have received little attention. This poses a substantial knowledge gap which needs to be closed; nearly half of shrubland bird species have had population declines over the past 50 years (Sauer et al., 2014).

We aim to provide quantitative data on the impacts of unconventional gas development on shrubland songbirds in the eastern United States. Our objectives are to: (1) quantify and assess noise and light as gas well impacts to bird communities, (2) determine the effect of gas development on shrubland songbird nest success at different spatial scales (among sites and within a site), and (3) determine the effect of gas development on breeding songbird communities at these spatial scales. Meeting these objectives will fill substantial knowledge gaps on the avian impacts of unconventional gas development.

\section{METHODS}

STUDY AREA

The study was conducted during the breeding season of 2013 on shrubland sites in southwestern Pennsylvania and the northern panhandle of West Virginia, a largely agricultural and developed landscape in the Appalachian Mountains Bird Conservation Region (AMBCRP 2005 ) with low elevation (average $~ 325 \mathrm{~m}$ ) and rolling topography (Appendix Figure A1). One 
site was a 237 ha portion of a former surface mine in Pennsylvania which was abandoned in the late 1960s and is now partially in early succession and partly in forest (Hillman State Park, HSP). One site in West Virginia is a former agricultural property, historically orchards and pasture, where we sampled on 141 ha of shrubland interspersed with maintained fields, wetlands, and forest (Hillcrest Wildlife Management Area, HWMA). A second West Virginia site is 158 ha of shrubland on a former surface mine that was reclaimed in the late 1980s with primarily autumn olive (Eleagnus umbellata) and tall fescue (Festuca arundinacea) (Cross Creek Wildlife Management Area, CCWMA) (Appendix Figure A2).

The shrubland areas of HSP and CCWMA consisted predominantly of exotic woody shrubs, namely bush honeysuckle (Lonicera spp.) and autumn olive, which occurred in clusters within open areas of grass and forbs. HWMA had little invasive-exotic woody vegetation; its shrublands consisted largely of Rubus, regenerating trees, hawthorn (Crataegus spp.), and remnant orchard trees, which structurally resembled native shrubs due to cultivation history (Appendix Figure A3).

All three sites were used by the public nearly every day for hunting and recreation, but HSP and HWMA had no other anthropogenic pressures. Two gas well pads existed within the bounds of CCWMA. A 2.4 ha pad in the northern shrubland area of the property (UTM 540109 E, $4465695 \mathrm{~N}$ ) was developed and initially drilled in 2012. A second pad (unmeasured but roughly the same size) in the forested part of the property, about $750 \mathrm{~m}$ south of the shrubland area, was being drilled during the 2013 breeding season (UTM 539498 E, 4463494 N) (Fig. 1). Anthropogenic presence on CCWMA was typical of gas-impacted sites; roads (paved and unpaved) which were heavily trafficked by large trucks permeated the shrubland area, as did a large pipeline right-of-way ( $25 \mathrm{~m}$ wide) which was being expanded during the 2013 breeding 
season. In 2013, the already-developed north well was extracting gas, so the anthropogenic activities there involved vehicle noise and a steady flow of workers on and off the pad, in addition to generator noise associated with pipeline infrastructure and construction. The south well which was being developed had a steady stream of vehicles as well, but also occasional loud noise from the hydraulic fracturing process for a short period of time.

\section{FIELD METHODS}

Eight sample points were established at each site and sampled nearly all available shrubland habitat. Each point was $>50 \mathrm{~m}$ from forest edge and at least $250 \mathrm{~m}$ from any other point. All points were placed in vegetation typical for the sites and as close to the center of their respective shrubland patch as possible. Points at CCWMA were placed to cover as many distances from the well as possible; the closest point was $150 \mathrm{~m}$ from the well and the rest extended out to $1300 \mathrm{~m}$ (Fig. 1).

Noise and Light.---We measured light with HOBO Pendant Light/Temperature Data Loggers manufactured by Onset Computer Corporation, which recorded the light intensity in lux (lumens per square meter) every 1 minute. We placed one monitor at each point count station at CCWMA to capture any attenuations in brightness with increasing distance from the north wellpad, with the monitors all positioned such that the sensor faced the direction of the pad. We also placed 4 monitors each at HSP and HWMA to determine site-level differences in brightness, all positioned to face 1 pre-defined point on each site to simulate the positioning array at CCWMA. We collected lux data continuously from 28 April through 10 July; 71 days were covered at CCWMA, 69 at HSP, and 59 at HWMA.

We recorded noise from 28 April through 10 July during sampling periods with the SongMeter Model SM2+ manufactured by Wildlife Acoustics Inc. Each sampling period 
consisted of a continuous recording which lasted 4-6 days; the average length of sampling periods was 106 hours $(\mathrm{SE}=2.49)$. Four recorders were rotated through the 8 CCWMA point count stations, 3 were rotated among points at HWMA, and 2 were rotated among points at HSP. Not all points were sampled with the same number of periods, but rotation was done as frequently as possible to increase evenness of effort. CCWMA had 48 total sampling periods, HSP had 23, and HWMA had 27. Noise and light recording equipment was placed 1-1.5 m above the ground to reflect the conditions perceived by birds that nest at this height.

Nest Success.---We searched for and monitored nests of three locally common species representative of Mid-Atlantic early-successional forests (Blue-winged Warbler (Vermivora pinus, BWWA), Eastern Towhee (Pipilo erythrophtalamus, EATO), and Field Sparrow (Spizella pusilla, FISP)) from early May to mid-July. We followed the protocols of Martin and Geupel (1993) and Martin et al., (1997) to minimize risk of increasing depredation or abandonment. Nest searching was opportunistic and based on pair behavior; observers watched adults of the focal species which exhibited signs of breeding such as aggression or carrying nest material until the nest was found. All shrubland areas were searched, but effort was concentrated around point count stations for efficiency. Once found, the contents of each nest were checked every other day. We anticipated projected fledge dates based on nestling development and considered a nest successful if at least one fledgling was visually confirmed after this date. Failures were recorded to have occurred on the day between the last two nest checks. We reported the number of eggs in nests that were counted on the last check when the nest was active before hatching or failing, and the number of fledglings as the number of chicks counted in successful nests at the last nest check. 
We recorded the species and UTM of detection for all nest predators observed in shrubland areas during the breeding season as an index of predation pressure. We assessed this index as a potential influence on nest success rates. Possible nest predators according to the literature included black rat snakes (Elaphe obsoleta), rodents (Sciurus spp., Peromyscus spp., Tamiasciurus spp., and Tamias spp.), and mammalian mesocarnivores (see Bradley and Marzluff 2003, Chalfoun et al. 2002, Maxson and Oring 1978, Reitsma et al. 1990, and Thompson et al. 1999).

Avian Community.---We conducted point counts from mid-May to late June, in three bouts each of which were two weeks long. The counts were completed between the hours of 0530 and 1000 on days without inclement weather (Ralph et al., 1993). Each count lasted 10 minutes. For each individual detected during the count, we recorded the estimated distance to the individual and time interval during which it was detected. The time intervals were $0-3$ minutes, $>3-5$ minutes, and > 5-10 minutes. The counts had a $75 \mathrm{~m}$ fixed radius. Observers were experienced and trained in point count techniques and distance estimation and highly skilled in songbird identification by both sight and sound. Distance estimation accuracy was facilitated further by equipping observers with rangefinders and placing reference flagging 25 and $50 \mathrm{~m}$ from each point.

Vegetation Sampling.---We measured a variety of vegetative characteristics to assess as possible factors influencing the avian community or breeding success, following a sampling protocol adapted largely from the Golden-winged Warbler working group (Bulluck and Buehler 2008) with additional measurements from James and Shugart (1970) and Martin et al., (1997). Vegetation sampling began on 18 June after the majority of nest attempts ended to avoid disturbing active nests. We placed vegetation sampling plots at each nest, point count, and 
randomly generated point across the available shrubland habitat. We used the Geospatial Modelling Environment platform (Beyer 2012) in ArcGIS 10.1 (ESRI 2012) to generate a 1-ha grid over the searched shrubland area and generated one random sampling point within each cell. These points represent all conditions that were available to birds on the sites, including some non-shrubland habitat features such as roads, gas pipelines, and some forest edge.

Vegetation plots were circular, with an 11.3 m radius. From the center of each plot, we measured the litter depth in each cardinal direction at $1 \mathrm{~m}$ from plot center and visually estimated the percentage of canopy closure directly above plot center. We used a rangefinder to measure distance to nearest habitat edge, which was classified as mature forest, shrubland (if the plot was not in the shrubland), or non-habitat (i.e., pipelines, agricultural fields). We visually estimated the ground cover within $1 \mathrm{~m}$ of each plot center, to the $1 \%$ level, as the percentage of the ground covered by each of the following categories which sum to $100 \%$ : litter (leaves or dead grass), grass, bare (i.e., rock, pavement), forbs, woody (live stems), vines, and Rubus.

Within the $11.3 \mathrm{~m}$ radius of all plots, we recorded the diameter at breast height (DBH) and species of each canopy tree which had a DBH $>10.0 \mathrm{~cm}$, the number of snags (standing dead trees with DBH $>10 \mathrm{~cm}$ ), and the height of the herbaceous (grass and forb), shrub-Rubus, and sapling layers by measuring an individual which was representative of the estimated average height of that layer. We measured plot composition, the percentage of the plot surface where a plant is present in each vegetation category (grass, forb, vine, Rubus, shrub, sapling, or canopy), by recording the number of times that each was encountered at marked $1.1 \mathrm{~m}$ intervals radiating from plot center in each cardinal direction. These percentages do not sum to 100 because tallies are recorded separately for each category. 
At all plots, we tallied species and number of individuals $>1 \mathrm{~m}$ tall of shrubs and saplings within $5 \mathrm{~m}$ of the plot center. We used two categories for shrubs, those 1-2 $\mathrm{m}$ tall and those $>2 \mathrm{~m}$ tall, because shrub height can be linked to stage of succession. Understory species richness was the sum of the number of unique species for each of the three categories. We measured vegetation density in each cardinal direction at $10 \mathrm{~m}$ from each plot's center with a cover-board where squares at least $50 \%$ obscured by vegetation were tallied; the cover-board was $2 \mathrm{~m}$ tall and $0.4 \mathrm{~m}$ wide, divided into twenty $0.2 \mathrm{~m} \times 0.2 \mathrm{~m}$ squares. We averaged the four values to determine vegetation density.

At nest plots, we recorded the height of the nest, substrate (defined as the plant which supports or provides the main structure for the nest) height and species, all plant species responsible for concealing the nest, the percentage of the nest concealed by vegetation from above and at each cardinal direction (estimated $1 \mathrm{~m}$ away from the nest at nest-level), and the following metrics of the nearest shrub (the shrub with the closest stem): species, height, width (at the maximum and perpendicular to the maximum), distance from nest to the nearest stem, distance from nest to the nearest branch, and the number of stems at $10 \mathrm{~cm}$ above the ground.

\section{STATISTICAL ANALYSES}

Analyses were performed at two scales: between sites, to determine if the presence of gas development affected birds at the site level, and within the impacted site, to determine if our variables of noise, light, nest survival, or avian community differed based on distance to gas development. Comparisons at both scales were not fully replicated due to logistical constraints: at the between-site level we compare variables between sites using data gathered within sites as samples and at the within-site level we compare variables between distances using data gathered at points as samples. 
Noise and Light.---We calculated the maximum, minimum, and mean lux readings across all 1-minute recording intervals at each point to summarize light data. For noise data, we used Song Scope version 4.1.3A to calculate the minimum, maximum, and mean $\mathrm{dB}$ recorded for each sampling period at each point. We used ANOVAs on summarized light data to test for differences in maximum, minimum, and mean light levels among sites, using points within sites as replicates. We also used ANOVAs on summarized noise data to test for differences among sites, using sampling periods as replicates.

We used ANOVAs to test the relationships between distance to the developed well at CCWMA and light and noise levels to determine local within-site effects. Tests for light were on mean, maximum, and minimum lux readings at the eight points. Tests for noise were on mean, maximum, and minimum $\mathrm{dB}$ recordings at the eight points, using sampling periods as replicates, and included a factor for calendar date of the sampling period. All analyses on light levels were performed using data from all 24 hours and again from a subset of the data which was recorded at night (between 2045 and 0550) to confirm that sunlight was not outweighing anthropogenic light sources.

Nest Success.---We tested for differences in nest survival, clutch size, and number of fledglings produced from successful nests among sites to determine if the presence of shale gas wellpads had an effect on shrubland songbird breeding success at the site level. We compared among sites for number of eggs over all nests and number of fledglings per successful nest using ANOVAs at $\alpha=0.05$ for species whose sample sizes were sufficiently large.

Sample sizes for FISP nests were high enough to assess success alone, but too low to assess individually for EATO and BWWA nests, so we combined the 3 species to assess the influence of gas development on shrubland guild nest survival. We used an information-theoretic 
framework (Burnham and Anderson 2002) to determine the importance of gas well presence on nest survival relative to other factors (site and species) in Program MARK Nest Survival Analysis (White and Burnham 1999, Rotella et al., 2004), which also allowed us to estimate nest survival probabilities. MARK estimates nest survival rates with maximum likelihood estimation, determining which models of survival (e.g. variation in nest survival by site vs. variation by species) are most likely given the collected data. We modeled nest fate data binomially (where success is coded 0 and failure 1) with a logit-link function and covariates for site and presence of gas development for FISPs and site, presence of gas development, and species for the guild. We standardized dates by designating April 20 as day 1, with observation dates progressing until day 80 (July 10), the end of the breeding season. Each nest was coded for Program MARK with the day a nest was found, the last day a nest was checked and alive, the last day a nest was checked, the nest fate, the frequency of that specific encounter history, and indicator covariates for use in model ranking.

The candidate models for FISP nest survival were: 1) site-dependent survival, 2) gasdependent survival, 3) constant survival (which implies no differences in survival by site or gas well presence), and 4) gas and site-dependent survival. The candidate models for guild nest survival were: 1) site-dependent survival, 2) gas well-dependent survival, 3) species-dependent survival, 4) site and species-dependent survival, 5) gas well and species-dependent survival, 6) constant survival (i.e., no differences in survival based on species, gas well presence, or site), 7) survival depending on site, species, and gas well presence, and 8) gas and site-dependent survival. We determined the model which best fit the observed data using Akaike's Information Criterion with a correction for small sample size (AICc) (Burnham and Anderson 2002). A smaller AICc score denotes less distance between the model and the truth (i.e., the observed 
data), so we ranked the candidate models in order of increasing AICc scores. We considered models with $\Delta \mathrm{AICc}<2.0$ to have support from the candidate set. We transformed the MARKderived nest survival probabilities with the logit-link function to determine daily survival rate (DSR) of nests.

We tallied the number of nest predators detected within $250 \mathrm{~m}$ of each nest to use as an index of predation risk. We assessed mechanisms of nest failures by building a candidate model set (Table 4) which included predation risk, site, and avian species for ranking, also within the information theoretic paradigm using Program MARK. Our objective of this test was to determine if variation in nest survival was related to predation pressure rather than other sitespecific causes.

We assessed the local-scale impacts of gas development presence by examining FISP nest success rates in relation to the wellpads and infrastructure at CCWMA, again within the information theoretic paradigm using Program MARK as detailed above. Our objectives were to determine the impact of the wellpads, the impact of infrastructure (a pipeline, unpaved access roads, and paved roads), and the role of a vegetation gradient suspected to occur on the site. We built an a priori set of 27 candidate models (Table 5) based on the following eight variables and a subset of plausible interactions: 1) distance to the northern gas well, 2) distance to the southern gas well, 3) distance to the nearest gas well, 4) which well is nearest, 5) distance to the pipeline, 6) distance to the unpaved access road (internal road), 7) distance to the paved road (external road), and 8) the vegetation gradient (described below).

We built an additional candidate set of models which combined important variables from the analyses of predation risk (Table 4) and local-scale gas development impacts on FISP nest survival (Table 5). The objective of this model ranking was to determine the contribution of 
predators to gas development effects on FISP nest success. The candidate set had 10 models (Table 6): the 4 top models from the local-scale impact analysis, 4 models which added predation risk from rodents and black rat snakes to those top models, 1 model of just predation risk, and 1 of constant survival.

We tested for spatial autocorrelation of successful and failed nests by running a series of Average Nearest Neighbor assessments in the spatial statistics toolbox of ArcGIS 10.1 (ESRI 2012). This analysis determined the extent to which successful and failed nests were clustered around particular points on the landscape, which could have confounded the relationships between survival and gas well impacts or vegetation.

Vegetative Gradient.---To test for the presence of a vegetation gradient at CCWMA from north to south, we analyzed vegetative differences between quartiles of vegetation plot points by distance to the north well. To compare overall vegetative composition between the quartiles from the north well, we used non-parametric MANOVA (function adonis in the vegan library, Oksanen et al., 2013, R Development Core Team 2013). This is a Multivariate Analysis of Variance, which partitions the sums of squares of the groups in a distance matrix for the 30 variables (Bray-Curtis coefficient) among quartiles and statistically tests for differences using permutations (999).

We applied a non-metric multidimensional scaling (NMDS) ordination (function metaMDS in the vegan library, Oksanen et al., 2012, R Development Core Team 2013) to the Bray-Curtis distance matrix of vegetation data to graphically evaluate the strength and nature of the vegetative gradient. NMDS is a non-parametric, unconstrained ordination technique which represents a full dataset in a newly defined dimensional space while attempting to preserve the distances between each observation from a dissimilarity matrix (Faith et al., 1987). It places each 
multivariate observation in a multidimensional space using ranked distances such that stress, a measure of the disparity between the original distance matrix and the distance in the newly ordinated space, is minimized (Clarke and Green 1988). We used a square root transformation and Wisconsin double standardization, and ran the ordination with multiple random starts to increase the chances of stability. Gradients in habitat variables were correlated to the ordination to examine relations for each variable (function ordisurf in the vegan library, Oksanen et al., 2012, R Development Core Team 2013).

To describe the vegetative gradient, we reduced the multivariate matrix using a canonical discriminant/correlation analysis (function candisc in the candisc library, Friendly and Fox 2013, R Development Core Team 2013). This analysis reduces multivariate data into a lowdimensional space corresponding to linear combinations of original variables which best discriminate values of the continuous distance to the north gas well (Gittins 1985). We applied scores of this discriminant function derived for each distance from the north gas well as a continuous variable in Program MARK to assess the importance of the vegetative gradient in affecting nest survival.

Avian Community.---We removed all flyovers, raptors, waterbirds, transitory migrants, and detections $>75 \mathrm{~m}$ from the observer for all counts. We then used the count data with the maximum number of detections of each species over the three bouts for all analyses. We determined detection probabilities for all species with sufficient sample sizes using the time-ofdetection removal method (Farnsworth et al., 2002) in Program SURVIV (White 1992). Because all of the detection probabilities were $>0.9$, we used unadjusted count data to enable assessments for all species rather than just the most frequently-occurring ones. 
We analyzed differences in the avian community among sites to assess the impacts of gas development at the site-level. We tested for differences in diversity by performing ANOVAs at $\alpha$ $=0.05$ on species richness (number of unique species detected) and Shannon's diversity index (a measure of richness and evenness). To compare overall avian species composition, we used nonparametric MANOVA (function adonis in the vegan library, Oksanen et al., 2012, R Development Core Team 2013) on a Bray-Curtis dissimilarity matrix of the species data and tested for differences in these assemblages among development type (gas-impacted vs nonimpacted) after accounting for site, specified for 999 permutations. We applied an NMDS ordination (function metaMDS in the vegan library, Oksanen et al., 2012, R Development Core Team 2013) to the Bray-Curtis distance matrix of count data to visualize these communities' relationships to each other and the individual species which drove the relationships.

We tested site-level vegetative community differences with a non-parametric MANOVA on a Bray-Curtis dissimilarity matrix of count station vegetation data (again with the adonis function, specifying for 999 permutations). This was performed to assess vegetation as a confounding factor; vegetative differences between sites could drive community differences more than gas development impacts.

We assessed the local-scale impacts of gas well presence by examining the relationship between diversity indices and distance to wells at CCWMA, again using species richness and Shannon's diversity index. We tested the significance of linear regression models expressing each index as a function of distance to the north well with ANOVAs at $\alpha=0.05$. All analyses were performed in the R Language and Environment for Statistical Computing (program R) ( R Development Core Team 2013). 


\section{RESULTS}

SITE-LEVEL COMPARISONS

Noise and Light.---We collected approximately 71 days of luminance levels at CCWMA with each of the 8 data loggers, 69 days at HSP with each of the 4 loggers, and 59 days at HWMA with each of the 4 loggers. We found no significant differences in mean (Fig. 2; F = $1.34, \mathrm{df}=2 / 13, \mathrm{P}=0.30)$, maximum $(\mathrm{F}=1.47, \mathrm{df}=2 / 13, \mathrm{P}=0.27)$, or minimum $(\mathrm{F}=0.00, \mathrm{df}=$ $2 / 13, \mathrm{P}=1.0$ ) luminance levels between sites, indicating that CCWMA was not subjected to higher levels of light than the two non-impacted sites. Test results using only night recordings were identical.

We recorded 5,063 total hours of sound data at CCWMA, 2,853 hours at HWMA, and 2,279 hours at HSP. We found no significant differences in mean (Fig. 2; $\mathrm{F}=1.55$, df = 2/95, $\mathrm{P}=$ 0.21), maximum $(\mathrm{F}=0.82, \mathrm{df}=2 / 95, \mathrm{P}=0.49)$, or minimum $(\mathrm{F}=1.24, \mathrm{df}=2 / 95, \mathrm{P}=0.30)$ sound levels between sites. Thus, CCWMA also was not subjected to higher noise levels than the two non-impacted sites.

Nest Success.---We monitored 96 nests: 78 FISPs, 12 EATOs, and 6 BWWAs. Number of eggs $(F=2.65, \mathrm{df}=3 / 75, \mathrm{P}=0.08)$ and fledglings per nest $(\mathrm{F}=0.82, \mathrm{df}=3 / 21, \mathrm{P}=0.46)$ did not significantly differ between sites for FISPs, the only species with sufficient sample size to test (Table 1).

Two of the four models of FISP nest survival had $\Delta$ AICc $<2.0$ (Table 2). The top model, with $41 \%$ of the weight in the data, was for constant survival, implying that there were no differences in survival based on site variation or gas impacts. The model for survival depending on gas impacts had $34 \%$ of support by the data, and produced DSR estimates of $0.95(\mathrm{SE}=0.01)$ for gas-impacted sites and $0.92(\mathrm{SE}=0.01)$ for non-impacted sites (Fig. 3). The most evidence points to constant survival, but almost as much supports the model for survival depending on gas 
impacts. We can thus interpret that there was differential FISP survival on gas-impacted and non-impacted sites, but the difference was not substantial.

Four of the 8 models of guild survival had $\Delta$ AICc $<2.0$ (Table 2). The model for species-dependent survival was highest ranked, with $21 \%$ of the support in the data. The next best model, with $20 \%$ of the support in the data, was for survival dependent on species and presence of gas development. The model for only gas-dependent survival, which had $18 \%$ of the support in the model, produced DSR estimates of $0.95(\mathrm{SE}=0.01)$ for gas-impacted sites and $0.92(\mathrm{SE}=0.01)$ for non-impacted sites (Fig. 3).

Fifty nest predator detections occurred at HSP, 36 at HWMA, and 19 at CCWMA. Of the predators detected, the majority were rodents (98\% at HSP, $92 \%$ at HWMA, and $68 \%$ at CCWMA; Table 3). Six of the 15 models in the candidate set assessing mechanisms of failure had $\Delta$ AICc $<2.0$ (Table 4). They all modeled variation in survival by predation risk, indicating that predators drove the differences in success rates. The model for survival dependent on risk from rodents and black snakes was highest ranked, with $20 \%$ of the support in the data. Predation risk from only rodents was next best, with $12 \%$ of the support, followed by risk from eastern chipmunks (12\% of the support), variation due to avian species and risk from all predators (9\% of the support), gray squirrel risk (8\% of the support), and risk from all three predator types additively ( $8 \%$ of the support). The model of predation risk from just black rat snakes was not very likely (6\% of the support), and models for mesocarnivores, fox squirrels, mice, and red squirrels ranked very low $(2 \%, 1 \%, 1 \%$, and $1 \%$ of the support respectively).

Avian Community.---We detected 49 unique species at all sites; HSP had 37 species, HWMA had 33 species, and CCWMA had 37 species. Shannon's diversity $(\mathrm{F}=0.98, \mathrm{df}=2 / 21$, 
$\mathrm{P}=0.39)$ and species richness $(\mathrm{F}=0.97, \mathrm{df}=2 / 21, \mathrm{P}=0.39)$ did not differ significantly by site (Fig. 4).

The adonis test comparing bird communities found significant differences in composition by type (gas impacted vs. not impacted) once accounting for site $(\mathrm{P}=0.011)$. The 2 dimensional NMDS had a stress of 0.19 which is a little high but acceptable (Clarke and Green 1988); we did not increase dimensionality for ease of interpretation. The ordination showed CCWMA and nonimpacted sites to have avian communities that differed, but did not discriminate fully (Fig. 5B). The adonis test of vegetative communities at counts also found significant differences by type (P $=0.001)$ and site $(\mathrm{P}=0.001)$. Overlaying highly correlated vegetation variables $($ Fig. $5 \mathrm{~A})$ and displaying avian species used in the ordination (Fig. 5B) showed that the site-level discrimination in species can largely be explained by the vegetation at points. For example, ordinated points correlated with the amount of plot covered by grass were related to abundances of Grasshopper Sparrows (GRSP; Ammodramus savannarum) and Red-winged Blackbirds (RWBL; Agelaius phoeniceus), which use open fields, and points correlated with number of trees were related to abundances of Hooded Warblers (HOWA; Setophaga citrina) and Ovenbirds (OVEN; Seiurus aurocapilla), which are mature forest specialists.

\section{LOCAL WITHIN-SITE COMPARISONS}

Noise and Light.---We found no significant differences in mean $(\mathrm{F}=0.01$, $\mathrm{df}=1 / 7, \mathrm{P}=$ 0.91), maximum $(\mathrm{F}=0.35, \mathrm{df}=1 / 7, \mathrm{P}=0.58)$, or minimum $(\mathrm{F}=0.00, \mathrm{df}=1 / 7, \mathrm{P}=1.0)$ lux levels between different point count stations at CCWMA. Thus, brightness did not differ based on distance to the north wellpad (Fig. 6).

We found no difference in minimum and mean $\mathrm{dB}$ (Fig. 6) by distance to the north wellpad $(\min \mathrm{F}=2.02, \mathrm{df}=1 / 44, \mathrm{P}=0.16$; mean $\mathrm{F}=0.02, \mathrm{df}=1 / 44, \mathrm{P}=0.89)$ but did have 
differences by date $(\min \mathrm{F}=5.75, \mathrm{df}=1 / 44, \mathrm{P}=0.021$; mean $\mathrm{F}=10.39$, $\mathrm{df}=1 / 44, \mathrm{P}=0.002)$ :

the minimum became quieter and the mean louder as time elapsed (Fig. 7). Maximum dB did not differ significantly by distance $(\mathrm{F}=1.14, \mathrm{df}=1 / 44, \mathrm{P}=0.29)$ or by date $(\mathrm{F}=2.99, \mathrm{df}=1 / 44, \mathrm{P}=$ $0.09)$.

Vegetation Gradient.---The adonis test on vegetative composition within quartiles from north to south was significant $(\mathrm{P}=0.002)$, confirming our suspicion of a vegetative gradient. The NMDS was performed with a k-value of 2 (2 dimensions) for 9 runs and had a stress of 0.149. NMDS plots show a well-defined vegetative gradient from north to south driven largely by woody plant structure (Fig. 8); sapling and canopy influences decreased towards the south.

The canonical discriminant analysis of vegetation by distance to the north gas well found one function that explained $100 \%$ of the data. It had a canonical $\mathrm{R}^{2}$ of 0.43 , an eigenvalue of 0.766, and was highly significant $(\mathrm{P}=2.2 \mathrm{e}-16)$. Appendix Figure A5 shows the discriminant function's scores (the values for each point in the new function) and structure (how important each variable is to determining scores) and appendix Table A4 shows the structure values for each variable. This vegetation function was used as a variable in nest success models.

Nest Success.---Four models of FISP nest survival at CCWMA had a $\Delta \mathrm{AICc}<2$ and explained $11-26 \%$ of the variation (Table 5). Nest survival was dependent on: vegetation and distance to nearest gas well (26\% of the support in the data); vegetation, distance to nearest gas well, and distance to the paved external road (16\% of the support); vegetation, distance to nearest gas well, and distance to the pipeline (12\% of the support); and vegetation, distance to nearest gas well, and distance to the unpaved access road (11\% of the support). Thus, the vegetation gradient and distance to gas-related infrastructure explained most of the variability in nest survival. FISP nest survival probabilities increased with increasing distance from the nearest well 
and decreased with increasing distance from the pipeline, paved road, and unpaved access road (Fig. 9).

The candidate model set incorporating predation risk and gas development had seven models of FISP nest survival with $\Delta$ AICc $<2$ which explained 9-21\% of the variation (Table 6). Nest survival was best explained (21\% of the support) by the vegetative gradient and distance to nearest well, without the addition of predators. The model which added predation risk to vegetation and distance to the nearest well was the next best (16\% of the support). Models incorporating distance to pipelines and internal roads were improved by adding predation risk, while the model incorporating distance to the external road was not. The model of variation in nest survival by predation alone was not very likely ( $2 \%$ of the support).

We found no significant clustering patterns of successful or failed FISP nests with Average Nearest Neighbor assessments; all nests exhibited a dispersed pattern (z-score 3.03, $\mathrm{P}=$ 0.002), failed nests exhibited no pattern ( $\mathrm{z}$-score $-0.17, \mathrm{P}=0.866)$, and successful nests had a dispersed pattern ( $\mathrm{z}$-score 3.03, $\mathrm{P}=0.002)$.

Avian Community.---Shannon's diversity and species richness did not have significant relationships to distance from the north well (Shannon's diversity $\mathrm{F}=1.99$, $\mathrm{df}=1 / 6, \mathrm{P}=0.21$ and species richness $\mathrm{F}=1.12, \mathrm{df}=1 / 6, \mathrm{P}=0.33$ ). Both had general trends of decreasing with increasing distance from the north well (Fig. 4).

\section{DISCUSSION}

NOISE AND LIGHT

Light and noise levels were not significantly different across sites; CCWMA was actually the quietest and dimmest site of the three. Our findings that noise and light emissions from the wellpad approximated background levels for other shrublands in the area is surprising; the pad was trafficked daily by large trucks and small groups of workers, which one would expect to at 
least increase mean noise levels. It is possible that recorders were placed in "acoustic shadows", areas where topographic features or vegetation blocked noise; future studies can insure against this by recording at multiple locations for each distance. Using only light data recorded at night also showed no significant differences, so it was not the case that daytime sunlight was masking effects from the wellpad.

Light and noise levels were not significantly different with increasing distance from the wellpad at CCWMA. We did find site-wide fluctuations in noise levels during different time periods which may have been associated with gas activity, but because they were site-wide this is not very likely. The existing well pad and infrastructure at CCWMA did not alter the acoustic landscape despite the human presence.

Some gas infrastructure such as compressor stations, which constantly emit noise, can be quite impactful to wildlife (Francis et al., 2011, Francis et al., 2012b), and affect avian communities more than gas wells without compressors (Habib et al., 2007). Constant, chronic noise sources are less tolerable to wildlife than brief, punctuated ones (Barber et al., 2010). It is thus important to know that already-developed wells without compressor stations do not emit a substantial amount of noise because they are now pervasive features within the Marcellus-Utica Shale play. This study is the first quantification of light and noise levels emitted from gas wells after drilling. Because the wellpad will be operating in its current state for 40-50 years (Mitchell and Casman 2011), it is an important period to examine for impacts. However, most of the concern regarding light and noise is focused on the well development and hydraulic fracturing stages (Kiviat 2013) which requires further study. 


\section{NEST SUCCESS}

Nest survival of FISPs differed between the gas-impacted and non-impacted sites according to a model which was not the highest ranked, but was highly competitive. Estimates for the entire guild were similar after accounting for variability among species. Although the gas impacted site (CCWMA) was a more successful site on average for these species, we cannot say that gas well-related forces were not negatively impacting CCWMA nests at the site level because it may be that the rates would be even higher in the absence of impacts. We were not able to collect pre-disturbance data. Our model testing for explanations of nest failure mechanisms suggested that predation risk drove differences in survival, indicating that the differences among sites was related to predator activity. Indeed, CCWMA had far less predator detections than the non-impacted sites, and only $1 / 3$ the number of rodents, which were found by the model ranking to be very important in determining nest survival.

Although site-level nest success was high for CCWMA relative to the non-impacted sites, it is possible that the presence of gas wells does negatively impact nest survival; distance to nearest well was in all four of the top models of FISP survival. Success was reduced until about $500 \mathrm{~m}$ away from the nearest well (Fig. 9). Infrastructure also impacted nest survival, but positively. Models of nest survival by distance to the pipeline and distance to the unpaved road were improved by adding predation, which implies that the increased survival around these infrastructures was due to lower predation risk. Adding predation risk to the model of nest survival by distance to the external, paved road did not improve the model's rank, which implies that the higher nest survival around the paved road was due to factors other than predators. The model of nest survival by distance to nearest well was also not improved by adding predation risk, but the model which incorporated predators was almost as well-supported, meaning that 
predation was likely an influence on the trend of low nest survival around wells, but that some other well-related factor explained the relationship better. Predation is the cause of most cupnesting songbird failures (Martin 1993), but nest abandonment occurs regularly, and the model ranking suggests that nests near wells had higher abandonment rates and (to a lesser extent) predation risk. A Barton and Holmes (2007) study of off-highway vehicle trails in sagebrush habitat found lower nest depredation but higher abandonment rates near the roads, which received similar perturbation pressures as the wellpad and roads at CCWMA. However, as discussed above, we found lower abandonment likelihood near the external road and the trends of decreasing nest success with increasing distance from the pipeline and unpaved internal road to be better explained by predation. Francis et al. (2009) found decreases in nest predator occurrence and nest predation rates around gas extraction infrastructure, but this included wellpads with noisy compressor stations.

The vegetative gradient was also important in explaining variation in FISP nest survival; it was in all four top models. The lack of support for the model of vegetation alone (only $0.4 \%$ of the support) suggests that it was not important in absence of the gas infrastructure, further solidifying the likelihood of gas development affecting nesting success. The vegetative gradient was statistically significant; plots closer to the north well were similar to each other based largely on sapling layer height, plot area covered by saplings, and canopy richness whereas those further from the well were similar to each other based on shrub counts and the percentage of exotic shrubs (Fig. 8). Plots in the north of the site, nearer to the north well, were closer to habitat edge, had taller and more abundant saplings, and more abundant trees. CCWMA becomes more open and less tree-dominated from north to south, essentially being in increasingly early successional conditions. This would help explain the vegetative gradient's role in the trend of increasing nest 
success with increasing distance from the north well; eastern chipmunks and gray squirrels are associated with forest conditions (Rosenblatt et al., 1999) and thus predation risk would be higher in this area of the site, where the well is also located.

Because we did not find noise or light levels to differ based on distance to the north well, it is unlikely that these were the factors contributing to lower survival rates. It may be that frequent human visits to the well were responsible for the increased abandonment, along with increased predation due to the vegetative structure. The reduced nest survival lasted about $500 \mathrm{~m}$ from the well, which is less than the $700 \mathrm{~m}$ of negative effects reported for noisy compressor stations in forests by Bayne et al., (2008). These trends for the FISP may not apply to other early-successional species; our nest sample sizes were too low to assess them for others. It is also important to note that we did not have data on nocturnal nest predators, which may have had different predation risks.

Success rates in our study were near those reported in the literature. We had $30 \%$ of FISP nests fledge where rates in the literature ranged from 20-63\% (Carey et al., 2008), 33\% of BWWA nests fledged where rates in the literature ranged from 21-77\% (Askins et al., 2007, Confer et al., 2010, Slay 2010), and 25\% of EATO nests fledged where rates in the literature ranged from 27-69\% (Greenlaw 1996). We monitored nests of these 3 species for other studies in 2012 and had higher survival probabilities for EATOs and BWWAs (RDD unpubl data), so 2013 may have been a stochastically poor year for nest survival in the region.

\section{AVIAN COMMUNITY}

We found no significant differences in site-level bird diversity between CCWMA and non-impacted shrublands. The avian communities recorded at each type did differ, but we could not extract the presence of gas wells from site-level differences. The bird community differences 
likely existed due to vegetation differences and not gas well presence; we found the more disparate points in the ordination to be driven by a few species' associations to different sites (Fig. 5). Many of these were specialists which are tied to specific habitats. For example, GRSPs were highly associated with points that had high grass cover and HOWAs and WOTHs (Wood Thrush, Hylocichla mustelina) with points that had more canopy trees and high canopy richness.

Shannon's diversity and species richness decreased slightly with increasing distance from the north gas well at CCWMA. The trends were likely due again to the north-south vegetative gradient described above. Plots near the gas well were closer to the forest edge and had more woody structural diversity, two factors which could explain the slightly higher bird diversity there.

A limitation to this study was the lack of multiple gas-impacted sites. This did not allow us to satisfactorily separate site-level effects from gas development impacts, or to make stronger inferences on the effects of gas wellpads and infrastructure on shrubland songbirds. Though we found no clear evidence of gas wells dampening avian diversity or altering community structure on our sites, this may not be the case elsewhere. The complexity of ecological systems and uncontrollable nature of field studies requires future studies aiming to determine effects of gas wells on avian communities to have a high number of study sites in order to separate contributions of development, vegetation, stochasticity, and individual species responses. Hamilton et al., (2011) found different grassland bird species to show unique occurrence and abundance changes in relation to the increased human activity associated with gas well densities. It may be the case that birds on our sites were responding to the anthropogenic perturbations, but these changes were not detectable due to our constrained study design. 
More specific, robust studies similar to this one should be conducted in the future to increase understanding of the impacts of shale gas development on terrestrial biota. Inferences based on our results are not broad, but similar relationships possibly exist elsewhere. Future studies should draw comparisons between multiple impacted and non-impacted sites, where sites are replicates and data gathered are samples within those replicates. This would improve statistical rigor and allow for the separation of site-level differences in vegetation and predator abundance from effects of the gas development. Our impacted site was coincidentally the site with the least amount of predators and simplest vegetation, so our results cannot speak to the effects from all gas impacts but just to the differences we saw at our sites. Replication of sampling points within impacted sites (multiple count stations and noise and light recorders per distance from a well) would also improve the inferential abilities of a future study. We only focused on a well post-development, which is important, but similar assessments are needed during all development stages, and ideally pre- and post-development. To determine the full impact of unconventional gas development on terrestrial biota, improved versions of this study should be conducted in all habitat types and on all taxonomic groups.

\section{CONCLUSIONS}

We found no clear evidence of gas development negatively impacting nest survival or avian communities on one site where the pad was already built and drilling was completed. Close proximity to the wellpad reduced nest success, but it increased closer to pipelines and roads. Site-level differences in nest survival were clearer, with our focal species having higher breeding success on the impacted site. It may be that non-pad infrastructure boosting nest survival balanced the decreases due to proximity to the wellpad. Noise and light were not factors which differed based on the presence of gas development at our sites or with increasing distance from 
the developed well at CCWMA. Nest predators were important in explaining nest survival variation at the site-level, but within the developed site nest abandonment was a more likely force around wells. Community dynamics at both the site level and within the impacted site appear to have been driven by vegetation and not pressures from human presence. The decreased nest survival close to the pad lasted less than $500 \mathrm{~m}$, which is smaller than distances reported for negative effects in contiguous forests, and the higher survival near infrastructure is the opposite of the effect reported in forests (Bayne et al., 2008). Our constrained study design does not allow broad inferences, and it is difficult to explain why heavily trafficked roads would increase nest survival while the similarly trafficked wellpad decreased success. These trends may not hold for other guilds or even other early-successional species. Negative influences may also arise from compressor stations or the pads during construction and drilling, which needs to be assessed for eastern ecosystems, in both forest and human-dominated landscape contexts.

Gas development may impose different forces on nesting shrubland songbirds than on those adapted to interior forests, and birds inhabiting a human-dominated landscape may be accustomed to perturbations such as truck noise and human presence. They may already be subject to the negative impacts of habitat perforation such as increased predator abundance beyond a threshold of further declines. If this is the case, the tendency for wells to be developed in an already modified landscape context may be positive because it means less habitat degradation for the more sensitive forest interior specialists. The large footprint of unconventional gas development means that even if their presence in shrubland habitats does not detriment songbirds after placement, large amounts of habitat (8.8 acres per pad, Johnson 2010) are still being lost for several decades until reclamation. Unconventional gas development in shrublands may not degrade these habitats as much as it does others, but habitat loss is still a 
serious issue for specialists of this seral stage and the replacement of large areas of early succession should not be taken lightly. 


\section{LITERATURE CITED}

Alldredge, M. W., K. H. Pollock, T. R. Simons, J. A. Collazo, and S. A. Shriner. 2007b. Timeof-detection method for estimating abundance from point-count surveys. The Auk 124:653-664.

Alldredge, M. W., T. R. Simons, and K. H. Pollock. 2007a. A field evaluation of distance measurement error in auditory avian point count surveys. Journal of Wildlife Management 71:2759-2766.

AMBCRP (Appalachian Mountains Bird Conservation Region Partnership). 2005. Appalachian Mountains Bird Conservation Initiative Concept Plan. Can be accessed online at: http://www.acjv.org/documents/bcr28_concept_plan.pdf.

Askins, R. A., B. Zuckerberg, and L. Novak. 2007. Do the size and landscape context of forest openings influence the abundance and breeding success of shrubland songbirds in southern New England? Forest Ecology and Management 250:137-147.

Barber, J. R., K. R. Crooks, and K. M. Fristrup. 2010. The costs of chronic noise exposure for terrestrial organisms. Trends in Ecology and Evolution 25:180-189.

Barton, D. C. and A. L. Holmes. 2007. Off-highway vehicle trail impacts on breeding songbirds in Northeastern California. Journal of Wildlife Management 71:1617-1620.

Bayne, E. M., L. Habib, and S. Boutin. 2008. Impacts of chronic anthropogenic noise from energy-sector activity on abundance of songbirds in the boreal forest. Conservation Biology 22:1186-1193.

Beyer, H.L. 2012. Geospatial Modeling Environment (Version 0.7.2.1). Available at: http://www.spatialecology.com/gme. Last accessed 15 June 2013. 
Blickley, J. L. and G. L. Patricelli. 2012. Potential acoustic masking of Greater Sage-grouse (Centrocercus urophasianus) display components by chronic industrial noise. Ornithological Monographs 74:23-35.

Bradley, J. E., and J. M. Marzluff. 2003. Rodents as nest predators: Influences on predatory behavior and consequences to nesting birds. The Auk 120:1180-1187.

Bulluck, L. P. and D. A. Buehler. 2008. Factors influencing Golden-winged Warbler (Vermivora chrysoptera) nest-site selection and nest survival in the Cumberland Mountains of Tennessee. The Auk 125:551-559.

Burnham, K. P. and D. R. Anderson, D. R. 2002. Model selection and inference: a practical information-theoretic approach, 2nd ed. Springer-Verlag, New York, NY.

Carey, M., D. E. Burhans and D. A. Nelson. 2008. Field Sparrow (Spizella pusilla), The Birds of North America Online (A. Poole, Editor). Cornell Lab of Ornithology, Ithaca, New York, U.S.A. http://bna.birds.cornell.edu.bnaproxy.birds.cornell.edu/bna/species/103 (accessed 10 December 2013).

Chalfoun, A. D., M. J. Ratnaswamy, and F. R. Thompson. 2002. Songbird nest predators in forest-pasture edge and forest interior in a fragmented landscape. Ecological Applications 12:858-867.

Clarke, K. R. and R. H. Green. 1988. Statistical design and analysis for a "biological effects" study. Marine Ecology Progress Series 46:213-226.

Colborn, T., C. Kwiatkowski, K. Shultz, and M. Bachran. 2011. Natural gas operations from a public health perspective. Human and Ecological Risk Assessment 17:1039-1056.

Colborn, T., K. Shultz, L. Herrick, and C. Kwiatkowski. 2012. An exploratory study of air quality near natural gas operations. Human and Ecological Risk Assessment 20:86-105. 
Confer, J. L., K. W. Barnes, and E. C. Alvey. 2010. Golden- and Blue-Winged Warblers:

Distribution, nesting success, and genetic differences in two habitats. Wilson Journal of Ornithology 122:273-278.

DeGraaf, R. M. and M. Yamasaki. 2003. Options for managing early-successional forest and shrubland bird habitats in the northeastern United States. Forest Ecology and Management 185:179-191.

Dettmers, R. 2003. Status and conservation of shrubland birds in the northeastern US. Forest Ecology and Management 185:81-93.

Drohan, P.J., M. Brittingham, J. Bishop, and K. Yoder. 2012. Early trends in landcover change and forest fragmentation due to shale-gas development in Pennsylvania: a potential outcome for the northcentral Appalachians. Environmental Management 49:1061-1075.

ESRI 2012. ArcGIS Desktop: Release 10.1. Redlands, CA: Environmental Systems Research Institute.

Faith, D. P., P. R. Minchin, and L. Belbin. 1987. Compositional dissimilarity as a robust measure of ecological distance. Vegetatio 69:57-68.

Farnsworth, G. L., K. H. Pollock, J. D. Nichols, T. R. Simons, J. E. Hines, and J. R. Sauer. 2002. A removal model for estimating detection probabilities from point-count surveys. The Auk 119:414-425.

Francis, C. D., C. P. Ortega, and A. Cruz. 2009. Noise pollution changes avian communities and species interactions. Current Biology 19:1415-1419.

Francis, C. D., C. P. Ortega, R. I. Kennedy, and P. J. Nylander. 2012b. Are nest predators absent from noisy areas or unable to locate nests? Ornithological Monographs 74:101-110. 
Francis, C. D., J. Paritsis, C. P. Ortega, and A. Cruz. 2011. Landscape patterns of avian habitat use and nest success are affected by chronic gas well compressor noise. Landscape Ecology 26:1269-1280.

Francis, C. D., N. J. Kleist, C. P. Ortega, and A. Cruz. 2012a. Noise pollution alters ecological services: enhanced pollination and disrupted seed dispersal. . Proceedings of the Royal Society Biological Sciences 279:2727-2735.

Friendly, M. and J. Fox. 2013. candisc: Visualizing Generalized Canonical Discriminant and Canonical Correlation Analysis. R package version 0.6-5. http://CRAN.Rproject.org/package $=$ candisc .

Gill, F. B., R. A. Canterbury and J. L. Confer. 2001. Blue-winged Warbler (Vermivora cyanoptera), The Birds of North America Online (A. Poole, Editor). Ithaca: Cornell Lab of Ornithology, Ithaca, New York, U.S.A. http://bna.birds.cornell.edu. bnaproxy.birds.cornell.edu/bna/species/584doi:10.2173/bna.584 (accessed 10 December 2013).

Gittins, R. 1985. Canonical Analysis: A review with applications in ecology. Springer, Berlin. Greenlaw, Jon S. 1996. Eastern Towhee (Pipilo erythrophthalmus), The Birds of North America Online (A. Poole, Editor). Ithaca: Cornell Lab of Ornithology, Ithaca, New York,U.S.A.. http://bna.birds.cornell.edu.bnaproxy.birds.cornell.edu/bna/species/262doi:10.2173/bna.2 62 (accessed 10 December 2013).

GWPC (Ground Water Protection Council) and ALL Consulting. 2009. Modern shale gas development in the United States: a primer. Report commissioned by the United States Department of Energy, Office of Fossil Energy and National Energy Technology 
Laboratory. Accessible online at: http://www.netl.doe.gov/technologies/oilgas/publications/epreports/shale_gas_primer_2009.pdf.

Habib, L., E. M. Bayne, and S. Boutin. 2007. Chronic industrial noise affects pairing success and age structure of ovenbirds Seiurus aurocapilla. Journal of Applied Ecology 44:176-184.

Hamilton, L. E., B. C. Dale, and C. A. Paszkowski. 2011. Effects of disturbance associated with natural gas extraction on the occurrence of three grassland songbirds. Avian Cons Ecol, 6: article 7. [Online] Available at www.ace-eco.org/vol6/iss1/art7/.

Holloran, M. J. 2005. Greater Sage-Grouse (Centrocercus urophasianus) population response to natural gas field development in western Wyoming. Ph.D. dissertation, University of Wyoming, Laramie.

Jackson, R. B., A. Vengosh, T. H. Darrah, N. R. Warner, A. Down, R. J. Poreda, S. G. Osborn, K. Zhao, and J. D. Karr. 2013. Increased stray gas abundance in a subset of drinking water wells near Marcellus shale gas extraction. Proceedings of the National Academy of Sciences of the United States of America 110:11250-11255.

James, F. C. and H. H. Shugart Jr.. 1970. A quantitative method of habitat description. Audubon Field Notes 24:727-736.

Johnson, N. 2010. Pennsylvania Energy Impacts Assesment, Report 1: Marcellus Shale Natural Gas and Wind. The Nature Conservancy. Online, available at http://www.nature.org/media/pa/tnc_energy_analysis.pdf.

Kiviat, E. 2013. Risks to biodiversity from hydraulic fracturing for natural gas in the Marcellus and Utica shales. Annals of the New York Academy of Sciences 1286:1-14.

Martin, T. E. 1993. Nest predation and nest sites. BioScience 43:523-532. 
Martin, T. E., C. J. Conway, W. M. Hochachaka, P. Allen, and W. Jenkins. 1997. BBIRD field protocols. U.S.G.S. Biological Resources Division, Montana Cooperative Wildlife Research Unit, University of Montana, Missoula, Montana, U.S.A. Available at http://www.umt.edu/bbird/protocol/veg.aspx.

Martin, T., and G. Geupel. 1993. Nest-monitoring plots: methods for locating nests and monitoring success. Journal of Field Ornithology 64:507-519.

Maxson, S. J. and L. W. Oring. 1978. Mice as a source of egg loss in ground-nesting birds. The Auk 95:582-584.

Mitchell, A. L. and E. A. Casman. 2011. Economic incentives and regulatory framework for shale gas well site reclamation in Pennsylvania. Environmental Science and Technology 45:9506-9514.

Oksanen, J., F. G. Blanchet, R. Kindt, P. Legendre, P. R. Minchin, R. B. O'Hara, G. L. Simpson, P. Solymos, M. H. H. Stevens, and H. Wagner. 2013. vegan: Community Ecology Package. $\mathrm{R}$ package version 2.0-9. http://CRAN.R-project.org/package=vegan.

PADEP (Pennsylvania Department of Environmental Protection) 2011. Oil and Gas Well Drilling and Production in Pennsylvania Fact Sheet. Accessible online at: http://www.elibrary.dep.state.pa.us/dsweb/Get/Document-83620/5500-FS-DEP2018.pdf.

R Development Core Team. 2013. R: A language and environment for statistical computing. R Foundation for Statistical Computing, Vienna, Austria. ISBN 3-900051-07-0, URL http://www.R-project.org/.

Ralph, C. J., G. R. Geupel, P. Pyle, T. E. Martin, and D. F. DeSante. 1993. Handbook of Field Methods for Monitoring Landbirds. Gen. Tech. Re. PSW-GTR-144. Albany, CA: Pacific Southwest Research Station, Forest Service, U.S. Department of Agriculture. 
Ralph, C. J., J. R. Sauer, and S. Droege (Editors). 1995. Monitoring bird populations by point counts. United States Forest Service General Technical Report PSW-GTR-149.

Reitsma, L. R., R. T. Holmes, and T. W. Sherry. 1990. Effects of removal of red squirrels, Tamiasciurus hudsonicus, and eastern chipmunks, Tamias striatus, on nest predation in a northern hardwood forest: an artificial nest experiment. Oikos 57:375-380.

Rosenblatt, D. L., E. J. Heske, S. L. Nelson, D. M. Barber, M. A. Miller, and B. MacAllister. 1999. Forest fragments in east-central Illinois: islands or habitat patches for mammals? American Midlands Naturalist 141:115-123.

Rotella, J. J., S. J. Dinsmore, and T. L. Shaffer. 2004. Modeling nest-survival data: a comparison of recently developed methods that can be implemented in MARK and SAS. Animal Biodiversity and Conservation 27:187-205.

Sauer, J. R., J. E. Hines, J. E. Fallon, K. L. Pardieck, D. J. Ziolkowski, Jr., and W. A. Link. 2014. The North American Breeding Bird Survey, Results and Analysis 1966 - 2012. Version 02.19.2014 USGS Patuxent Wildlife Research Center, Laurel, MD.

Slay, C. M. 2010. An evaluation of reproductive success, adult survivorship and habitat use of shrubland birds on conservation-managed fields in western Connecticut. Dissertation. University of Arkansas, Fayetteville, U.S.A.

Soeder, D. J., and W. M. Kappel. 2009. Water resources and natural gas production from the Marcellus Shale. U.S. Department of the Interior, U.S. Geological Survey, Reston, VA.

Sutherland, W. J., S. Bardsley, L. Bennun, M. Clout, I. M. Cote, M. H. Depledge, L. V. Dicks, A. P. Dobson, L. Fellman, E. Fleishman, D. W. Gibbons, A. J. Impey, J. H. Lawton, F. Lickorish, D. B. Lindenmayer, T. E. Lovejoy, R. MacNally, J. Madgwick, L. S. Peck, J. Pretty, S. V. Prior, K. H. Redford, J. P. W. Scharlemann, M. Spalding, and A. R. 
Watkinson. 2011. Horizon scan of global conservation issues for 2011. Trends in Ecology and Evolution 26:10-16.

Thomas, E. H. 2011. Effects of oil and gas development on songbird abundance in the Alleghenty National Forest. Thesis. Pennsylvania State University, State College, U.S.A. Thompson, F. R., W. Dijak, and D. E. Burhans. 1999. Video identification of predators at songbird nests in old fields. The Auk 116:259-264.

Trani, M. K., R. T. Brooks, T. L. Schmidt, V. A., Rudis, C. M., Gabbard. 2001. Patterns and trends of early successional forests in the eastern United States. Wildlife Society Bulletin 29:413-424.

Weltman-Fahs, M. and J. M. Taylor. 2013. Hydraulic fracturing and brook trout habitat in the Marcellus Shale region: potential impacts and research needs. Fisheries 38:4-15.

White, G. C., and K. P. Burnham. 1999. Program MARK: survival estimation from populations of marked animals. Bird Study 46:120-139.

White, G.C. 1992. PC SURVIV User's Manual. Dept. of Fishery and Wildlife Biology, Colorado State University, Fort Collins, CO. 
Table 1. Nest metrics for all species. Number of eggs/nest is the average number of eggs from all nests. Number of fledglings/nest is the average number of nestlings at the last check before fledging from all successful nests. CCWMA (Cross Creek Wildlife Management Area) was gas-impacted, HSP (Hillman State Park) and HWMA (Hillcrest Wildlife Management Area) were not. FISP = Field Sparrow, BWWA $=$ Blue-Winged Warbler, and EATO $=$ Eastern Towhee. FISPs did not significantly differ in number of eggs $(\mathrm{F}=2.65, \mathrm{df}=3 / 75, \mathrm{P}=0.08)$ or fledglings per nest $(\mathrm{F}=0.82, \mathrm{df}=3 / 21, \mathrm{P}=0.46)$ across sites.

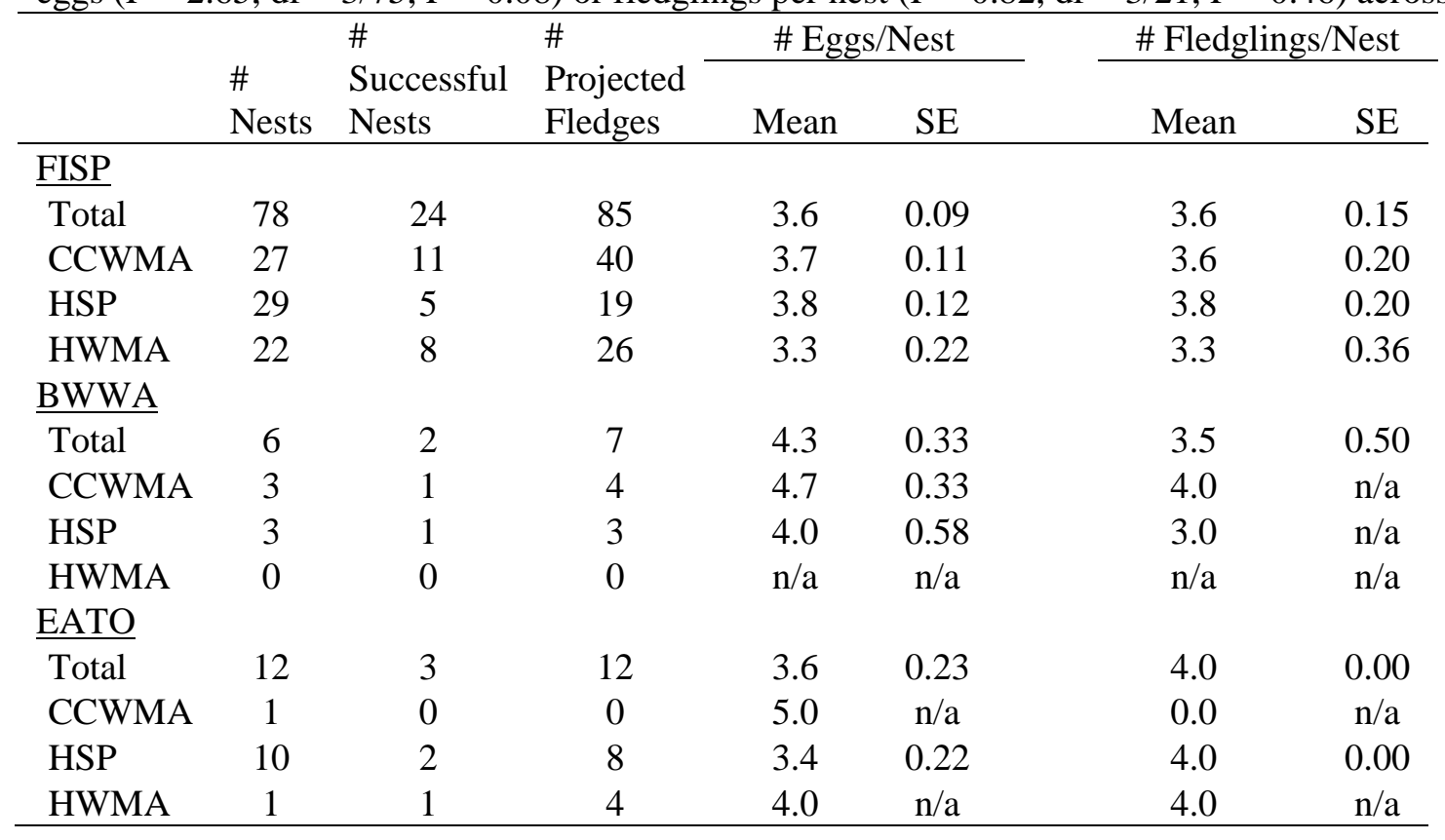

Table 2. Candidate models of nest survival for site-level comparisons. Models with $\Delta$ AICc $<2$ are considered to be highly supported and are bolded for emphasis. Species monitored in the shrubland guild are the Field Sparrow, Blue-winged Warbler, and Eastern Towhee.

\begin{tabular}{|c|c|c|c|c|}
\hline Model of Survival Dependent on: & $\mathrm{AICc}$ & $\begin{array}{c}\Delta \\
\mathrm{AICc}\end{array}$ & $\begin{array}{c}\text { AICc } \\
\text { Weight }\end{array}$ & $\begin{array}{c}\text { Model } \\
\text { Likelihood }\end{array}$ \\
\hline \multicolumn{5}{|l|}{ Field Sparrow } \\
\hline Constant - No Effect Gas or Site & 323.73 & $\mathbf{0 . 0 0}$ & 0.413 & 1.00 \\
\hline Gas Development & 324.13 & 0.40 & 0.339 & 0.82 \\
\hline Site & 326.14 & 2.41 & 0.124 & 0.30 \\
\hline Site and Gas Development & 326.14 & 2.41 & 0.124 & 0.30 \\
\hline \multicolumn{5}{|l|}{ Shrubland Guild } \\
\hline Species & 390.56 & 0.00 & 0.214 & 1.00 \\
\hline Gas and Species & 390.72 & 0.16 & 0.198 & 0.92 \\
\hline Gas & 390.86 & 0.30 & 0.184 & 0.86 \\
\hline Constant- No Gas, Site, or Species Effect & 391.98 & 1.42 & 0.105 & 0.49 \\
\hline Gas and Site & 392.62 & 2.06 & 0.077 & 0.36 \\
\hline Site & 392.62 & 2.06 & 0.077 & 0.36 \\
\hline Site and Species & 392.73 & 2.17 & 0.073 & 0.34 \\
\hline Site, Species, and Gas & 392.73 & 2.17 & 0.073 & 0.34 \\
\hline
\end{tabular}


Table 3. Predators detected by site. CCWMA (Cross Creek Wildlife Management Area) was gas-impacted. HSP (Hillman State Park) and HWMA (Hillcrest Wildlife Management Area) were not.

\begin{tabular}{lcccc}
\hline & Total & $\begin{array}{c}\text { Total } \\
\text { Rodent }\end{array}$ & $\begin{array}{c}\text { Black Rat } \\
\text { Snake }\end{array}$ & $\begin{array}{c}\text { Other } \\
\text { Mammal }\end{array}$ \\
\hline CCWMA & 19 & 13 & 4 & 2 \\
HSP & 50 & 49 & 1 & 0 \\
HWMA & 36 & 33 & 1 & 2
\end{tabular}

Number of Rodents by Species

\begin{tabular}{lccccc} 
& $\begin{array}{c}\text { Eastern } \\
\text { Chipmunk }\end{array}$ & $\begin{array}{c}\text { Gray } \\
\text { Squirrel }\end{array}$ & $\begin{array}{c}\text { Fox } \\
\text { Squirrel }\end{array}$ & Mouse & $\begin{array}{c}\text { Red } \\
\text { Squirrel }\end{array}$ \\
\cline { 2 - 6 } CCWMA & 9 & 0 & 1 & 2 & 1 \\
HSP & 34 & 6 & 1 & 2 & 6 \\
HWMA & 24 & 2 & 1 & 6 & 0 \\
\hline
\end{tabular}

Table 4. Candidate models of nest survival for determining site-level mechanisms of failure. Models with $\Delta$ AICc $<2$ are considered to be highly supported and are bolded for emphasis. Species monitored are the Field Sparrow, Blue-winged Warbler, and Eastern Towhee.

\begin{tabular}{|l|c|c|c|c|}
\hline \multicolumn{1}{|c|}{ Model of Survival Dependent on: } & AICc & $\begin{array}{c}\Delta \\
\text { AICc }\end{array}$ & $\begin{array}{c}\text { AICc } \\
\text { Weights }\end{array}$ & $\begin{array}{c}\text { Model } \\
\text { Likelihood }\end{array}$ \\
\hline Predators: all rodents and black rat snakes & $\mathbf{3 8 8 . 0 9}$ & $\mathbf{0 . 0 0}$ & $\mathbf{0 . 1 9 6}$ & $\mathbf{1 . 0 0}$ \\
\hline Predators: all rodents & $\mathbf{3 8 9 . 0 2}$ & $\mathbf{0 . 9 2}$ & $\mathbf{0 . 1 2 4}$ & $\mathbf{0 . 6 3}$ \\
\hline Predators: eastern chipmunk & $\mathbf{3 8 9 . 1 4}$ & $\mathbf{1 . 0 5}$ & $\mathbf{0 . 1 1 6}$ & $\mathbf{0 . 5 9}$ \\
\hline Avian Species and All Predators & $\mathbf{3 8 9 . 7 0}$ & $\mathbf{1 . 6 1}$ & $\mathbf{0 . 0 8 8}$ & $\mathbf{0 . 4 5}$ \\
\hline Predators: gray squirrel & $\mathbf{3 8 9 . 7 9}$ & $\mathbf{1 . 6 9}$ & $\mathbf{0 . 0 8 4}$ & $\mathbf{0 . 4 3}$ \\
\hline $\begin{array}{l}\text { Predators: all rodents, black rat snakes, and } \\
\text { other mammals }\end{array}$ & $\mathbf{3 9 0 . 0 1}$ & $\mathbf{1 . 9 2}$ & $\mathbf{0 . 0 7 5}$ & $\mathbf{0 . 3 8}$ \\
\hline Predators: all predators & 390.29 & 2.20 & 0.065 & 0.33 \\
\hline Predators: black rat snakes & 390.50 & 2.41 & 0.059 & 0.30 \\
\hline Avian Species & 390.56 & 2.47 & 0.057 & 0.29 \\
\hline $\begin{array}{l}\text { Constant Survival - No effect of site, species, or } \\
\text { predators }\end{array}$ & 391.98 & 3.89 & 0.028 & 0.14 \\
\hline Site & 392.62 & 4.53 & 0.020 & 0.10 \\
\hline Avian Species and Site & 392.73 & 4.64 & 0.019 & 0.10 \\
\hline Predators: other mammals & 393.12 & 5.02 & 0.016 & 0.08 \\
\hline Site and All Predators & 393.23 & 5.13 & 0.015 & 0.08 \\
\hline Predators: fox squirrels & 393.34 & 5.24 & 0.014 & 0.07 \\
\hline Predators: mice & 393.74 & 5.65 & 0.012 & 0.06 \\
\hline Predators: red squirrels & 393.76 & 5.67 & 0.012 & 0.06 \\
\hline
\end{tabular}


Table 5. Candidate models of Field Sparrow nest survival at the gas-impacted Cross Creek Wildlife Management Area. Models with $\triangle \mathrm{AICc}<2$ are considered to be highly supported and are bolded for emphasis.

\begin{tabular}{|c|c|c|c|c|}
\hline Model of Survival Dependent on: & $\mathrm{AICc}$ & $\begin{array}{c}\Delta \\
\mathrm{AICc}\end{array}$ & $\begin{array}{c}\text { AICc } \\
\text { Weights }\end{array}$ & $\begin{array}{c}\text { Model } \\
\text { Likelihood }\end{array}$ \\
\hline Vegetation and Distance to Nearest Well & 97.98 & $\mathbf{0 . 0 0}$ & 0.263 & 1.00 \\
\hline $\begin{array}{l}\text { Vegetation, Distance to Nearest Well, and Distance } \\
\text { to External Road }\end{array}$ & 98.93 & 0.95 & 0.164 & 0.62 \\
\hline $\begin{array}{l}\text { Vegetation, Distance to Nearest Well, and Distance } \\
\text { to Pipeline }\end{array}$ & 99.50 & 1.52 & 0.123 & 0.47 \\
\hline $\begin{array}{l}\text { Vegetation, Distance to Nearest Well, and Distance } \\
\text { to Internal Road }\end{array}$ & 99.67 & 1.69 & 0.113 & $\mathbf{0 . 4 3}$ \\
\hline $\begin{array}{l}\text { Vegetation, Distance to Nearest Well, Distance to } \\
\text { Internal Road, and Distance to External Road }\end{array}$ & 100.50 & 2.52 & 0.075 & 0.28 \\
\hline Vegetation and Distance to South Well & 101.96 & 3.98 & 0.036 & 0.14 \\
\hline $\begin{array}{l}\text { Distance to Internal Road, Distance to Nearest Well, } \\
\text { Distance to Pipeline, and Distance to External } \\
\text { Road }\end{array}$ & 102.68 & 4.70 & 0.025 & 0.10 \\
\hline Distance to Pipeline & 102.91 & 4.93 & 0.022 & 0.09 \\
\hline Distance to External Road & 103.07 & 5.09 & 0.021 & 0.08 \\
\hline Vegetation and Distance to North Well & 103.36 & 5.38 & 0.018 & 0.07 \\
\hline $\begin{array}{l}\text { Distance to External Road and Distance to Nearest } \\
\text { Well }\end{array}$ & 103.41 & 5.43 & 0.017 & 0.07 \\
\hline Vegetation and Distance to Pipeline & 103.75 & 5.77 & 0.015 & 0.06 \\
\hline Distance to Pipeline and Distance to Nearest Well & 103.84 & 5.86 & 0.014 & 0.05 \\
\hline Distance to External Road and Distance to Pipeline & 104.11 & 6.13 & 0.012 & 0.05 \\
\hline Vegetation and Distance to External Road & 104.43 & 6.45 & 0.010 & 0.04 \\
\hline Distance to Nearest Well & 104.62 & 6.64 & 0.010 & 0.04 \\
\hline Distance to Internal Road and Distance to Pipeline & 104.90 & 6.92 & 0.008 & 0.03 \\
\hline $\begin{array}{l}\text { Vegetation, Distance to External Road, and Distance } \\
\text { to Pipeline }\end{array}$ & 104.92 & 6.94 & 0.008 & 0.03 \\
\hline $\begin{array}{l}\text { Distance to Internal Road and Distance to Nearest } \\
\text { Well }\end{array}$ & 105.14 & 7.16 & 0.007 & 0.03 \\
\hline Constant Survival & 105.19 & 7.21 & 0.007 & 0.03 \\
\hline $\begin{array}{l}\text { Vegetation, Distance to Internal Road, and Distance to } \\
\text { Pipeline }\end{array}$ & 105.24 & 7.26 & 0.007 & 0.03 \\
\hline Which Well is Nearest & 105.60 & 7.62 & 0.006 & 0.02 \\
\hline Distance to South Well & 105.68 & 7.70 & 0.006 & 0.02 \\
\hline Vegetation & 106.43 & 8.45 & 0.004 & 0.01 \\
\hline Distance to North Well & 106.63 & 8.65 & 0.003 & 0.01 \\
\hline Distance to Internal Road & 107.19 & 9.21 & 0.003 & 0.01 \\
\hline Vegetation and Distance to Internal Road & 108.45 & 10.47 & 0.001 & 0.01 \\
\hline
\end{tabular}


Table 6. Candidate models of Field Sparrow nest survival at the gas-impacted Cross Creek Wildlife Management Area, incorporating effects of gas development and predation risk. Models with $\Delta$ AICc $<2$ are considered to be highly supported.

\begin{tabular}{|l|c|c|c|c|}
\hline \multicolumn{1}{|c|}{ Model of Survival Dependent on: } & AICc & $\Delta$ AICc & $\begin{array}{c}\text { AICc } \\
\text { Weight } \\
\text { s }\end{array}$ & $\begin{array}{c}\text { Model } \\
\text { Likelihoo } \\
\text { d }\end{array}$ \\
\hline Vegetation and Distance to Nearest Well & 97.98 & 0.00 & 0.210 & 1.00 \\
\hline $\begin{array}{l}\text { Vegetation, Distance to Nearest Well, and Risk from } \\
\text { Predators: all rodents and black rat snakes }\end{array}$ & 98.58 & 0.60 & 0.155 & 0.74 \\
\hline $\begin{array}{l}\text { Vegetation, Distance to Nearest Well, and Distance to } \\
\text { External Road }\end{array}$ & 98.93 & 0.95 & 0.131 & 0.62 \\
\hline $\begin{array}{l}\text { Vegetation, Distance to Nearest Well, Distance to Pipeline, } \\
\text { and Risk from Predators: all rodents and black rat } \\
\text { snakes }\end{array}$ & 98.93 & 0.95 & 0.131 & 0.62 \\
\hline $\begin{array}{l}\text { Vegetation, Distance to Nearest Well, and Distance to } \\
\text { Pipeline }\end{array}$ & 99.50 & 1.52 & 0.098 & 0.47 \\
\hline $\begin{array}{l}\text { Vegetation, Distance to Nearest Well, Distance to Internal } \\
\text { Road, and Risk from Predators: all rodents and black } \\
\text { rat snakes }\end{array}$ & 99.54 & 1.56 & 0.096 & 0.46 \\
\hline $\begin{array}{l}\text { Vegetation, Distance to Nearest Well, and Distance to } \\
\text { Internal Road }\end{array}$ & 99.67 & 1.69 & 0.090 & 0.43 \\
\hline $\begin{array}{l}\text { Vegetation, Distance to Nearest Well, Distance to External } \\
\text { Road, and Risk from Predators: all rodents and black } \\
\text { rat snakes }\end{array}$ & 100.42 & 2.44 & 0.062 & 0.30 \\
\hline Risk from Predators: all rodents and black rat snakes & 102.64 & 4.66 & 0.020 & 0.10 \\
\hline Constant Survival & 105.19 & 7.21 & 0.006 & 0.03 \\
\hline
\end{tabular}




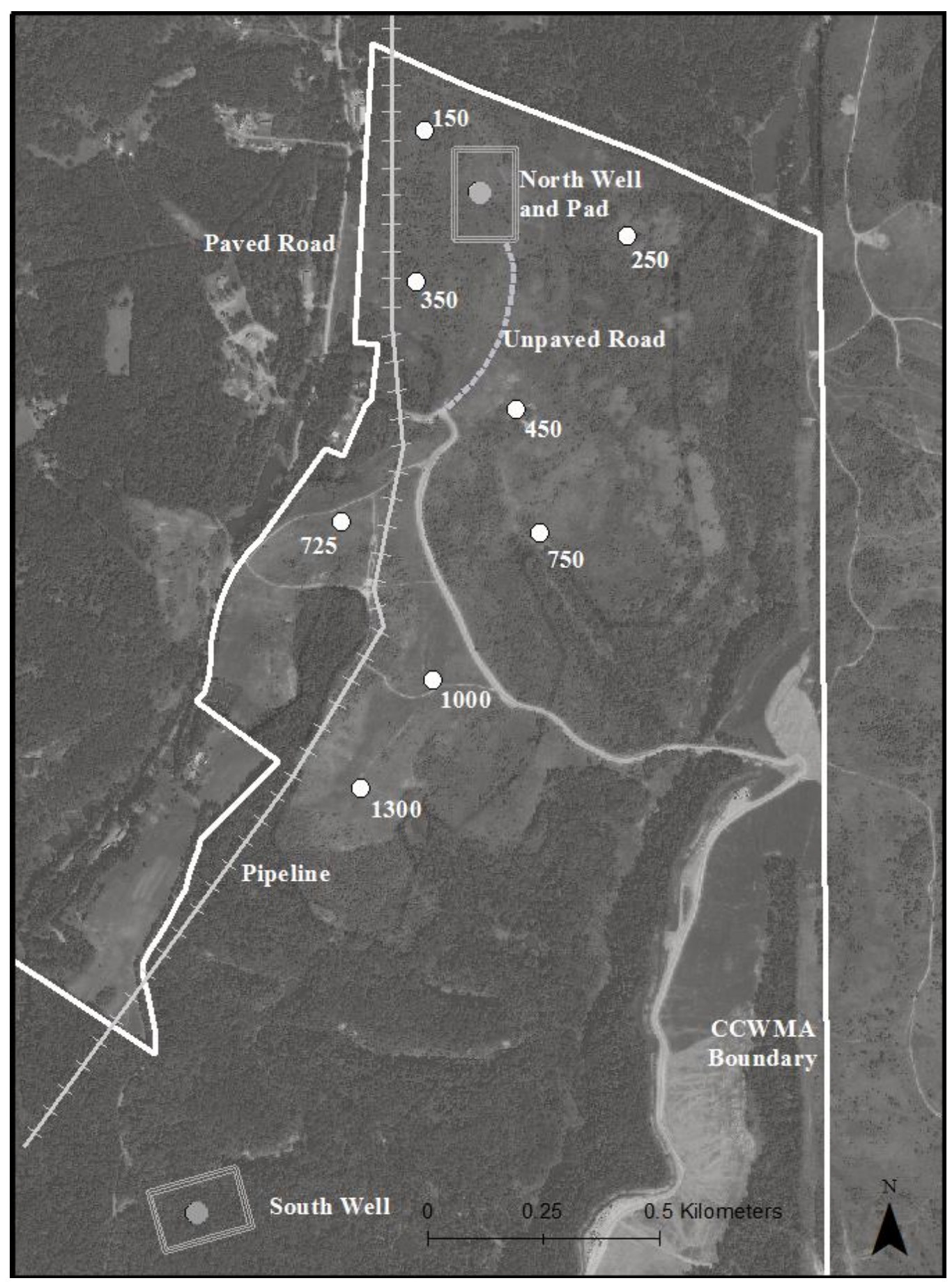

Figure 1. An aerial photograph of Cross Creek Wildlife Management Area (CCWMA), including both wells, the eight point count stations, and added approximations of infrastructure which has been added since the aerial was taken (2008). 

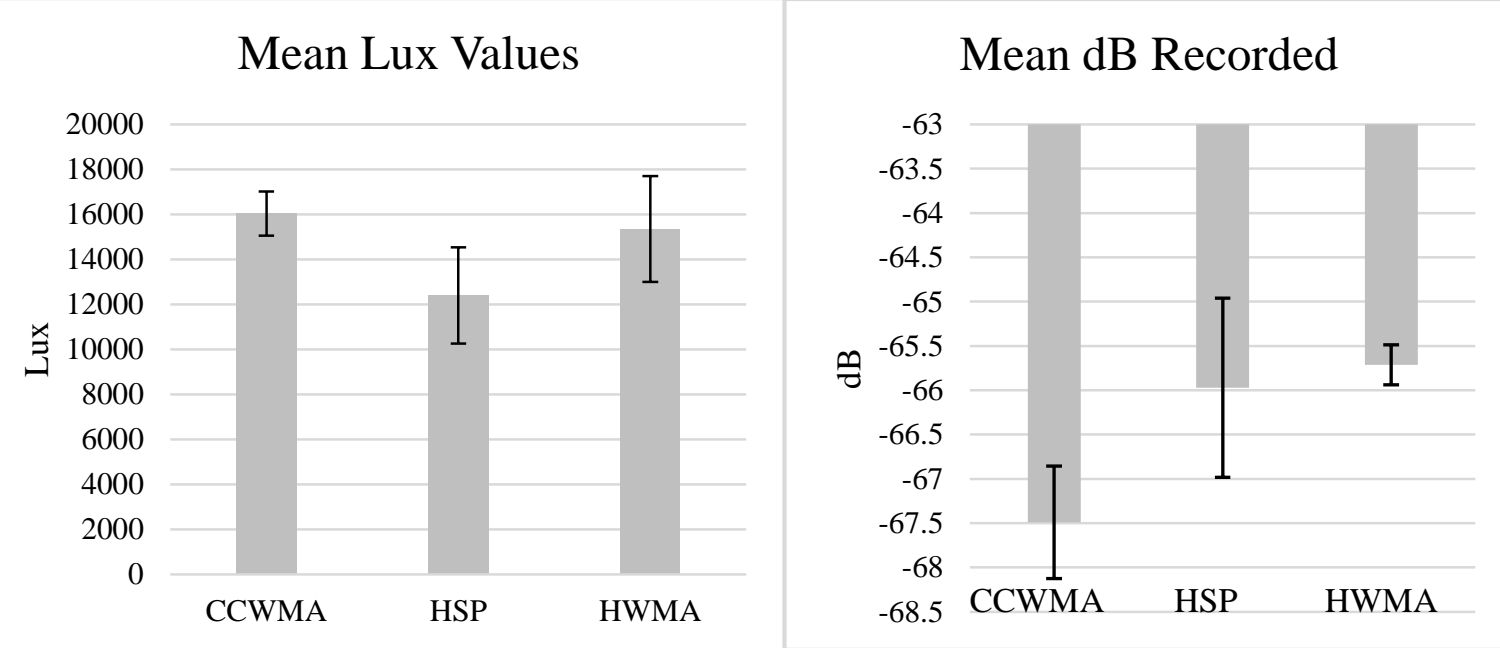

Figure 2. Site-wide comparison of mean and SE lux and dB values. There were no significant differences for either at $\alpha=0.05$. CCWMA (Cross Creek Wildlife Management Area) was gas-impacted, HSP (Hillman State Park) and HWMA (Hillcrest Wildlife Management Area) were not.
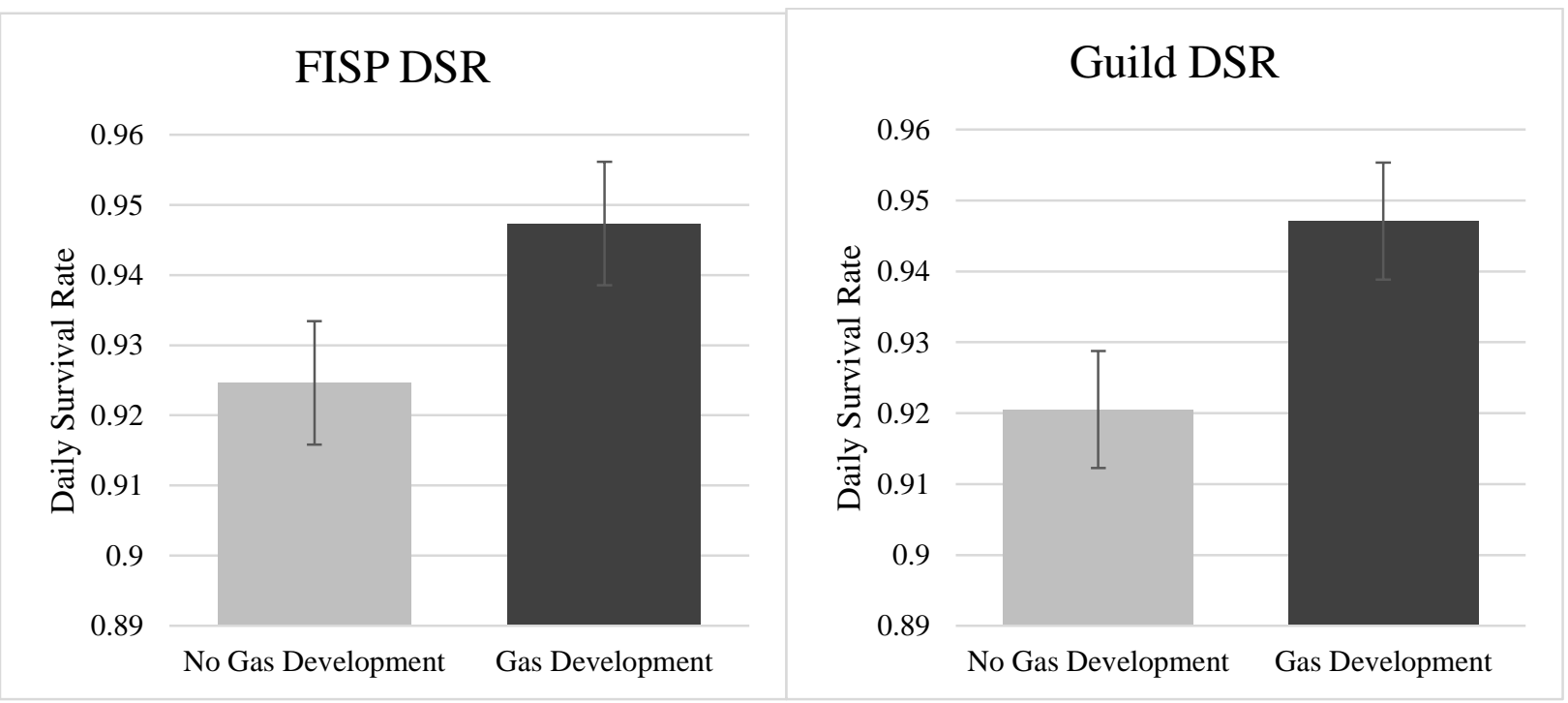

Figure 3. Comparisons of daily survival rate (DSR) for Field Sparrows (FISP) and three species in the shrubland guild (Blue-winged Warbler, Eastern Towhee, Field Sparrow), derived from Program MARK models of nest survival by presence of gas development. 

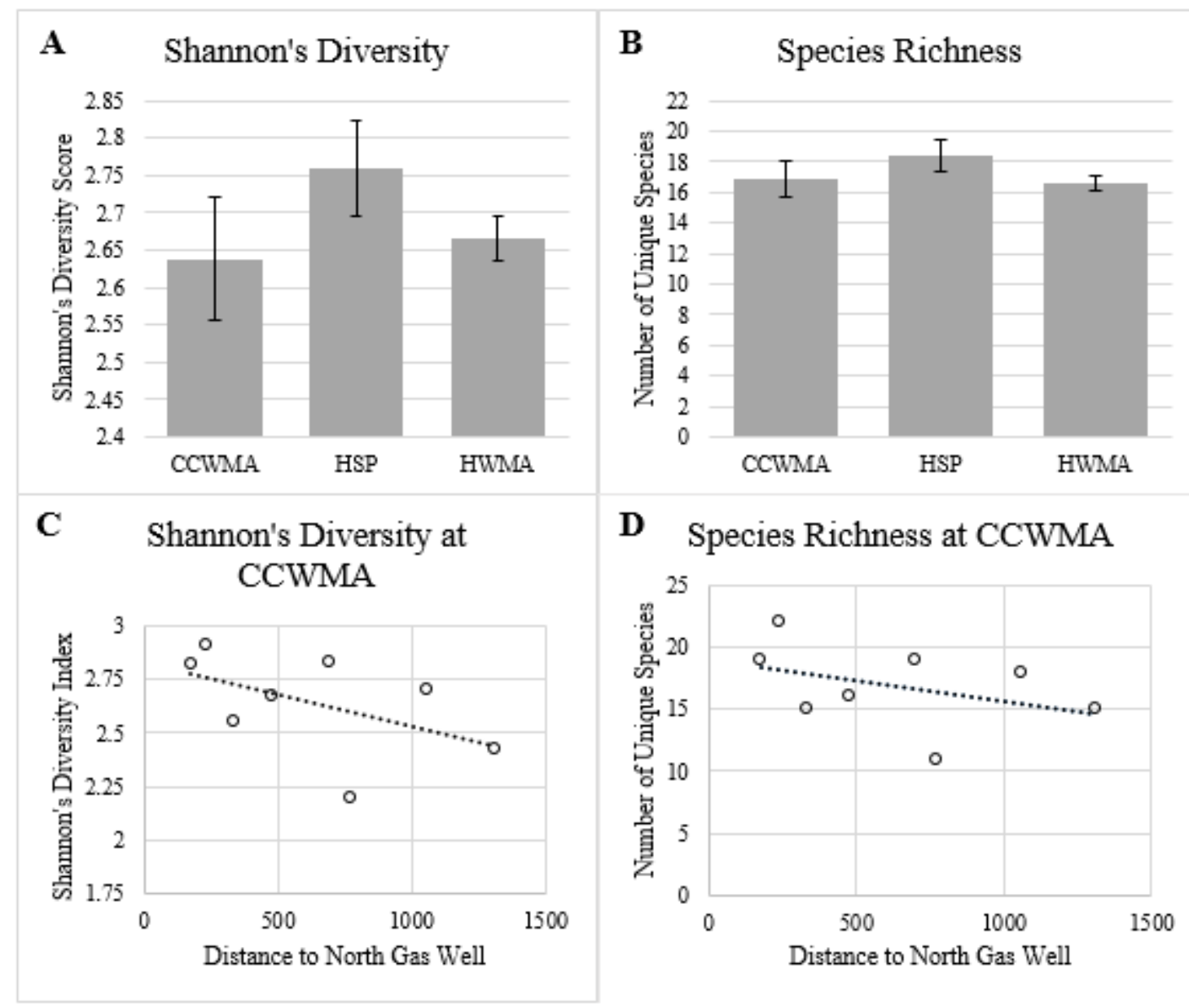

\section{Species Richness at CCWMA}

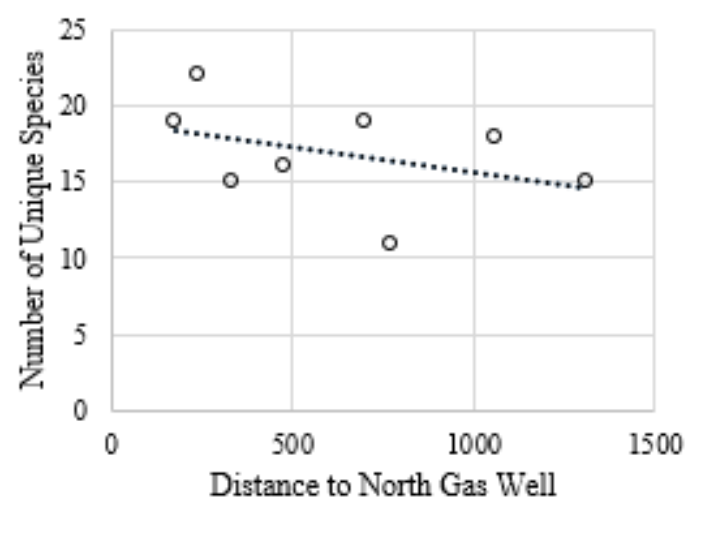

Figure 4. Mean and SE of A) Shannon's diversity and B) species richness by site; and trends in C) Shannon's diversity and D) species richness at CCWMA (Cross Creek Wildlife Management Area) with increasing distance from the north gas well. CCWMA was gas-impacted, HSP (Hillman State Park) and HWMA (Hillcrest Wildlife Management Area) were not. 


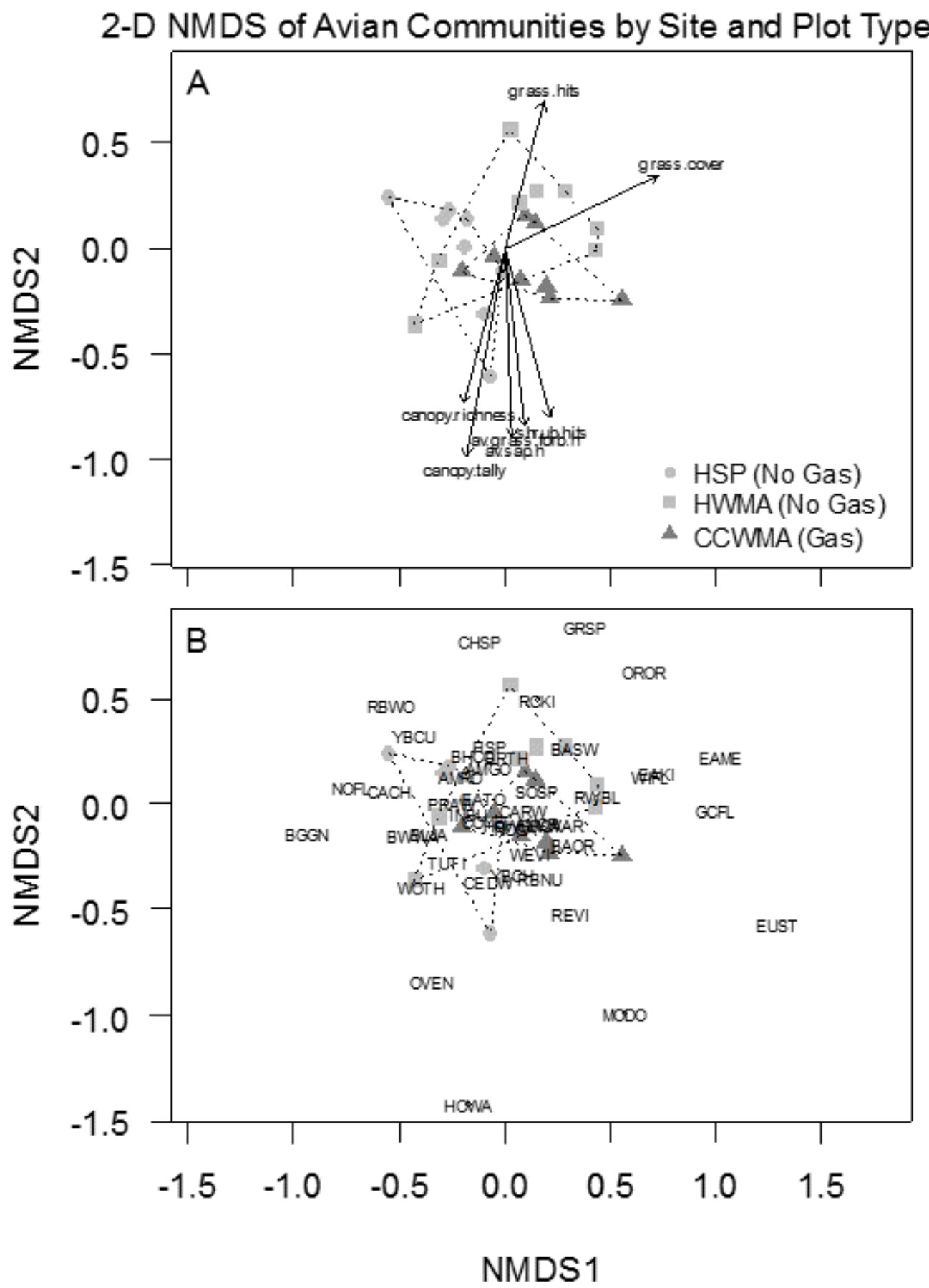

Figure 5. NMDS ordination of avian communities from point counts, with (A) overlays of highly correlated vegetative variables and (B) bird species displayed. Species are displayed with the standardized alpha code of The Institute for Bird Populations, available online at: http://www.birdpop.org/Download Documents/Alpha_codes_eng.pdf. 

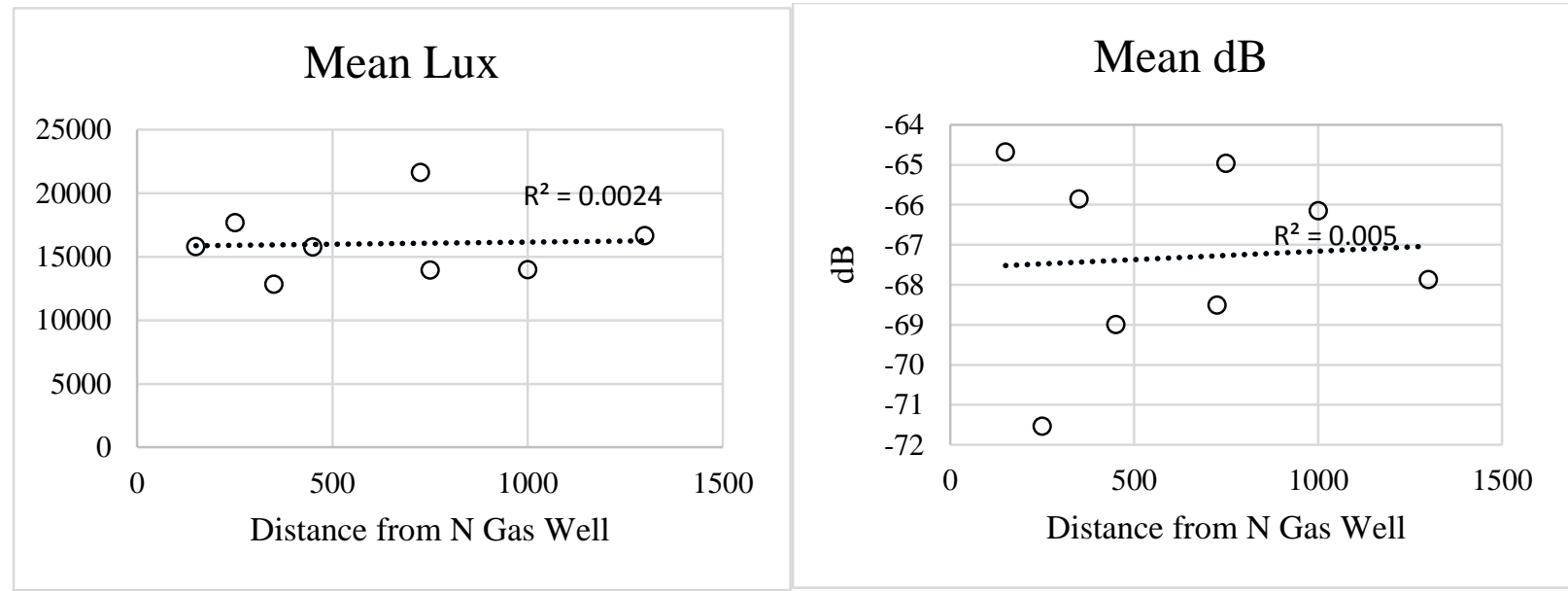

Figure 6. Mean lux values and mean decibels recorded at each CCWMA (Cross Creek Wildlife Management Area) point, which were arrayed in increasing distances from the north gas well. There were no significant differences in either at $\alpha=0.05$.

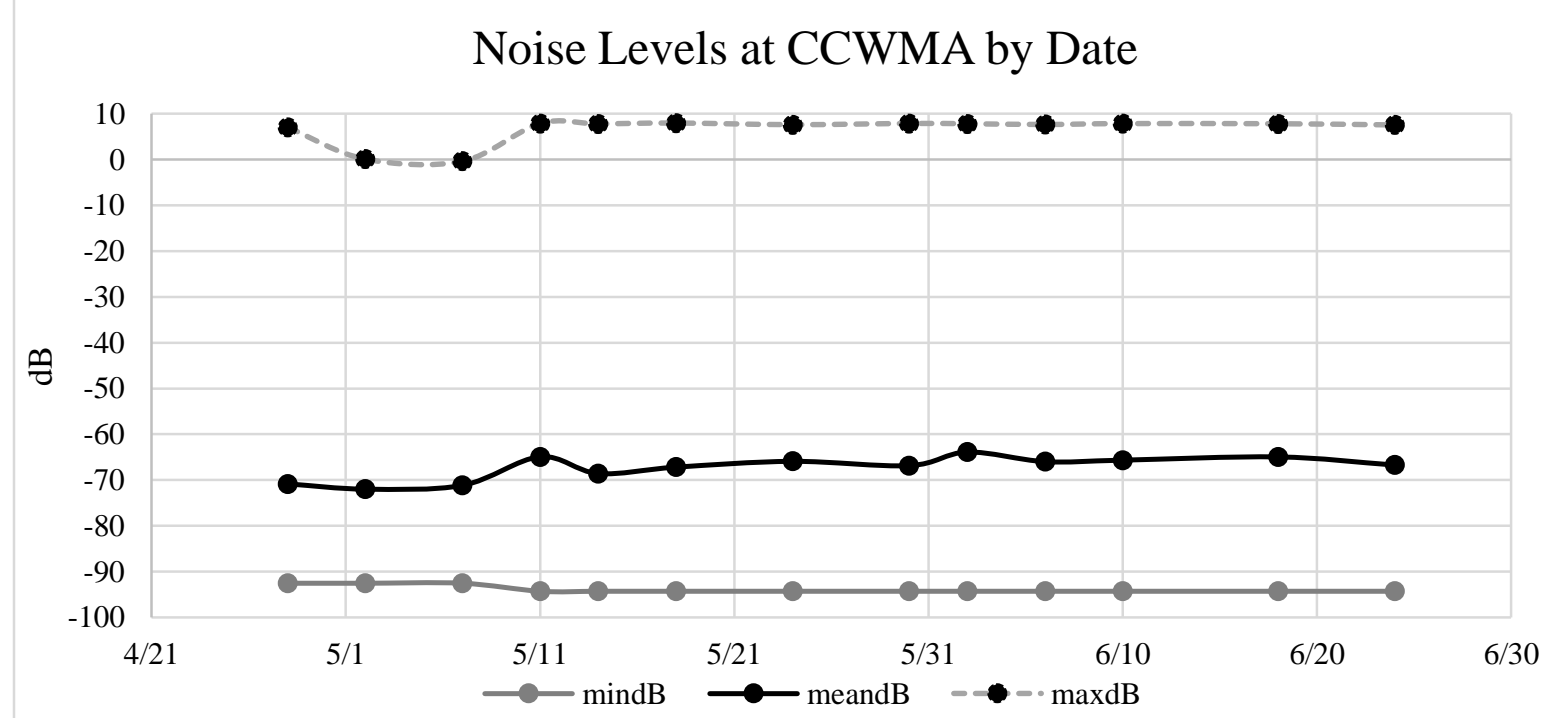

Figure 7. Minimum, mean, and maximum dB values for sampling periods at Cross Creek Wildlife Management Area, representing noise site-wide. Minimum and mean levels had significant differences by date $(\min \mathrm{F}=5.75, \mathrm{df}=1 / 44, \mathrm{P}=0.021 ;$ mean $\mathrm{F}=10.39$, $\mathrm{df}=1 / 44, \mathrm{P}=0.002)$ but not by distance to the north wellpad $(\min F=2.02, \mathrm{df}=1 / 44, \mathrm{P}=0.16$; mean $\mathrm{F}=0.02, \mathrm{df}=1 / 44, \mathrm{P}=0.89)$. 


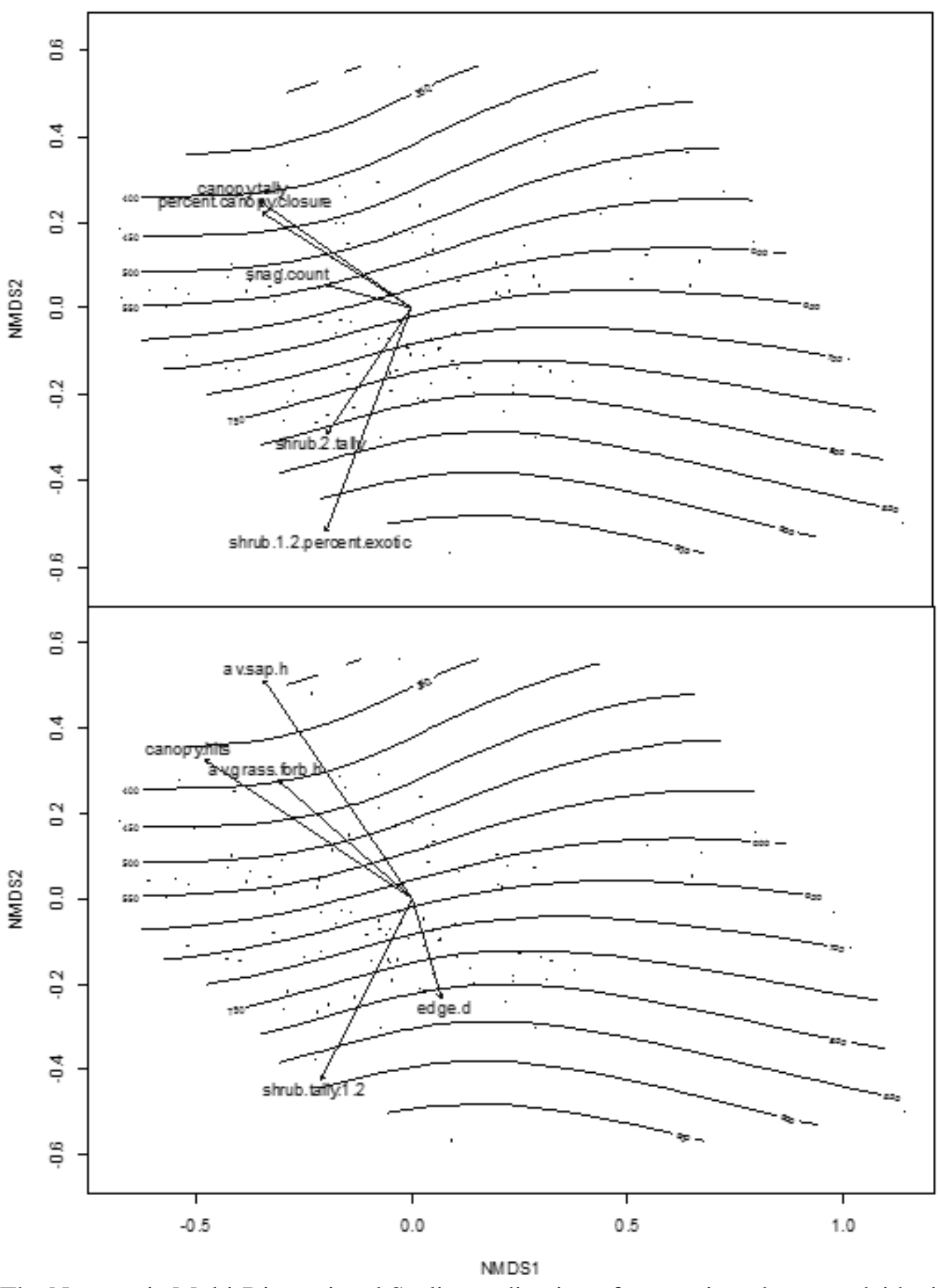

Figure 8. The Nonmetric Multi-Dimensional Scaling ordination of vegetation plots, overlaid with a surface gradient for distance from the north gas well and vectors representing variables which contribute most to the ordination. The 10 most highly correlated variables are shown. 


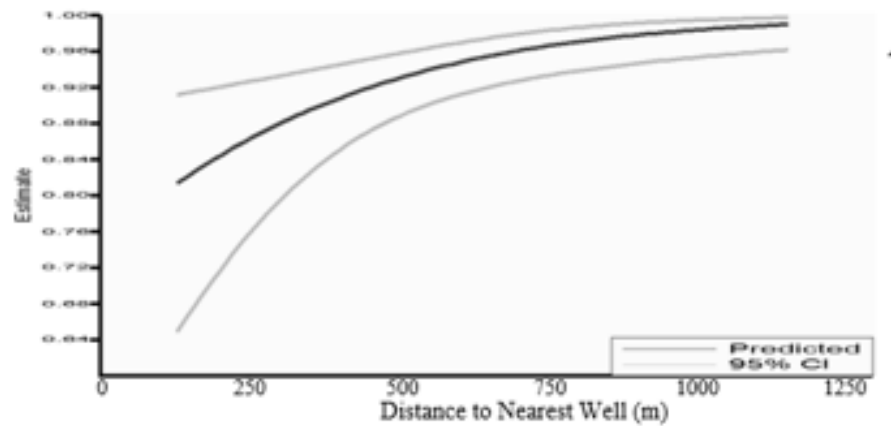

A) Variation in survival by vegetation gradient and distance to nearest well

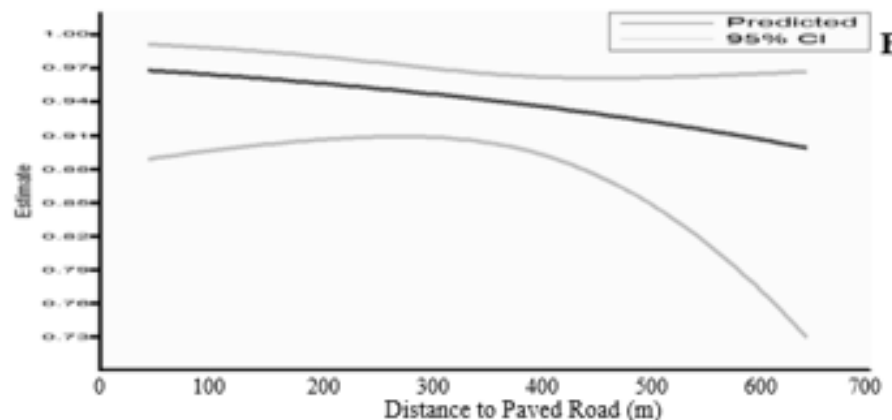

B) Variation in survival by vegetation gradient, distance to nearest well, and distance to paved road

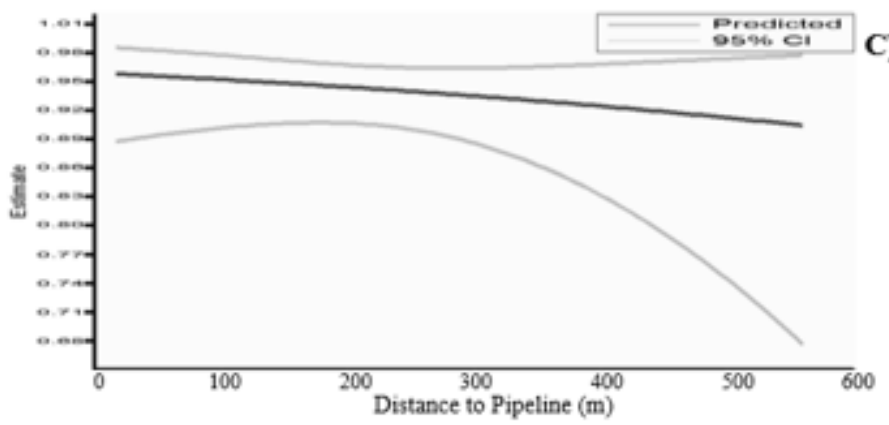

\section{C) Variation in} survival by vegetation gradient, distance to nearest well, and distance to pipeline

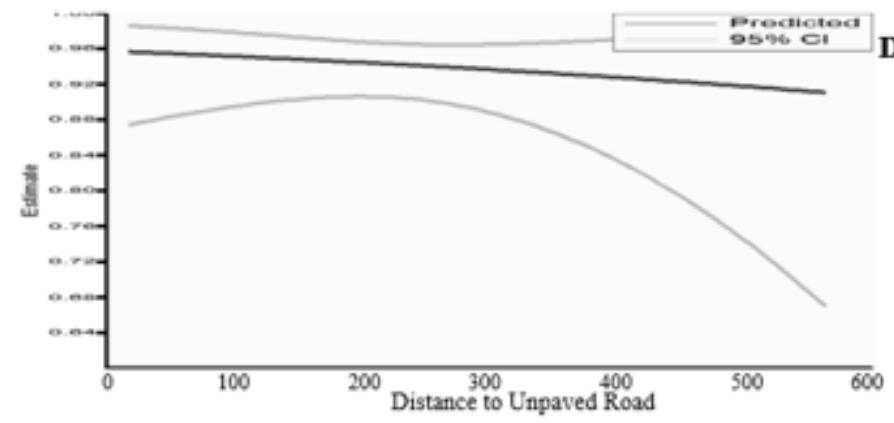

D) Variation in survival by vegetation gradient, distance to nearest well, and distance to unpaved road

Figure 9. The predicted nest survival curves of Field Sparrows at the gas-impacted site for variables in the top four models, holding all other variables in each model constant: (A) distance to nearest well, (B) distance to the paved road, (C) distance to the pipeline, and (D) distance to the unpaved road. 


\section{CHAPTER 4}

The Utility of Former Surface Mines as Shrubland Songbird BreEding HABITAT 
ABSTRACT.--- Shrubland songbirds are a highly imperiled guild due to reductions in the ephemeral, disturbance-dependent early-successional areas that they are adapted to. Surface mining is a common practice in Appalachia which results in large areas of low-quality topsoil and slowed vegetative succession. Once mining has ceased, these areas stay in early succession conditions for extended durations, providing habitat for early-successional species which endures on the landscape much longer than habitats in abandoned fields or recent clearcuts. Reclamation of surface mines to a vegetated state is mandated by federal law, but questions have been raised on the habitat quality of the resulting areas because they are often reclaimed to grassland. Many species are known to occupy former surface mines and studies have detailed the productivity of grassland songbirds in these areas, but their value to shrubland songbirds relative to non-mined shrublands has not been assessed. During the breeding seasons of 2012-2013, we quantified the utility of former surface mines as breeding habitat for shrubland songbirds. We monitored nests of three shrubland species: the Blue-winged Warbler (Vermivora pinus, BWWA), Eastern Towhee (Pipilo erythrophtalamus, EATO), and Field Sparrow (Spizella pusilla, FISP). We compared nest survival and productivity metrics of these species and avian abundance and community composition between former mines and unmined shrublands and also between a reclaimed and a non-reclaimed former surface mine. Whether a site was mined or not was an important factor influencing nest success, as was whether a mined site was reclaimed or not. Daily survival rates of nests for all three species were higher on mined sites and higher on the reclaimed former surface mine. Mean eggs per nest (FISP P $=0.37$, BWWA P $=0.80$, EATO P = 0.19 ) and fledglings per successful nest (FISP $\mathrm{P}=0.78$, BWWA P =0.84, EATO P = 0.65) did not differ across sites. We found no differences in avian communities between mined and nonmined sites $(\mathrm{P}=0.20)$ or in Shannon's diversity or species richness by site $(\mathrm{P}=0.31$ and $\mathrm{P}=$ 0.38, respectively). Community composition on the reclaimed and non-reclaimed former surface mine sites differed $(\mathrm{P}=0.001)$, but most species were detected on both. Vegetative conditions on mined sites were broader and encompassed the range of structure at non-mined sites, providing similar habitat for species found at unmined shrublands, plus more. All sites significantly differed in vegetative characteristics $(\mathrm{P}=0.001)$. Higher nest survival on mined sites may result from higher vegetative heterogeneity. The reclaimed mine site may have had higher nest survival than the unreclaimed mine site due to lower rodent and corvid nest predator abundances. Former surface mines in shrubland conditions provide productive, lasting habitats for breeding shrubland 
songbirds that accommodate the early-successional songbird guild comparably to unmined shrublands.

KEY WORDS: Early-successional songbirds, surface mines, mine reclamation, Appalachian region 


\section{INTRODUCTION}

Shrubland songbirds are a highly imperiled guild across much of North America due to wide-scale land use changes and loss of shrubland habitat (Dettmers 2003). Though formerly considered to be generalists and frequently ignored in management plans due to historically high abundances (DeGraaf and Yamasaki 2003), nearly half of shrubland bird species have seen population declines over the past 50 years (Sauer et al. 2014). Early-successional habitat comprises the sere spanning from the first growing season following a disturbance to young forest conditions (stands where most trees are less than $12.7 \mathrm{~cm}$ in diameter, Trani et al. 2001). The shrubland stage falls between the grassland period, which has little woody vegetation, and young forest period, which is dominated by saplings. Shrublands can be naturally maintained in early succession by fires and floods, both of which are now typically suppressed. They are also created by humans, but through practices which have become increasingly uncommon in the eastern United States: land abandonment and clearcut timber harvests. Early seral stages of forest succession (including grasslands, shrublands, and young regenerating forests) are rare and emphemeral, which compounds the plight of species which are highly specialized to these systems (DeGraaf and Yamasaki 2003).

Succession does not progress as quickly on poor soils, and thus land uses which remove the topsoil, such as surface mining, can harbor early successional species for longer periods of time after abandonment (Schneider et al. 2006, Stauffer et al. 2011, Walton 2012). Before the passage of the 1977 Surface Mining Control and Reclamation Act (SMCRA), former mines were typically left barren. They would proceed through succession naturally and tended to follow a distinct pattern of vegetation patch establishment, patch growth, and then the coalescence of patches into a fully vegetated site (Game et al. 1982), although this process proceeds more 
slowly than secondary succession such as clearcut regeneration or old-field succession. PostSMCRA reclaimed minelands often also do not progress fully to forests but stay instead in early successional seres due to poor soil quality, soil compaction, and aggressive herbaceous groundcover (Franklin et al. 2012, Zipper et al. 2011). While this may be detrimental to species which use later successional forests, it can provide habitat for early successional specialists that are imperiled in the region.

Grassland and shrubland songbirds are known to occur on former minelands. The utility of these areas as breeding habitat is well-documented for the grassland guild (Bajema et al. 2001, Ammer 2003, Wray et al. 1982) and shrubland songbird nest success on these areas has been measured (Ingold and Dooley 2013), but there have been no studies which compare abundance or nest success on former surface mines to levels on non-mined shrublands. Due to loss of early successional habitat, it is essential to know if shrubland songbird nest success and abundances on former mines are comparable to non-mine shrubland sites. The large amount of surface mined area in the Appalachian region may provide a long-lasting source of quality breeding habitat for this imperiled guild.

Our objectives are to compare reproductive success for three shrubland species and songbird abundances and community composition, with an emphasis on shrubland species, between 1) former surface mines and unmined shrublands and 2) between a former surface mine which was reclaimed under SMCRA and one which was abandoned pre-SMCRA. Fulfilling these objectives will determine the utility of former surface mines as breeding habitat for shrubland songbirds and address the question of reclamation efficacy for shrubland species, which are both important because of the guild's decline and the longevity and increasing presence of former surface mines on the landscape. 


\section{METHODS}

STUDY AREA

The study was conducted on shrubland sites in southwestern Pennsylvania and the northern panhandle of West Virginia (Appendix Fig. A1), a largely agricultural and developed landscape in the Appalachian Mountains Bird Conservation Region (AMBCRP 2005) with low elevation (average $\sim 325 \mathrm{~m}$ ) and rolling topography. We sampled two sites in 2012 in PA, one on 118 ha of private land which was historically managed for grazing and is currently a mix of mature forest and early succession (PRIV), and one on 237 ha of a former surface mine which was abandoned without reclamation in the late 1960s and is now partially in early succession and partly in forest (Hillman State Park, HSP). In 2013, we sampled again at HSP and at two sites in WV: one in 158 ha of shrubland on a former surface mine that was reclaimed in the late 1980s primarily with autumn olive (Eleagnus umbellata) and tall fescue (Festuca arundinacea) (Cross Creek Wildlife Management Area, CCWMA) and the second on a former agricultural property, historically orchards and pasture, where we sampled on 141 ha of shrubland interspersed with maintained fields, wetlands, and forest (Hillcrest Wildlife Management Area, HWMA) (Appendix Fig. A2). PRIV and HWMA were unmined, HSP was mined and not reclaimed, and CCWMA was mined and reclaimed.

The shrubland areas of PRIV, HSP, and CCWMA consisted predominantly of exotic woody shrubs, mainly bush honeysuckle (Lonicera spp.) and autumn olive, which occurred in clusters in open areas of grass and forbs. While PRIV was dominated by invasive vegetation, it also had some native woody shrubs, namely hawthorn (Crataegus spp.), and moderate amounts of Rubus and regenerating hardwood trees. HWMA had little invasive-exotic woody vegetation; its shrublands consisted largely of Rubus, regenerating trees, hawthorn, and remnant orchard trees, which structurally resemble native shrubs due to cultivation history (Appendix Fig. A3). 


\section{FIELD METHODS}

Eight point counts were established at each site which sampled nearly all available shrubland habitat (Appendix Fig. A2). Each point was $>50 \mathrm{~m}$ from forest edge and at least 250 $\mathrm{m}$ from any other point. All points were placed in vegetation typical for the sites and as close to the center of their respective shrubland patch as possible.

Nest Success.--- We searched for and monitored nests of three locally common species representative of Mid-Atlantic early-successional forests: the Blue-winged Warbler (Vermivora pinus, BWWA), Eastern Towhee (Pipilo erythrophtalamus, EATO), and Field Sparrow (Spizella pusilla, FISP) from late April to mid-July. We followed the protocols of Martin and Geupel (1993) and Martin et al. (1997) to minimize risk of increasing depredation or abandonment. Nest searching was opportunistic and based on pair behavior; observers watched adults of the focal species which exhibited signs of breeding, such as aggression or carrying nest material, until the nest was found. All shrubland areas were searched, but effort was concentrated around point count stations for efficiency. Once found, the contents of each nest were checked every other day. We anticipated projected fledge dates based on nestling development and considered a nest successful if at least one fledgling was visually confirmed after this date. Failures were recorded to have occurred on the day between the last two nest checks. We reported the number of eggs in nests that were counted on the last check where the nest was active before hatching or failing. The number of fledglings was the number of chicks counted in successful nests at the last nest check.

We recorded the species and UTM of detection for all nest predators incidentally observed in shrubland areas during the breeding season of 2013 to assess as a potential explanation of differing success rates. Possible nest predators according to the literature included 
black rat snakes (Elaphe obsoleta), rodents (Sciurus spp., Peromyscus spp., Tamiasciurus spp., and Tamias spp.), and mammalian mesocarnivores (see Bradley and Marzluff 2003, Chalfoun et al. 2002, Maxson and Oring 1978, Reitsma et al. 1990, and Thompson et al. 1999).

Avian Community.--- We conducted point counts from mid-May to late June in three bouts, each of which were two weeks long. The counts were completed between the hours of 0530 and 1000 on days without inclement weather and lasted 10 minutes (Ralph et al. 1993). For each individual detected during a count, we recorded the estimated distance to the individual and time interval during which it was detected. The time intervals were $0-3$ minutes, $>3-5$ minutes, and $>5-10$ minutes. The counts had a $75-\mathrm{m}$ fixed radius. Observers were experienced, trained in point count techniques and distance estimation, and highly skilled in songbird identification by both sight and sound. Distance estimation accuracy was facilitated further by equipping observers with rangefinders and placing reference flagging 25 and $50 \mathrm{~m}$ from each point.

Vegetation Sampling.--- We measured a variety of vegetative characteristics to assess as possible factors influencing the avian community composition or breeding success, following a sampling protocol adapted largely from the Golden-winged Warbler working group (Bulluck and Buehler 2008) with additional measurements from James and Shugart (1970) and Martin et al. (1997). Vegetation sampling began after the majority of the nesting period had ended to avoid disturbing active nests: on 19 June in 2012 and 18 June in 2013. We placed vegetation sampling plots at point counts and at randomly generated points across the available shrubland habitat. We used the Geospatial Modelling Environment platform (Beyer 2012) in ArcGIS 10.1 (ESRI 2012) to generate a 1-ha grid over the searched shrubland area and generated one random sampling point within each cell. 
Vegetation plots were circular, with an $11.3 \mathrm{~m}$ radius. From the center of each plot, we measured the litter depth in each cardinal direction at $1 \mathrm{~m}$ from plot center and visually estimated the percentage of canopy closure directly above plot center. We used a rangefinder to measure distance to nearest habitat edge, which was classified as mature forest, shrubland (if the plot was not in the shrubland), or non-habitat (i.e. pipelines, agricultural fields). We visually estimated the ground cover within $1 \mathrm{~m}$ of each plot center as the percentage of the ground covered by each of the following categories which sum to 100\%: litter (leaves or dead grass), grass, bare (i.e. rock, pavement), forbs, woody (live stems), vines, and Rubus.

Within the 11.3 m radius of all plots, we recorded the diameter at breast height (DBH) and species of each canopy tree which had a DBH $>10.0 \mathrm{~cm}$, the number of snags (standing dead trees with DBH $>10.0 \mathrm{~cm}$ ), and the height of the herbaceous (grass and forb), shrub-Rubus, and sapling layers by measuring an individual which was representative of the estimated average height of that layer. We measured plot composition, the percentage of the plot surface where a plant is present in each vegetation category (grass, forb, vine, Rubus, shrub, sapling, or canopy), by recording the number of times that each was encountered at marked $1.1 \mathrm{~m}$ intervals radiating from plot center in each cardinal direction. These percentages do not sum to 100 because tallies are recorded separately for each category.

At all plots, we tallied species and number of individuals $>1 \mathrm{~m}$ tall of shrubs and saplings within $5 \mathrm{~m}$ of the plot center. We used two categories for shrubs, those 1-2 $\mathrm{m}$ tall and those $>2 \mathrm{~m}$ tall, to represent earlier and later stages of succession. Understory species richness was the sum of the number of unique species for each of the three categories. We measured vegetation density in each cardinal direction at $10 \mathrm{~m}$ from each plot's center with a cover-board where squares at least $50 \%$ obscured by vegetation were tallied; the cover-board was $2 \mathrm{~m}$ tall and 
$0.4 \mathrm{~m}$ wide, divided into twenty $0.2 \mathrm{~m} \times 0.2 \mathrm{~m}$ squares. We averaged the four values to determine vegetation density.

\section{STATISTICAL ANALYSES}

Comparisons of nest survival and avian community composition were made between two treatment groups, mined and unmined sites, which each had 2 replicates (CCWMA and HSP for mined sites and PRIV and HWMA for unmined sites). Nest survival and avian community data gathered at points within sites were samples. Analyses of bird abundance and vegetation variables were done at the site scale; after analyzing differences between all sites, we conducted multiple comparisons on all combinations of sites to determine where differences existed.

Reproductive Success.--- For each species, we tested for differences in clutch size and fledgling production between sites and years with ANOVAs at $\alpha=0.05$. We computed, for each species, the mean number of eggs over all nests and mean number of fledglings for nests which were successful.

Nest Survival.---We examined nest survival of all three species within an informationtheoretic framework (Burnham and Anderson 2002) to determine the importance of site type (mined v unmined) on nest survival relative to other factors (site, species, year) in Program MARK Nest Survival Analysis (White and Burnham 1999, Rotella et al. 2004), which also allowed us to estimate nest survival probabilities. MARK estimates nest survival rates with maximum likelihood estimation, determining which models of survival (e.g. variation in nest survival by site vs. variation by species) are most likely given the collected data. We modeled nest fate data binomially (where success is coded 0 and failure 1 ) with a logit-link function and covariates for year, species, site, and site type (mined or unmined). We standardized dates by designating April 20 as day 1, with observation dates progressing until day 80 (July 10), the end 
of the season. Each nest was coded for Program MARK with the day a nest was found, the last day a nest was checked and alive, the last day a nest was checked, the nest fate, the frequency of that specific encounter history, and indicator covariates of the factors listed above for use in model ranking.

We built a set of candidate models for nest survival based on the following four variables and their interactions: 1) year, 2) species, 3) site, and 4) site type. We determined the model which best fit the observed data using Akaike's Information Criterion with a correction for small sample size (AICc) (Burnham and Anderson 2002). A smaller AICc score denotes less KullbackLeibler information loss (i.e. less distance between the model and the observed data), so we ranked the candidate models in order of increasing AICc scores. We considered models with $\Delta$ AICc $<2.0$ to have support from the candidate set. We transformed the MARK-derived nest survival probabilities with the logit-link function to determine daily survival rate (DSR) of nests.

Avian Community.--- We removed all flyovers, raptors, waterbirds, transitory migrants, and detections $>75 \mathrm{~m}$ from the observer for all counts. Of the three bouts, we used the count data with the maximum number of detections for every point in all analyses. We determined detection probabilities for all species with sufficient sample sizes using the time-of-detection removal method (Farnsworth et al. 2002) in Program SURVIV (White 1992). Because all of the detection probabilities were $>0.9$, we used unadjusted count data to enable assessments for all species rather than just the most frequently occurring ones.

We used ANOVAs at $\alpha=0.05$ to compare species richness (number of unique species detected) and Shannon's diversity index (a measure of richness and evenness) among sites and years. To compare overall avian species composition among site types, we used non-parametric MANOVA (function adonis in the vegan library, Oksanen et al. 2012, R Development Core 
Team 2013). This is a Multivariate Analysis of Variance, which partitions the sum of squares of the groups in a distance matrix (using the Bray-Curtis coefficient) among site types, and statistically tests for differences using permutations (999).

We applied a non-metric multidimensional scaling (NMDS) ordination (function metaMDS in the vegan library, Oksanen et al. 2012, R Development Core Team 2013) to the Bray-Curtis distance matrix of count data to graphically evaluate the relationships of point counts to each other based on site and site type. NMDS is a non-parametric, unconstrained ordination technique which represents a full dataset in a newly defined dimensional space while attempting to preserve the distances between each observation from a dissimilarity matrix (Faith et al. 1987). It places each multivariate observation in a multidimensional space using ranked distances such that stress, a measure of the disparity between the original distance matrix and the distance in the newly ordinated space, is minimized (Clarke and Green 1988). We used a square root transformation and Wisconsin double standardization, and ran the ordination with multiple random starts to increase the chances of stability. Habitat variables were correlated to the ordination to examine relationships between the community at large and each variable, expressed as vectors (function envfit in the vegan library, Oksanen et al. 2012, R Development Core Team 2013).

We repeated the avian community analysis using only early-successional species to focus on this guild. We applied another Bray-Curtis distance matrix and non-parametric MANOVA (function adonis in the vegan library, Oksanen et al. 2012, R Development Core Team 2013) test for differences in early-successional communities by site type (again specified for 999 permutations). We tested for significant differences between sites in mean abundances (mean number of detections per point) of early-successional species with the Kruskal-Wallis Rank Sum 
test at $\alpha=0.05$, which became $\alpha=0.0025$ after applying a Bonferroni adjustment $(0.05 / 20)$. We performed post-testing comparisons with the Kruskal-Wallis Rank Sum test to determine what between-site differences drove the overall differences, again at $\alpha=0.05$ which became $\alpha=0.01$ after applying a Bonferroni adjustment to each comparison set $(0.05 / 5)$.

Vegetation.--- We assessed vegetative differences between sites to help explain possible differences in nest success and avian community composition. We used the same techniques as the avian community analysis on 23 vegetation variables. The Bonferroni-adjusted $\alpha$ for the sitelevel Kruskal-Wallis Rank Sum tests was 0.0022 (0.05/23) and for the between-site post-tests was $0.0029(0.05 / 17)$. All analyses were performed in the R Language and Environment for Statistical Computing (program R) (R Development Core Team 2013).

\section{RESULTS}

FORMER SURFACE MINES V UNMINED SHRUBLANDS

Nest Success.--- We monitored 169 FISP, 14 BWWA, and 31 EATO nests during 20122013. We found no differences across sites once accounting for year in the number of eggs per nest or fledglings per successful nest for any species (Table 1).

Five of the 12 models of nest survival had $\Delta$ AICc $<2.0$ (Table 2). The top model, with $24 \%$ of the support of the data, was for variation in nest survival explained additively by species and year. The model of nest survival by species alone (24\% of support in the data) and species and site type ( $20 \%$ of the support in the data) were highly competitive for top model. The model explaining nest survival by site type alone was not very likely, with only $1 \%$ of the support in the data, but site type was an important factor as it appeared in two competing top models. The highest-ranked model which included site type (survival dependent on species and whether or not the site was mined) produced higher DSR estimates on mined than on non-mined sites for all species (Fig. 1). Raising daily survival rates to the power of each species' nesting cycle length 
(determined using nests in our study) gives the breeding season probability of survival for each nest: 0.15 on non-mined sites and 0.23 on mined sites for FISPs, 0.06 on non-mined sites and 0.09 on mined sites for EATOs, and 0.31 on non-mined sites and 0.40 on mined sites for BWWAs.

Nest predator detections were comparable for the non-mined site (HWMA) and average of the mined sites: 63 detections occurred on HWMA and an average of 64 occurred on the two mined sites, but the reclaimed mine site (CCWMA) had the fewest detections at 59. Of the predators detected, $22 \%$ on CCWMA were rodents, $71 \%$ on HSP were rodents, and $52 \%$ on HWMA were rodents (Table 3).

Avian Community.--- We detected 54 unique avian species at all sites; CCWMA had 37 species, HSP had 42 species, HWMA had 32 species, and PRIV had 42 species. Of the 20 earlysuccessional species detected over all sites, 18 were present at CCWMA, 19 at HSP, 18 at HWMA, and 16 at PRIV. Shannon's diversity $(\mathrm{F}=2.58, \mathrm{P}=0.07, \mathrm{df}=3 / 34)$ and species richness $(\mathrm{F}=2.69, \mathrm{P}=0.06, \mathrm{df}=3 / 34)$ did not differ significantly by site after accounting for year (Fig. 2).

Avian community composition on mined and non-mined sites was not significantly different $(\mathrm{P}=0.11)$. The 3 dimensional NMDS had a stress of 0.155 after 11 runs. The ordination showed little discrimination between mined and non-mined sites, but mined sites covered a wider range of the ordination space (Fig. 3). The early-successional guild followed the same trend; avian species composition was not significantly different between mined and nonmined shrublands $(\mathrm{P}=0.40)$.

Five species differed in abundance among all sites (Table 4). Post-testing between sites identified 4 species that differed in abundance between mined and non-mined sites (Table 5). 
Common Yellowthroats were least abundant on CCWMA and Song Sparrows on PRIV. Eastern Towhees were most abundant on PRIV and Prairie Warblers on HSP (Table 4).

Vegetation.--- Vegetative characteristics were significantly different between mined and non-mined sites $(\mathrm{P}=0.001)$ and among all sites $(\mathrm{P}=0.001)$. The NMDS was performed in two dimensions and had a stress of 0.17 after 20 runs. NMDS plots showed that unmined shrublands had more narrow vegetative conditions than former surface mines (Fig. 4). Seventeen factors differed over all sites at the Bonferroni-adjusted $\alpha$ of 0.002 (Table 6). Post-testing between sites revealed 48 significant differences, and 15 factors differed between combinations of a mined and unmined site (Table 7). Non-mined sites were closer to edge, had fewer saplings, taller grass, and shorter shrubs.

\section{RECLAIMED v NON-RECLAIMED FoRMER SURFACE Mines}

Nest Success.--- Nest survival estimates differed between the two mined sites (Fig. 5). The best model which included site (survival dependent on species and site, Table 2), received $14 \%$ of the support in the data. CCWMA, the reclaimed site, had higher DSR estimates for all species than the unreclaimed site HSP. These convert to breeding season probabilities of survival of: 0.29 on CCWMA and 0.19 on HSP for FISPs, 0.20 on CCWMA and 0.09 on HSP for EATOs, and 0.50 on CCWMA and 0.40 on HSP for BWWAs.

Avian Community.--- Avian communities between the two mined sites were significantly different $(\mathrm{P}=0.001)$. The 2 dimensional NMDS had a stress of 0.185 , and showed full discrimination between the reclaimed and non-reclaimed site with the exception of two CCWMA counts. The ordination correlated with the nine variables which significantly differed between the sites shows how the reclaimed and non-reclaimed sites differed vegetatively (Fig. 6). 
The early-successional bird communities were also significantly different between the reclaimed and non-reclaimed former mine sites $(\mathrm{P}=0.001)$. Three of the 20 early-successional species had significantly different mean abundances between the reclaimed and non-reclaimed mine sites: Common Yellowthroats and Prairie Warblers were more abundant on the nonreclaimed site, while Grasshopper Sparrows were on the reclaimed mine (Table 5). No Chestnutsided Warblers or Mourning Doves were detected at the reclaimed site and no Grasshopper Sparrows were detected at the non-reclaimed mine site (Table 4).

Vegetation.--- Vegetative composition between the two mined sites differed significantly $(\mathrm{P}=0.001)$. Twelve individual vegetation factors differed between plots on the reclaimed mine and the abandoned mine: plots on the reclaimed mine were further from the nearest edge, had shallower litter layers, taller herbaceous and shrub layers, less trees, less shrubs 1-2 m tall, less saplings, lower woody species richness in the understory and canopy, and lower Rubus, sapling, and canopy plot composition percentages (Table 6, Fig. 7).

\section{DISCUSSION}

Surface mines that contain shrubland provide useful breeding habitat to shrubland songbirds. Mined sites with shrublands had higher nest survival than unmined shrublands in the area and provided a broader range of habitat conditions, accommodating similar bird communities as unmined areas. A mine reclaimed to shrubland had higher nest survival than an abandoned mine that naturally revegetated to shrubland but they provided habitat for similar species.

\section{FORMER SURFACE MINES V UNMINED SHRUBLANDS}

Nest Success.--- Nest survival probabilities on former surface mines in shrubland conditions were higher than those on unmined shrubland sites for all species. Site type was not a factor in the highest-ranked model of nest survival; species and year ranked higher and were 
expected to because they presumably have high influences on variation in success (e.g.

McElhone et al. 2011, Ingold and Dooley 2013). Site type was an important factor however; it was competitive for top model with a $\triangle \mathrm{AICc}$ of 0.38 and ranked higher than site alone, indicating that differences in survival were truly due to whether or not a site was mined and not just site-level variation. Although nests on former surface mines did not produce more eggs or fledglings per nest than those on non-mined shrublands, they were more successful at producing fledglings.

Although the two mined sites had significantly different vegetative composition, they shared features which may have contributed to the higher nest success on these former surface mines. Re-vegetation of surface mines occurs in patches based on where higher-quality soil exists in the root zone (Game et al. 1982). This pertains especially to unreclaimed mines and may have contributed to the broader range of vegetative conditions at mined sites (see Fig. 4 and Table 6). Mined sites on average had more structural complexity; they had more saplings and canopy trees and more understory and canopy richness. While succession on mined sites has progressed very slowly in some portions of our sites, it has advanced more quickly in others, presumably because of variations in soil quality, planting regimes, and proximity to seed sources. This resulted in patches of later-successional conditions with saplings and tall shrubs in a matrix of very early-successional conditions, i.e. open spaces of grasses and forbs. Shrubland species may be more productive on former surface mines because of this increased likelihood for vegetative heterogeneity, which more closely replicates patchy conditions on regenerating areas from non-anthropogenic disturbances such as fire, which the guild evolved to breed in.

Nest success rates in our study were near those reported in the literature. We had $30 \%$ of FISP nests fledge young (unadjusted for exposure) while rates in the literature range from 20- 
63\% (Carey et al. 2008), 33\% of BWWA nests fledged while rates in the literature were $21-77 \%$ (Askins et al. 2007, Confer et al. 2010, Slay 2010), and 25\% of EATO nests fledged while rates in the literature were 27-69\% (Greenlaw 1996). Ingold and Dooley (2013) had higher unadjusted FISP success rates (33-60\%) on reclaimed surface mines than we did (17-41\%, Table 1, derived by dividing successful by total nests) and Wray et al. (1982) found higher FISP nest probability of survival (0.47) on reclaimed surface mines than we did (0.18-0.33, Table 1). Ingold and Dooley (2013) found early-successional songbirds on reclaimed surface mines which nested closer to the ground to have higher success rates than those which nested in shrubs, but this trend did not occur at our sites.

Avian Community.--- Former surface mines and unmined shrublands did not have significant differences in avian diversity indices or community composition even though vegetative conditions on mined sites were broader than on non-mined ones. Former surface mines provided similar early-successional songbird habitat as unmined shrublands, and additional conditions that do not exist on non-mined sites.

The abundance differences of some early-successional species are likely linked to vegetation. Common Yellowthroats may have been more abundant on non-mined sites because of the higher percentages of Rubus (Guzy and Ritchison 1999) and Prairie Warblers may have been more abundant on mined sites because of the taller, higher amounts of shrubs there (Nolan et al. 1999). Grasshopper Sparrows were only found on the one reclaimed mine site, which had more open grassland and less patches of shrubs than the non-reclaimed former surface mine, conditions that the species requires in the east (Vickery 1996). Some of the differences may be simply due to chance; sample sizes were relatively small and we only had two sites of each type, which differed significantly in vegetative composition themselves. 


\section{RECLAIMED v NON-RECLAIMED FORMER SURFACE MINES}

Nest Success.--- Between the two mined sites, nest survival probabilities for all species were higher on the one which was reclaimed. Reclamation practices result in different soil and thus vegetative conditions than those on abandoned mines, but most studies of post-SMCRA surface mines suggest reduced utility for many wildlife species. Overall, SMRCA-compliant reclamation can make re-establishing woody vegetation difficult; it often results in soil compaction from excessive grading, the burial of more fertile weathered materials, and the establishment of non-native plants which hamper long-term vegetative community health, resulting in arrested succession (Zipper et al. 2011). Indeed, the reclaimed site had less sapling and tree cover and less woody understory and canopy richness, representing more extensive early-successional conditions. Plots at the reclaimed site were also further from nearest edge than the non-reclaimed site, which indicates less habitat patchiness. Time elapsed since reestablishment of vegetation is also likely a factor influencing the differences; HSP was abandoned about 20 years earlier than CCWMA was reclaimed.

These vegetative conditions seem to contradict the above explanation of higher nest survival on former mines stemming from vegetative heterogeneity there, but clarification may lie in the predator data. Fewer nest predators were detected at the reclaimed site, and nearly four times as many rodents were detected on the non-reclaimed site. Most nest failures are caused by depredation (Martin 1993), and rodents are commonly implicated as heavy nest predators (Bradley and Marzluff 2003, Maxson and Oring 1978, Reitsma et al. 1990). Along with lower rodent abundances on the reclaimed site, there were few detections of Blue Jays, a major nest predator (Smith et al. 2013). It may be that the higher nest success on the reclaimed surface mine was due to the lower nest predator abundances there, even though the patchier, more 
heterogeneous non-reclaimed site had more suitable vegetative structure for high shrubland songbird breeding success.

Avian Community.--- Although avian diversity did not significantly differ between the two mined sites, communities were significantly different and showed a high amount of discrimination in the ordination (Fig. 6). Reclamation results in different vegetative conditions than would occur without it, and thus influences habitat suitability. The two sample points on the reclaimed site which were more similar in avian community to those on the non-reclaimed site were also more similar in vegetative conditions, further supporting the idea that vegetation drove the avian community differences. Points on the non-reclaimed site and the two unique reclaimed points were closer to edge and had more tree influences, likely leading to the different community composition there. Indeed, Blue Jays are associated with edges (Smith et al. 2013) and had significantly higher abundances on the non-reclaimed site, as did Common Yellowthroats which are associated with denser shrub layers (Guzy and Ritchison 1999), while Grasshopper Sparrows, which require more open grassland conditions (Vickery 1996, Ammer 2003), were more abundant on the reclaimed site. Although the communities and some species abundances were different, the reclaimed mine site was used by many of the same species as the non-reclaimed former surface mine.

\section{CONCLUSIONS}

The inferences which can be made based on this study are limited; we only had one reclaimed site with one year of data, and one non-reclaimed site with two years of data. The nonreclaimed mine site has been progressing through succession 20 years longer than the reclaimed site, so comparisons of their utility for breeding songbirds can only be general. Future studies could improve in rigor by replicating reclaimed and non-reclaimed sites. Our one reclaimed site 
had the highest nest survival, but may have had lower predator abundances due to coincidence, and comparing between treatment groups of replicated sites based on reclamation would help to separate random effects due solely to site and those resulting from the treatment. However, our results do allow some conclusions.

Because of the slow rate of succession on former surface mines, those with shrubland conditions will remain so for extended periods of time. This is beneficial for shrubland songbirds as these areas provide breeding habitat which is comparable in species accommodated and higher in nest success than non-mined shrublands in the region. While shrubland habitat is shrinking in the northeastern United States, former surface mines with shrubland conditions appear to provide lasting habitats for breeding shrubland songbirds. All surface mines whose operations ended after 1977 must comply with SMCRA and thus will be reclaimed, but they often are reclaimed to grasslands and rarely develop into shrublands. The utility of former surface mines as shrubland songbird breeding habitat can only be realized if these areas progress to shrubland conditions.

The Appalachian basin is globally unique in its extent of interior forest in temperate latitudes (Riiters et al. 2000). Although former surface mines can provide areas of arrested succession which are useful to shrubland songbirds, they are detrimental to populations of species which require contiguous mature forest, many of which are imperiled endemic or highly reliant on the Appalachian region (McElhone et al. 2011, Wickham et al. 2013, Wood and Williams 2013). Recent developments in mine reclamation, called the Forestry Reclamation Approach (FRA), result in more rapid succession and successful establishment of forests on both current mines (Burger et al. 2005) and those already reclaimed with conventional practices (Burger et al. 2013). Mines reclaimed under the FRA would still provide habitat for shrubland 
songbirds as with normal succession, but also eventually return to the forested conditions (Zipper et al. 2011) which make the Appalachian region so ecologically valuable. 


\section{LITERATURE CITED}

AMBCRP (Appalachian Mountains Bird Conservation Region Partnership). 2005. Appalachian Mountains Bird Conservation Initiative Concept Plan. Can be accessed online at: http://www.acjv.org/documents/bcr28_concept_plan.pdf.

Ammer, F. K. 2003. Population level dynamics of Grasshopper Sparrow populations breeding on reclaimed mountaintop mines in West Virginia. Ph.D. dissertation. West Virginia University, Morgantown.

Askins, R. A., B. Zuckerberg, L. Novak. 2007. Do the size and landscape context of forest openings influence the abundance and breeding success of shrubland songbirds in southern New England? Forest Ecology and Management 250:137-147.

Bajema, R. A., T. L. DeVault, P. E. Scott, and S. Lima. 2001. Reclaimed coal mine grasslands and their significance for Henslow's Sparrows in the American Midwest. Auk 188:422431.

Beyer, H. L. 2012. Geospatial Modeling Environment (Version 0.7.2.1). Available at: http://www.spatialecology.com/gme. Last accessed 15 June 2013.

Bradley, J. E., and J. M. Marzluff. 2003. Rodents as nest predators: Influences on predatory behavior and consequences to nesting birds. Auk 120:1180-1187.

Bulluck, L. P., and D. A. Buehler. 2006. Avian use of early successional habitats: Are regenerating forests, utility right-of-ways and reclaimed surface mines the same? Forest Ecology and Management 236:76-84.

Bulluck, L. P., and D. A. Buehler. 2008. Factors influencing Golden-winged Warbler (Vermivora chrysoptera) nest-site selection and nest survival in the Cumberland Mountains of Tennessee. Auk 125:551-559. 
Burger, J., D. Graves, P. Angel, V. Davis, and C. Zipper. 2005. The forestry reclamation approach. Forest Reclamation Advisory No. 2. U. S. Office of Surface Mining, Appalachian Regional Reforestation Initiative.

Burger, J. A., C. E. Zipper, P. N. Angel, N. Hall, J. G. Skousen, C. D. Barton, and S. Eggerud. 2013. Re-establishing native trees on legacy surface mines. Forest Reclamation Advisory No. 11. U. S. Office of Surface Mining, Appalachian Regional Reforestation Initiative.

Burnham, K. P. and D. R. Anderson, D. R. 2002. Model selection and inference: a practical information-theoretic approach, 2nd ed. Springer-Verlag, New York, NY.

Carey, M., D. E. Burhans and D. A. Nelson. 2008. Field Sparrow (Spizella pusilla), The Birds of North America Online (A. Poole, Editor). Cornell Lab of Ornithology, Ithaca, New York, USA. http://bna.birds.cornell.edu.bnaproxy.birds.cornell.edu/ bna/species/103 (accessed January 4 2014).

Chalfoun, A. D., M. J. Ratnaswamy, and F. R. Thompson. 2002. Songbird nest predators in forest-pasture edge and forest interior in a fragmented landscape. Ecological Applications $12: 858-867$.

Clarke, K. R. and R. H. Green. 1988. Statistical design and analysis for a "biological effects" study. Marine Ecology Progress Series 46:213-226.

Confer, J. L., K. W. Barnes, and E. C. Alvey. 2010. Golden- and Blue-Winged Warblers: Distribution, nesting success, and genetic differences in two habitats. Wilson Journal of Ornithology 122:273-278.

DeGraaf, R. M. and M. Yamasaki. 2003. Options for managing early-successional forest and shrubland bird habitats in the northeastern United States. Forest Ecology and Management 185:179-191. 
Dettmers, R. 2003. Status and conservation of shrubland birds in the northeastern US. Forest Ecology and Management 185:81-93.

ESRI. 2012. ArcGIS Desktop: Release 10.1. Redlands, CA: Environmental Systems Research Institute.

Faith, D. P., P. R. Minchin, and L. Belbin. 1987. Compositional dissimilarity as a robust measure of ecological distance. Vegetatio 69:57-68.

Farnsworth, G. L., K. H. Pollock, J. D. Nichols, T. R. Simons, J. E. Hines, and J. R. Sauer. 2002. A removal model for estimating detection probabilities from point-count surveys. Auk 119:414-425.

Franklin, J. A., C. E. Zipper, J. A. Burger, J. G. Skousen, and D. F. Jacobs. 2012. Influence of herbaceous ground cover on forest restoration of eastern US coal surface mines. New Forests 43:905-924.

Game, M., J. E. Carrel, and T. Hotrabhavandra. 1982. Patch dynamics of plant succession on abandoned surface coal mines: a case history approach. Journal of Ecology 70:707-720.

Greenlaw, J. S. 1996. Eastern Towhee (Pipilo erythrophthalmus), The Birds of North America Online (A. Poole, Editor). Cornell Lab of Ornithology, Ithaca, New York, USA. http://bna.birds.cornell.edu.bnaproxy.birds.cornell.edu/bna/species/262 (accessed 4 January 2014).

Guzy, M. J. and G. Ritchison. 1999. Common Yellowthroat (Geothlypis trichas), The Birds of North America Online (A. Poole, Editor). Cornell Lab of Ornithology, Ithaca, New York, USA. http://bna.birds.cornell.edu.bnaproxy.birds.cornell.edu/bna/species/448 (accessed 4 January 2014). 
James, F. C. and H. H. Shugart Jr.. 1970. A quantitative method of habitat description. Audubon Field Notes 24:727-736.

Martin, T. E. 1993. Nest predation and nest sites. BioScience 43:523-532.

Martin, T. E., C. J. Conway, W. M. Hochachaka, P. Allen, and W. Jenkins. 1997. BBIRD field protocols. U.S.G.S. Biological Resources Division, Montana Cooperative Wildlife Research Unit, University of Montana, Missoula, Montana, USA. Available at http://www.umt.edu/bbird/protocol/veg.aspx.

Martin, T. and G. Geupel. 1993. Nest-monitoring plots: methods for locating nests and monitoring success. Journal of Field Ornithology 64:507-519.

Maxson, S. J. and L. W. Oring. 1978. Mice as a source of egg loss in ground-nesting birds. Auk 95:582-584.

McElhone, P. M., P. B. Wood, and D. K. Dawson. 2011. Effects of stop-level habitat change on Cerulean Warbler detections along breeding bird survey routes in the Central Appalachians. Wilson Journal of Ornithology 123:699-708.

Nolan Jr., V., E. D. Ketterson and C. A. Buerkle. 1999. Prairie Warbler (Setophaga discolor), The Birds of North America Online (A. Poole, Editor). Cornell Lab of Ornithology, Ithaca, New York, USA. http://bna.birds.cornell.edu.bnaproxy.birds.cornell.edu/bna/ species/455 (accessed 4 January 2014).

Oksanen, J., F. G. Blanchet, R. Kindt, P. Legendre, P. R. Minchin, R. B. O'Hara, G. L. Simpson, P. Solymos, M. H. H. Stevens, and H. Wagner. 2013. vegan: Community Ecology Package. R package version 2.0-9. http://CRAN.R-project.org/package=vegan.

Pietz, P. J. and D. A. Granfors. 2000. White-tailed deer (Odocoileus virginianus) predation on grassland songbird nestlings. The American Midland Naturalist 144:419-422. 
R Development Core Team. 2013. R: A language and environment for statistical computing. R Foundation for Statistical Computing, Vienna, Austria. ISBN 3-900051-07-0, URL http://www.R-project.org/.

Ralph, C. J., G. R. Geupel, P. Pyle, T. E. Martin, and D. F. DeSante. 1993. Handbook of Field Methods for Monitoring Landbirds. Gen. Tech. Re. PSW-GTR-144. Albany, CA: Pacific Southwest Research Station, Forest Service, U.S. Department of Agriculture.

Reitsma, L. R., R. T. Holmes, and T. W. Sherry. 1990. Effects of removal of red squirrels, Tamiasciurus hudsonicus, and eastern chipmunks, Tamias striatus, on nest predation in a northern hardwood forest: an artificial nest experiment. Oikos 57:375-380.

Riiters, K., J. Wickham, R. O’Neill, B. Jones, and E. Smith. 2000. Global-scale patterns of forest fragmentation. Conservation Ecology 4:3. [Online] Available at http://www.consecol.org/ vol4/iss $2 /$ art $3 /$

Rotella, J. J., S. J. Dinsmore, and T. L. Shaffer. 2004. Modeling nest-survival data: a comparison of recently developed methods that can be implemented in MARK and SAS. Animal Biodiversity and Conservation, 27:187-205.

Sauer, J. R., J. E. Hines, J. E. Fallon, K. L. Pardieck, D. J. Ziolkowski, Jr., and W. A. Link. 2014. The North American Breeding Bird Survey, Results and Analysis 1966 - 2012. Version 02.19.2014 USGS Patuxent Wildlife Research Center, Laurel, MD.

Schneider, J., D. S. Maehr, K. J. Alexy, J. J. Cox, J. L. Larkin, and B. C. Reeder. 2006. Food habitats of reintroduced elk in southeastern Kentucky. Southeastern Naturalist 5:535-546.

Slay, C. M. 2010. An evaluation of reproductive success, adult survivorship and habitat use of shrubland birds on conservation-managed fields in western Connecticut. Dissertation. University of Arkansas, Fayetteville, USA. 
Smith, K. G., K. A. Tarvin, and G. E. Woolfenden. 2013. Blue Jay (Cyanocitta cristata), The Birds of North America Online (A. Poole, Editor). Cornell Lab of Ornithology, Ithaca, New York, USA. http://bna.birds.cornell.edu.bnaproxy.birds. cornell.edu/bna/species/469 (accessed 4 January 2014).

Stauffer, G. E., D. R. Diefenbach, M. R. Marshall, and D. W. Brauning. 2011. Nest success of grassland sparrows on reclaimed surface mines. The Journal of Wildlife Management 75:548-557.

Thompson, F. R., W. Dijak, and D. E. Burhans. 1999. Video identification of predators at songbird nests in old fields. The Auk 116:259-264.

Trani, M. K., R. T. Brooks, T. L. Schmidt, V. A., Rudis, C. M., Gabbard. 2001. Patterns and trends of early successional forests in the eastern United States. Wildlife Society Bulletin 29:413-424.

Vickery, P. D. 1996. Grasshopper Sparrow (Ammodramus savannarum), The Birds of North America Online (A. Poole, Editor). Cornell Lab of Ornithology, Ithaca, New York, USA. http://bna.birds.cornell.edu.bnaproxy.birds.cornell.edu/bna/species/239 (accessed 4 January 2014).

Walton, J. L. 2012. The effects of mine land reclamation on herpetofaunal communities. Thesis. University of Texas at Arlington, USA.

White, G. C., and K. P. Burnham. 1999. Program MARK: survival estimation from populations of marked animals. Bird study 46:120-139.

White, G.C. 1992. PC SURVIV User's Manual. Dept. of Fishery and Wildlife Biology, Colorado State University, Fort Collins, CO. 
Wickham, J. D., P. B. Wood, M.C. Nicholson, W. Jenkins, D. Druckenbrod, G.W. Suter, M.P. Strager, C. Mazzarella, W. Galloway, and J. Amos. 2013. The overlooked terrestrial impacts of mountaintop mining. BioScience 63:335-349.

Wood, P.B., and J.M. Williams. 2013. Terrestrial salamander abundance on reclaimed mountaintop removal mines. Wildlife Society Bulletin. doi: 10.1002/wsb.319.

Wray, T. II, K. A. Strait, and R. C. Whitmore. 1982. Reproductive success of grassland sparrows on a reclaimed surface mine in West Virginia. Auk 99:157-164.

Zipper, C. E., J. A. Burger, J. G. Skousen, P. N. Angel, C. D. Barton, V. Davis, and J. A. Franklin. 2011. Restoring forests and associated ecosystem services on Appalachian coal surface mines. Environmental Management 47:751-765. 
Table 1. Nest metrics for all species. Number of eggs/nest is the average number of eggs from all nests. Number of fledglings/nest is the average number of nestlings from all nests that survived to the nestling stage. CCWMA (Cross Creek Wildlife Management Area) and HSP (Hillman State Park) were former surface mines. HWMA (Hillcrest Wildlife Management Area) and PRIV (Private land) were unmined shrublands. FISP= Field Sparrow, BWWA= BlueWinged Warbler, and EATO=Eastern Towhee. Yearly total breeding season survival was derived from the model of nest survival by species and year. Survival for each site and year was derived from the model of nest survival by species, year, and site. $\mathrm{F}$ and $\mathrm{P}$ values are from ANOVA models comparing among sites and accounting for year.

\begin{tabular}{|c|c|c|c|c|c|c|c|}
\hline & \multicolumn{3}{|c|}{ \# Eggs/Nest } & \multicolumn{3}{|c|}{ \# Fledges/Successful Nest } & \multirow{2}{*}{$\begin{array}{c}\text { Breeding Season } \\
\text { Probability of } \\
\text { Survival } \\
\end{array}$} \\
\hline & \# Nests & Mean & SE & $\begin{array}{c}\text { \# Successful } \\
\text { Nests }\end{array}$ & Mean & SE & \\
\hline \multicolumn{8}{|l|}{$\underline{\text { FISP }}$} \\
\hline 2012 Total & 91 & 3.5 & 0.09 & 22 & 3.3 & 0.18 & 0.16 \\
\hline HSP (2012) & 43 & 3.6 & 0.12 & 16 & 3.3 & 0.23 & 0.20 \\
\hline PRIV (2012) & 48 & 3.5 & 0.15 & 6 & 3.5 & 0.22 & 0.14 \\
\hline 2013 Total & 78 & 3.6 & 0.09 & 24 & 3.6 & 0.15 & 0.24 \\
\hline HSP (2013) & 29 & 3.7 & 0.15 & 5 & 3.8 & 0.20 & 0.18 \\
\hline CCWMA (2013) & 27 & 3.7 & 0.11 & 11 & 3.6 & 0.20 & 0.33 \\
\hline \multirow[t]{2}{*}{ HWMA (2013) } & 22 & 3.3 & 0.22 & 8 & 3.3 & 0.36 & 0.23 \\
\hline & \multicolumn{3}{|c|}{$\mathrm{F}=1.06, \mathrm{df}=3 / 164, \mathrm{P}=0.37$} & \multicolumn{3}{|c|}{$\mathrm{F}=0.36, \mathrm{df}=3 / 40, \mathrm{P}=0.78$} & \\
\hline \multicolumn{8}{|l|}{ BWWA } \\
\hline 2012 Total & 8 & 4.4 & 0.63 & 4 & 5.0 & 1.00 & 0.49 \\
\hline HSP (2012) & 3 & 5.0 & 1.00 & 2 & 6.0 & 0.00 & 0.43 \\
\hline PRIV (2012) & 5 & 4.0 & 0.84 & 2 & 4.0 & 2.00 & 0.36 \\
\hline 2013 Total & 6 & 4.3 & 0.33 & 2 & 3.5 & 0.50 & 0.40 \\
\hline HSP (2013) & 3 & 4.0 & 0.58 & 1 & 3.0 & - & 0.41 \\
\hline CCWMA (2013) & 3 & 4.7 & 0.33 & 1 & 4.0 & - & 0.56 \\
\hline \multirow[t]{2}{*}{ HWMA (2013) } & 0 & 0.0 & $\mathrm{n} / \mathrm{a}$ & 0 & 0.0 & $\mathrm{n} / \mathrm{a}$ & $\mathrm{n} / \mathrm{a}$ \\
\hline & \multicolumn{3}{|c|}{$\mathrm{F}=0.23, \mathrm{df}=2 / 10, \mathrm{P}=0.80$} & \multicolumn{3}{|c|}{$\mathrm{F}=0.19, \mathrm{df}=2 / 2, \mathrm{P}=0.84$} & \\
\hline \multicolumn{8}{|l|}{$\underline{\text { EATO }}$} \\
\hline 2012 Total & 19 & 3.2 & 0.21 & 3 & 3.3 & 0.33 & 0.07 \\
\hline HSP (2012) & 5 & 3.4 & 0.24 & 2 & 3.0 & 0.00 & 0.09 \\
\hline PRIV (2012) & 14 & 3.1 & 0.27 & 1 & 4.0 & - & 0.06 \\
\hline 2013 Total & 12 & 3.6 & 0.23 & 3 & 4.0 & 0.00 & 0.03 \\
\hline HSP (2013) & 10 & 3.4 & 0.22 & 2 & 4.0 & 0.00 & 0.08 \\
\hline CCWMA (2013) & 1 & 5.0 & - & 0 & 0.0 & $\mathrm{n} / \mathrm{a}$ & 0.00 \\
\hline HWMA (2013) & 1 & 4.0 & - & 1 & 4.0 & - & 0.11 \\
\hline & \multicolumn{3}{|c|}{$\mathrm{F}=1.70, \mathrm{df}=3 / 26, \mathrm{P}=0.19$} & \multicolumn{3}{|c|}{$\mathrm{F}=0.50, \mathrm{df}=2 / 2, \mathrm{P}=0.65$} & \\
\hline
\end{tabular}


Table 2. Model candidates for nest survival. Models with $\Delta \mathrm{AICc}<2$ are considered supported and are bolded for emphasis.

\begin{tabular}{lcccc}
\hline Model of Survival Dependent on: & AICc & Delta AICc & $\begin{array}{c}\text { AICc } \\
\text { Weights }\end{array}$ & $\begin{array}{c}\text { Model } \\
\text { Likelihood }\end{array}$ \\
\hline Species and Year & $\mathbf{8 5 6 . 0 6}$ & $\mathbf{0 . 0 0}$ & $\mathbf{0 . 2 3 8}$ & $\mathbf{1 . 0 0}$ \\
Species & $\mathbf{8 5 6 . 0 8}$ & $\mathbf{0 . 0 2}$ & $\mathbf{0 . 2 3 6}$ & $\mathbf{0 . 9 9}$ \\
Species and Type & $\mathbf{8 5 6 . 4 4}$ & $\mathbf{0 . 3 8}$ & $\mathbf{0 . 1 9 7}$ & $\mathbf{0 . 8 3}$ \\
Species and Site & $\mathbf{8 5 7 . 1 9}$ & $\mathbf{1 . 1 3}$ & $\mathbf{0 . 1 3 6}$ & $\mathbf{0 . 5 7}$ \\
Species, Type, and Year & $\mathbf{8 5 7 . 4 8}$ & $\mathbf{1 . 4 2}$ & $\mathbf{0 . 1 1 7}$ & $\mathbf{0 . 4 9}$ \\
Species, Year, and Site & 859.16 & 3.10 & 0.048 & 0.21 \\
Site & 861.44 & 5.38 & 0.015 & 0.07 \\
Site and Type & 861.44 & 5.38 & 0.015 & 0.07 \\
Type & 861.86 & 5.79 & 0.013 & 0.06 \\
Year & 861.95 & 5.89 & 0.012 & 0.05 \\
Constant Survival & 862.37 & 6.31 & 0.010 & 0.04 \\
Type and Year & 862.87 & 6.81 & 0.008 & 0.03 \\
\hline
\end{tabular}

Table 3. Predators detected by site during the 2013 breeding season. CCWMA (Cross Creek Wildlife Management Area) and HSP (Hillman State Park) were former surface mines. HWMA (Hillcrest Wildlife Management Area) was not mined.

\begin{tabular}{lccccc}
\hline & Total & $\begin{array}{c}\text { White- } \\
\text { tailed Deer }\end{array}$ & $\begin{array}{c}\text { Black Rat } \\
\text { Snake }\end{array}$ & Rodent & $\begin{array}{c}\text { Other } \\
\text { Mammal }\end{array}$ \\
\hline CCWMA & 59 & 40 & 4 & 13 & 2 \\
HSP & 69 & 19 & 1 & 49 & 0 \\
Mean Mined & 64 & 29.5 & 2.5 & 31 & 1 \\
HWMA & 63 & 27 & 1 & 33 & 2 \\
\hline
\end{tabular}


Table 4. Mean abundance comparisons for the 20 early-successional species detected over all sites. Species with significantly different abundances at $\alpha=0.0025$ are bolded for emphasis. CCWMA (Cross Creek Wildlife Management Area) was reclaimed and HSP (Hillman State Park) was not. HWMA = Hillcrest Wildlife Management Area, PRIV = Private land.

\begin{tabular}{|c|c|c|c|c|c|c|c|c|c|c|c|c|}
\hline & & & \multicolumn{4}{|c|}{ Mined $(n=23)$} & \multicolumn{4}{|c|}{ Nonmined $(n=16)$} & \multirow{2}{*}{\multicolumn{2}{|c|}{$\begin{array}{c}\text { Kruskal-Wallis } \\
\quad(\mathrm{df}=3)\end{array}$}} \\
\hline & & & \multicolumn{2}{|c|}{$\operatorname{HSP}(n=15)$} & \multicolumn{2}{|c|}{$\operatorname{CCWMA}(\mathrm{n}=8)$} & \multicolumn{2}{|c|}{ PRIV (n=8) } & \multicolumn{2}{|c|}{ HWMA $(n=8)$} & & \\
\hline & & & Mean & $\mathrm{SE}$ & Mean & SE & Mean & SE & Mean & SE & $x^{2}$ & $\mathrm{p}$ \\
\hline AMGO & American Goldfinch & Spinus tristis & 1.4 & 0.19 & 1.3 & 0.45 & 0.8 & 0.25 & 1.5 & 0.38 & 3.92 & 0.27 \\
\hline BHCO & Brown-headed Cowbird & Molothrus ater & 0.8 & 0.22 & 0.8 & 0.25 & 1.1 & 0.23 & 0.8 & 0.16 & 2.12 & 0.55 \\
\hline BLJA & Blue Jay & Cyanocitta cristata & 1.2 & 0.20 & 0.1 & 0.13 & 1.0 & 0.27 & 0.4 & 0.26 & 13.77 & 0.003 \\
\hline BRTH & Brown Thrasher & Toxostoma rufum & 0.8 & 0.28 & 1.0 & 0.19 & 0.5 & 0.19 & 0.3 & 0.16 & 6.20 & 0.10 \\
\hline BWWA & Blue-winged Warbler & Vermivora cyanoptera & 0.6 & 0.16 & 0.5 & 0.27 & 1.4 & 0.32 & 0.3 & 0.16 & 8.61 & 0.03 \\
\hline CEDW & Cedar Waxwing & Bombycilla cedrorum & 1.1 & 0.18 & 0.3 & 0.16 & 1.1 & 0.30 & 1.0 & 0.33 & 7.05 & 0.07 \\
\hline CHSP & Chipping Sparrow & Spizella passerina & 0.1 & 0.13 & 0.4 & 0.26 & 0.0 & 0.00 & 0.0 & 0.00 & 4.48 & 0.21 \\
\hline COYE & Common Yellowthroat & Geothlypis trichas & 2.9 & 0.19 & 1.3 & 0.31 & 3.4 & 0.26 & 3.4 & 0.56 & 15.04 & 0.0018 \\
\hline CSWA & Chestnut-sided Warbler & Setophaga pensylvanica & 0.1 & 0.07 & 0.0 & 0.00 & 0.0 & 0.00 & 0.1 & 0.13 & 1.78 & 0.62 \\
\hline EATO & Eastern Towhee & Pipilo erythrophthalmus & 3.2 & 0.31 & 2.4 & 0.26 & 3.9 & 0.23 & 1.9 & 0.30 & 16.53 & $<.001$ \\
\hline FISP & Field Sparrow & Spizella pusilla & 3.5 & 0.47 & 3.8 & 0.90 & 3.8 & 0.37 & 2.9 & 0.67 & 1.19 & 0.76 \\
\hline GRCA & Gray Catbird & Dumetella carolinensis & 1.6 & 0.25 & 0.9 & 0.23 & 1.6 & 0.42 & 1.6 & 0.38 & 4.05 & 0.26 \\
\hline GRSP & Grasshopper Sparrow & Ammodramus savannarum & 0.0 & 0.00 & 0.9 & 0.40 & 0.0 & 0.00 & 0.0 & 0.00 & 16.77 & $<.001$ \\
\hline INBU & Indigo Bunting & Passerina cyanea & 1.8 & 0.31 & 2.0 & 0.63 & 1.6 & 0.38 & 1.5 & 0.33 & 0.35 & 0.95 \\
\hline MODO & Mourning Dove & Zenaida macroura & 0.1 & 0.09 & 0.0 & 0.00 & 0.1 & 0.13 & 0.1 & 0.13 & 1.13 & 0.77 \\
\hline PRAW & Prairie Warbler & Setophaga discolor & 1.6 & 0.27 & 0.1 & 0.13 & 0.0 & 0.00 & 0.1 & 0.13 & 24.32 & $<.001$ \\
\hline SOSP & Song Sparrow & Melospiza melodia & 1.3 & 0.23 & 2.5 & 0.33 & 0.9 & 0.35 & 2.8 & 0.41 & 15.32 & 0.0016 \\
\hline WEVI & White-eyed Vireo & Vireo griseus & 0.9 & 0.19 & 0.8 & 0.25 & 0.9 & 0.30 & 0.8 & 0.25 & 0.22 & 0.98 \\
\hline WIFL & Willow Flycatcher & Empidonax traillii & 0.1 & 0.09 & 1.4 & 0.53 & 0.1 & 0.13 & 0.6 & 0.26 & 9.76 & 0.02 \\
\hline $\mathrm{YBCH}$ & Yellow-breasted Chat & Icteria virens & 1.1 & 0.23 & 0.5 & 0.27 & 0.5 & 0.27 & 1.9 & 0.52 & 7.87 & 0.05 \\
\hline
\end{tabular}


Table 5. Post-testing Kruskal-Wallis results for species found to have significantly different abundances across sites (Table 4a). Significant differences at $\alpha=0.01$ are bolded for emphasis. CCWMA (Cross Creek Wildlife Management Area) was reclaimed and HSP (Hillman State Park) was not. HWMA = Hillcrest Wildlife Management Area, PRIV = Private land. $\mathrm{df}=1 \mathrm{for}$ all tests.

\begin{tabular}{|c|c|c|c|c|c|c|c|c|c|c|c|c|}
\hline & \multirow{2}{*}{\multicolumn{2}{|c|}{$\begin{array}{l}\text { Unreclaimed Mine } \\
\text { v Reclaimed Mine } \\
\text { HSP v CCWMA }\end{array}$}} & \multirow{2}{*}{\multicolumn{2}{|c|}{$\begin{array}{c}\begin{array}{c}\text { Non-Mine } \\
\text { v Non-Mine }\end{array} \\
\text { PRIV v HWMA }\end{array}$}} & \multicolumn{4}{|c|}{ Unreclaimed Mine v Non-Mine } & \multicolumn{4}{|c|}{ Reclaimed Mine v Non-Mine } \\
\hline & & & & & \multicolumn{2}{|c|}{ HSP v PRIV } & \multicolumn{2}{|c|}{ HSP v HWMA } & \multicolumn{2}{|c|}{$\begin{array}{l}\text { CCWMA v } \\
\text { PRIV }\end{array}$} & \multicolumn{2}{|c|}{$\begin{array}{c}\text { CCWMA v } \\
\text { HWMA }\end{array}$} \\
\hline & $\chi^{2}$ & $\mathrm{P}$ & $\chi^{2}$ & $\mathrm{P}$ & $\chi^{2}$ & $\mathrm{P}$ & $\chi^{2}$ & $\mathrm{P}$ & $\chi^{2}$ & $\mathrm{P}$ & $\chi^{2}$ & $\mathrm{P}$ \\
\hline COYE & 10.76 & 0.001 & 0.05 & 0.83 & 2.31 & 0.13 & 0.61 & 0.43 & 9.87 & 0.002 & 7.10 & 0.008 \\
\hline EATO & 3.48 & 0.06 & 11.61 & 0.0007 & 2.05 & 0.15 & 6.75 & 0.009 & 9.47 & 0.002 & 1.68 & 0.19 \\
\hline GRSP & 8.60 & 0.003 & $\mathrm{n} / \mathrm{a}$ & $\mathrm{n} / \mathrm{a}$ & $\mathrm{n} / \mathrm{a}$ & $\mathrm{n} / \mathrm{a}$ & $\mathrm{n} / \mathrm{a}$ & $\mathrm{n} / \mathrm{a}$ & 4.89 & 0.03 & 4.89 & 0.03 \\
\hline PRAW & 10.59 & 0.001 & 1.00 & 0.32 & 12.60 & 0.0004 & 10.59 & 0.001 & 1.00 & 0.32 & 0.00 & 1.00 \\
\hline SOSP & 6.22 & 0.01 & 8.17 & 0.004 & 1.66 & 0.20 & 7.40 & 0.007 & 7.01 & 0.008 & 0.03 & 0.87 \\
\hline
\end{tabular}


Table 6. Kruskal-Wallis Rank Sum results for a test of means on 23 vegetation variables over all sites. Variables that differed at the Bonferroni-adjusted $\alpha$ of 0.002 are bolded for added emphasis. CCWMA (Cross Creek Wildlife Management Area) was reclaimed and HSP (Hillman State Park) was not. HWMA = Hillcrest Wildlife Management Area, PRIV = Private land.

\begin{tabular}{|c|c|c|c|c|c|c|c|c|c|c|}
\hline \multirow{2}{*}{ Plot Variables (11.3m radius) } & \multicolumn{4}{|c|}{ Mined $(n=256)$} & \multicolumn{4}{|c|}{ Not Mined (n=85) } & \multicolumn{2}{|c|}{$\begin{array}{l}\text { Kruskal- Wallis } \\
\text { by Site }(\mathrm{df}=3)\end{array}$} \\
\hline & \multicolumn{2}{|c|}{$\begin{array}{c}\text { HSP } \\
(n=166)\end{array}$} & \multicolumn{2}{|c|}{$\begin{array}{c}\text { CCWMA } \\
(\mathrm{n}=90)\end{array}$} & \multicolumn{2}{|c|}{$\begin{array}{l}\text { PRIV } \\
(\mathrm{n}=12)\end{array}$} & \multicolumn{2}{|c|}{$\begin{array}{c}\text { HWMA } \\
(\mathrm{n}=73)\end{array}$} & \multirow[t]{2}{*}{$\chi^{2}$} & \multirow[t]{2}{*}{$\mathrm{P}$} \\
\hline & & & & & & & & & & \\
\hline \% Canopy Closure & 21.7 & 2.77 & 14.4 & 3.38 & 10.0 & 7.18 & 11.3 & 3.37 & 9.43 & 0.02 \\
\hline Snag Count & 0.2 & 0.07 & 0.2 & 0.13 & 0.3 & 0.18 & 0.1 & 0.03 & 3.42 & 0.33 \\
\hline $\begin{array}{l}\text { Distance to Edge (m) } \\
\text { Avg Litter Depth 1m from }\end{array}$ & 40.9 & 2.53 & 82.5 & 7.83 & 35.7 & 7.13 & 82.6 & 7.26 & 37.94 & $<0.001$ \\
\hline Plot Center & 0.04 & 0.00 & 0.02 & 0.00 & 0.05 & 0.01 & 0.02 & 0.00 & 62.05 & $<0.001$ \\
\hline Grass/Forb Layer Height & 0.8 & 0.05 & 0.6 & 0.03 & 0.8 & 0.08 & 1.0 & 0.10 & 36.49 & $<0.001$ \\
\hline Shrub Layer Height & 2.4 & 0.08 & 2.9 & 0.12 & 2.0 & 0.13 & 1.8 & 0.09 & 59.75 & $<0.001$ \\
\hline $\begin{array}{l}\text { Sapling Layer Height } \\
\text { Avg Vertical Vegetation }\end{array}$ & 2.7 & 0.18 & 1.8 & 0.23 & 2.4 & 0.57 & 2.1 & 0.21 & 9.45 & 0.02 \\
\hline Density & 13.5 & 0.43 & 12.7 & 0.68 & 14.5 & 1.29 & 12.4 & 0.54 & 3.70 & 0.30 \\
\hline $\begin{array}{l}\text { Canopy Tree Count } \\
\text { Plot Composition (\% of } \\
11.3 \mathrm{~m} \text { radius plot containing } \\
\text { Cover tvne) }\end{array}$ & 3.9 & 0.45 & 2.6 & 0.54 & 2.3 & 0.84 & 2.4 & 0.50 & 15.07 & 0.002 \\
\hline Grass & 67.2 & 2.32 & 70.3 & 3.00 & 75.4 & 6.37 & 68.7 & 2.86 & 1.71 & 0.63 \\
\hline Forb & 59.7 & 1.62 & 59.8 & 2.28 & 84.6 & 3.55 & 44.7 & 2.77 & 40.74 & $<0.001$ \\
\hline Vine & 4.5 & 0.68 & 5.4 & 0.94 & 35.6 & 6.19 & 4.5 & 0.94 & 33.26 & $<0.001$ \\
\hline Rubus & 15.8 & 1.38 & 5.1 & 1.02 & 8.5 & 1.93 & 34.7 & 2.82 & 88.00 & $<0.001$ \\
\hline Shrub & 33.4 & 2.09 & 33.5 & 3.21 & 41.9 & 8.05 & 13.5 & 1.84 & 36.00 & $<0.001$ \\
\hline Sapling & 15.2 & 1.60 & 6.7 & 1.59 & 8.8 & 3.85 & 6.0 & 1.42 & 25.11 & $<0.001$ \\
\hline Canopy & 19.8 & 1.91 & 11.6 & 2.33 & 11.0 & 4.84 & 13.5 & 2.73 & 16.53 & $<0.001$ \\
\hline Variables in $5 \mathrm{~m}$ Radius & & & & & & & & & & \\
\hline $\begin{array}{l}\text { 1-2m Shrub Count } \\
\text { 1-2m Shrub \% Exotic }\end{array}$ & 4.9 & 0.52 & 2.4 & 0.35 & 11.7 & 2.77 & 3.3 & 0.62 & 31.04 & $<0.001$ \\
\hline Species & 0.6 & 0.03 & 0.6 & 0.05 & 0.8 & 0.07 & 0.6 & 0.06 & 2.08 & 0.56 \\
\hline $\begin{array}{l}>2 \mathrm{~m} \text { Shrub Count } \\
>2 \mathrm{~m} \text { Shrub \% Exotic }\end{array}$ & 5.0 & 0.44 & 3.6 & 0.47 & 4.9 & 1.31 & 1.9 & 0.43 & 24.03 & $<0.001$ \\
\hline Species & 0.6 & 0.04 & 0.7 & 0.05 & 0.8 & 0.11 & 0.4 & 0.05 & 22.78 & $<0.001$ \\
\hline Sapling Count & 5.2 & 0.81 & 4.5 & 2.87 & 2.7 & 0.90 & 2.5 & 0.71 & 23.07 & $<0.001$ \\
\hline Understory Richness & 4.3 & 0.25 & 2.4 & 0.24 & 5.1 & 0.54 & 2.4 & 0.29 & 34.52 & $<0.001$ \\
\hline Canopy Richness & 1.1 & 0.09 & 0.6 & 0.14 & 0.9 & 0.34 & 0.6 & 0.10 & 27.66 & $<0.001$ \\
\hline
\end{tabular}


Table 7. Post-testing Kruskal-Wallis results for vegetation variables found to have significantly different means across sites (Table 5a). Significant differences at $\alpha=0.0029$ are bolded for emphasis. CCWMA (Cross Creek Wildlife Management Area) was reclaimed and HSP (Hillman State Park) was not. HWMA = Hillcrest Wildlife Management Area, PRIV = Private land. $\mathrm{df}=1 \mathrm{for}$ all tests.

\begin{tabular}{|c|c|c|c|c|c|c|c|c|c|c|c|c|}
\hline & \multirow{2}{*}{\multicolumn{2}{|c|}{$\begin{array}{c}\text { Unreclaimed v } \\
\text { Reclaimed Mine } \\
\text { HSP v } \\
\text { CCWMA }\end{array}$}} & \multirow{2}{*}{\multicolumn{2}{|c|}{$\begin{array}{c}\text { Non-Mine v } \\
\text { Non-Mine } \\
\text { PRIV v } \\
\text { HWMA }\end{array}$}} & \multicolumn{4}{|c|}{ Unreclaimed Mine v Non-Mine } & \multicolumn{4}{|c|}{ Reclaimed Mine v Non-Mine } \\
\hline & & & & & \multicolumn{2}{|c|}{$\begin{array}{l}\text { HSP v } \\
\text { PRIV }\end{array}$} & \multicolumn{2}{|c|}{$\begin{array}{c}\text { HSP v } \\
\text { HWMA }\end{array}$} & \multicolumn{2}{|c|}{$\begin{array}{l}\text { CCWMA v } \\
\text { PRIV }\end{array}$} & \multicolumn{2}{|c|}{$\begin{array}{c}\text { CCWMA v } \\
\text { HWMA }\end{array}$} \\
\hline & $\chi 2$ & $\mathrm{P}$ & $\chi^{2}$ & $\mathrm{P}$ & $\chi^{2}$ & $\mathrm{P}$ & $\chi^{2}$ & $\mathrm{P}$ & $\chi^{2}$ & $\mathrm{P}$ & $\chi^{2}$ & $\mathrm{P}$ \\
\hline \multicolumn{13}{|c|}{$\underline{\text { Plot Variables }(11.3 \mathrm{~m} \text { radius })}$} \\
\hline Distance to Edge (m) & 16.86 & $<0.001$ & 8.54 & 0.0035 & 0.10 & 0.75 & 30.91 & $<0.001$ & 4.15 & 0.04 & 0.61 & 0.44 \\
\hline $\begin{array}{l}\text { Avg Litter Depth } 1 \mathrm{~m} \\
\text { from Plot Center }\end{array}$ & 34.31 & $<0.001$ & 14.32 & 0.0002 & 2.76 & 0.10 & 39.46 & $<0.001$ & 12.13 & $<0.001$ & 0.08 & 0.78 \\
\hline $\begin{array}{l}\text { Grass/Forb Layer } \\
\text { Height }\end{array}$ & 10.07 & 0.0015 & 1.04 & 0.31 & 0.91 & 0.34 & 15.38 & $<0.001$ & 4.41 & 0.04 & 33.65 & $<0.001$ \\
\hline Shrub Layer Height & 14.87 & $<0.001$ & 3.20 & 0.07 & 4.72 & 0.03 & 33.21 & $<0.001$ & 9.16 & 0.0025 & 42.70 & $<0.001$ \\
\hline Canopy Tree Count & 12.15 & $<0.001$ & 0.23 & 0.63 & 0.63 & 0.43 & 6.83 & 0.0089 & 0.64 & 0.42 & 0.49 & 0.48 \\
\hline \multicolumn{13}{|c|}{$\underline{\text { Plot Composition (\% of } 11.3 \mathrm{~m} \text { radius plot containing cover type) }}$} \\
\hline Forb & 0.05 & 0.83 & 21.56 & $<0.001$ & 16.68 & $<0.001$ & 20.46 & $<0.001$ & 15.62 & $<0.001$ & 16.32 & $<0.001$ \\
\hline Vine & 2.00 & 0.16 & 26.72 & $<0.001$ & 31.08 & $<0.001$ & 0.48 & 0.49 & 26.06 & $<0.001$ & 0.42 & 0.52 \\
\hline Rubus & 31.30 & $<0.001$ & 13.38 & $<0.001$ & 0.52 & 0.47 & 35.19 & $<0.001$ & 7.66 & 0.0057 & 73.93 & $<0.001$ \\
\hline Shrub & 0.17 & 0.68 & 15.00 & $<0.001$ & 1.17 & 0.28 & 31.51 & $<0.001$ & 1.77 & 0.18 & 18.76 & $<0.001$ \\
\hline Sapling & 20.30 & $<0.001$ & 0.40 & 0.53 & 0.92 & 0.34 & 10.72 & 0.0011 & 1.61 & 0.20 & 2.11 & 0.15 \\
\hline Canopy & 14.11 & $<0.001$ & 0.03 & 0.86 & 1.21 & 0.27 & 6.13 & 0.01 & 0.48 & 0.49 & 1.12 & 0.29 \\
\hline \multicolumn{13}{|l|}{ Variables in $5 \mathrm{~m}$ Radius } \\
\hline 1-2m Shrub Count & 11.95 & $<0.001$ & 17.03 & $<0.001$ & 11.16 & $<0.001$ & 7.46 & 0.0063 & 22.26 & $<0.001$ & 0.01 & 0.91 \\
\hline$>2 \mathrm{~m}$ Shrub Count & 1.70 & 0.19 & 9.22 & 0.0024 & 0.18 & 0.68 & 20.44 & $<0.001$ & 1.72 & 0.19 & 12.90 & $<0.001$ \\
\hline $\begin{array}{l}>2 \mathrm{~m} \text { Shrub \% Exotic } \\
\text { Species }\end{array}$ & 7.41 & 0.0065 & 6.71 & 0.0096 & 1.79 & 0.18 & 8.08 & 0.0045 & 0.02 & 0.89 & 19.56 & $<0.001$ \\
\hline Sapling Count & 19.01 & $<0.001$ & 3.63 & 0.06 & 0.13 & 0.72 & 5.70 & 0.02 & 8.94 & 0.0028 & 3.85 & 0.05 \\
\hline Understory Richness & 18.62 & $<0.001$ & 12.42 & 0.0004 & 0.68 & 0.41 & 17.84 & $<0.001$ & 16.25 & $<0.001$ & 0.31 & 0.58 \\
\hline Canopy Richness & 22.08 & $<0.001$ & 1.03 & 0.31 & 0.49 & 0.48 & 12.52 & $<0.001$ & 2.59 & 0.11 & 1.18 & 0.28 \\
\hline
\end{tabular}




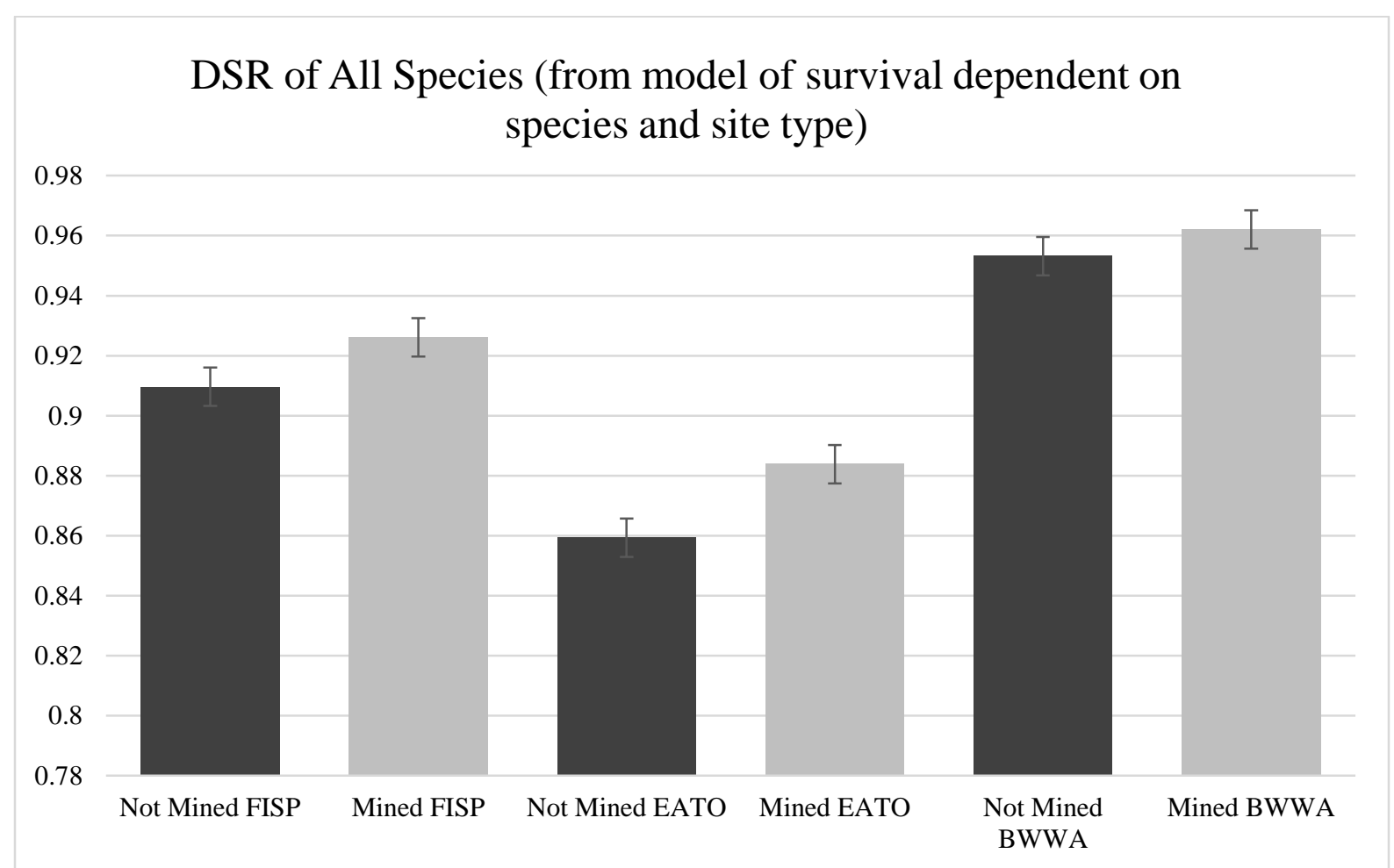

Fig. 1. A comparison of daily survival rates (DSR) of all species between mined and non-mined sites, derived from the highest-ranked model which included site type; nest survival dependent on species and type. FISP= Field Sparrow, BWWA= Blue-Winged Warbler, and EATO=Eastern Towhee. 


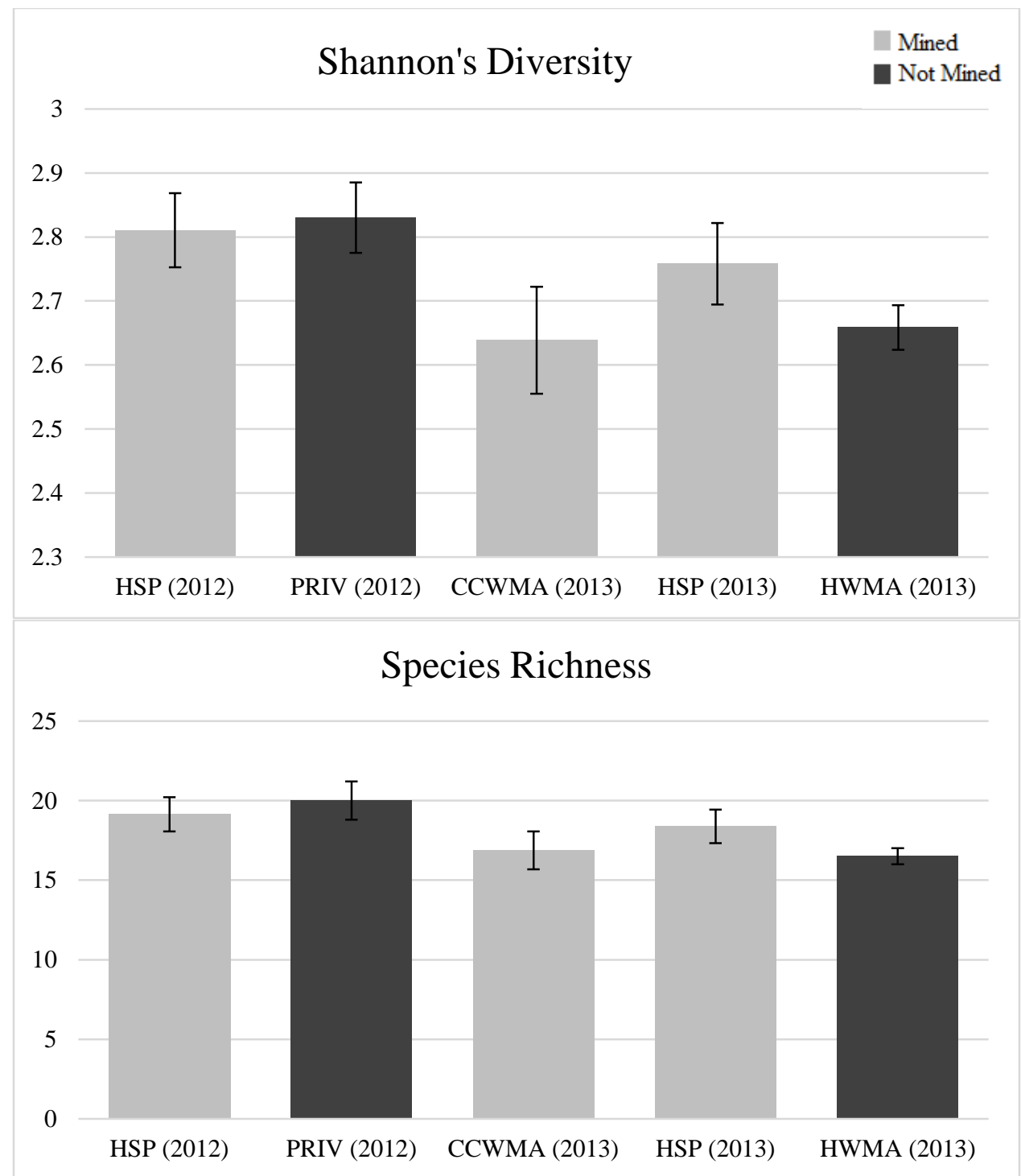

Fig. 2. Mean and standard error of Shannon's diversity and species richness by site and year. CCWMA (Cross Creek Wildlife Management Area) and HSP (Hillman State Park) were former surface mines. HWMA (Hillcrest Wildlife Management Area) and PRIV (Private land) were unmined shrublands. 


\section{NMDS of Avian Counts}

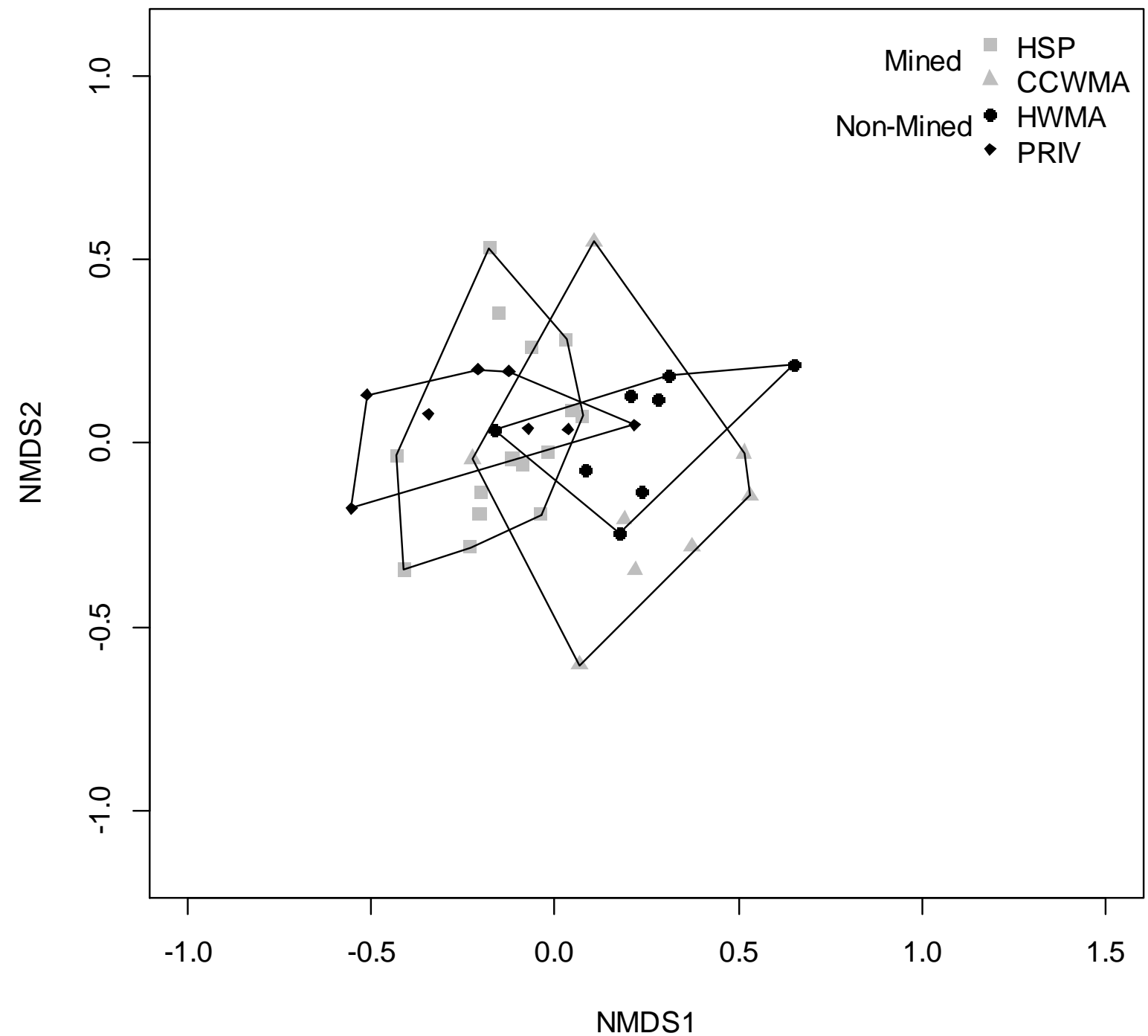

Fig. 3. NMDS results of the point count data. CCWMA (Cross Creek Wildlife Management Area) and HSP (Hillman State Park) were former surface mines. HWMA (Hillcrest Wildlife Management Area) and PRIV (Private land) were unmined shrublands. 


\section{NMDS of Vegetative Composition}

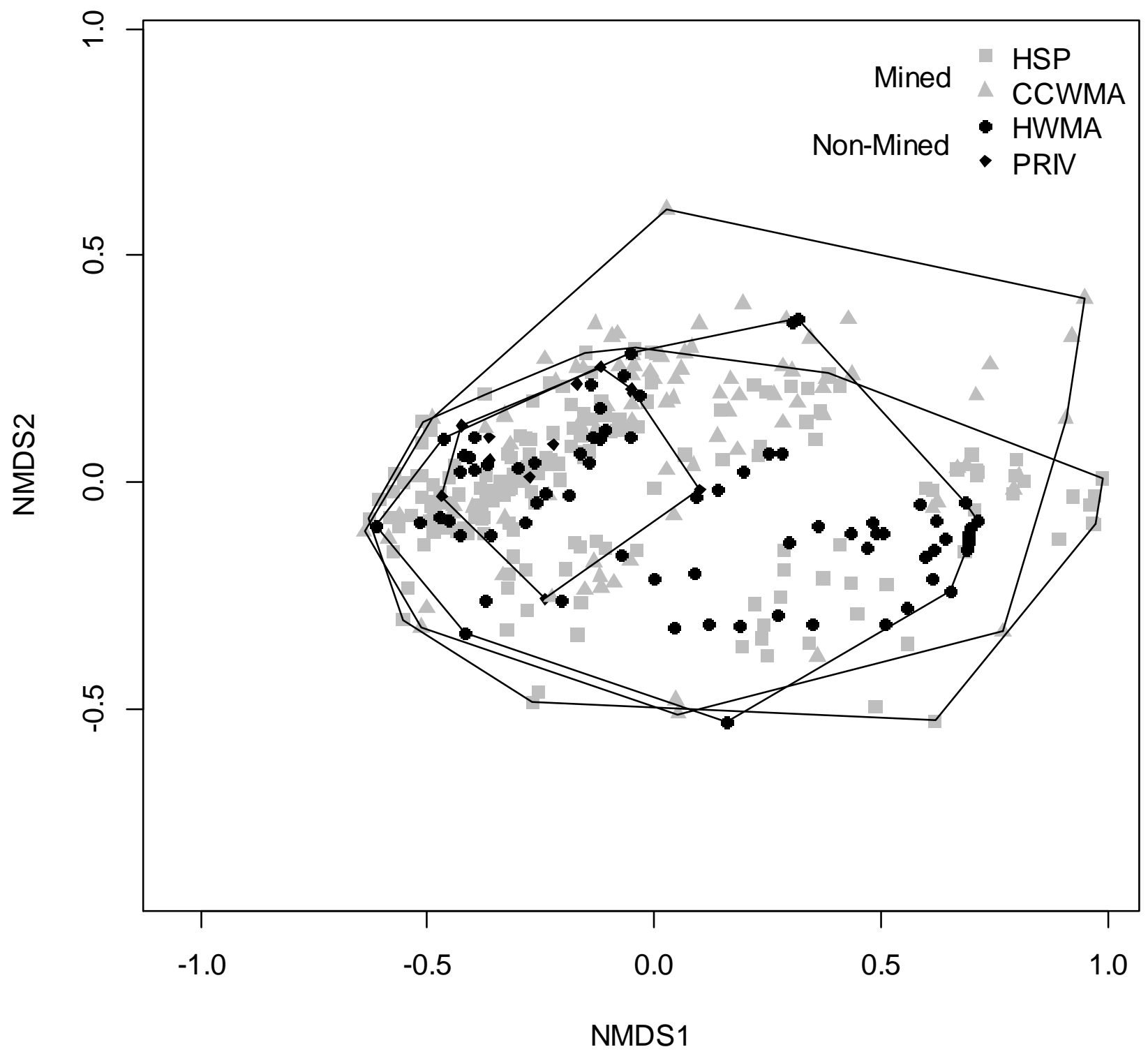

Fig. 4. NMDS results of vegetation plot data. CCWMA (Cross Creek Wildlife Management Area) and HSP (Hillman State Park) were former surface mines. HWMA (Hillcrest Wildlife Management Area) and PRIV (Private land) were unmined shrublands. 


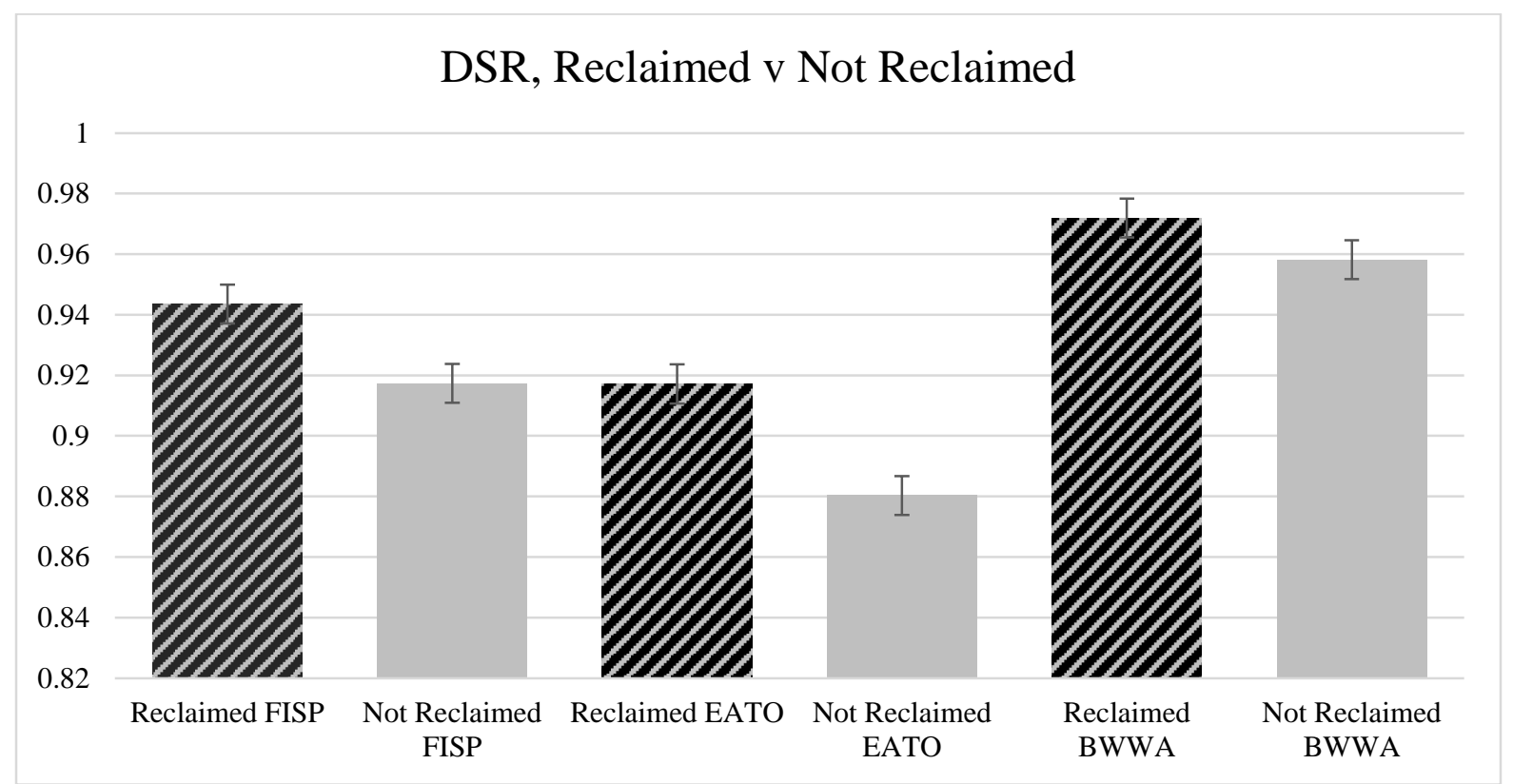

Fig. 5. A comparison of daily survival rates (DSR) of all species between the two mined sites, CCWMA (Cross Creek Wildlife Management Area) which was reclaimed and HSP (Hillman State Park) which was not reclaimed. The estimates are derived from the highest-ranked model which included site (nest survival dependent on species and site; Table 2). FISP= Field Sparrow, BWWA= Blue-Winged Warbler, and EATO=Eastern Towhee. 


\section{Avian Community Ordination for the Two Mined Sites}

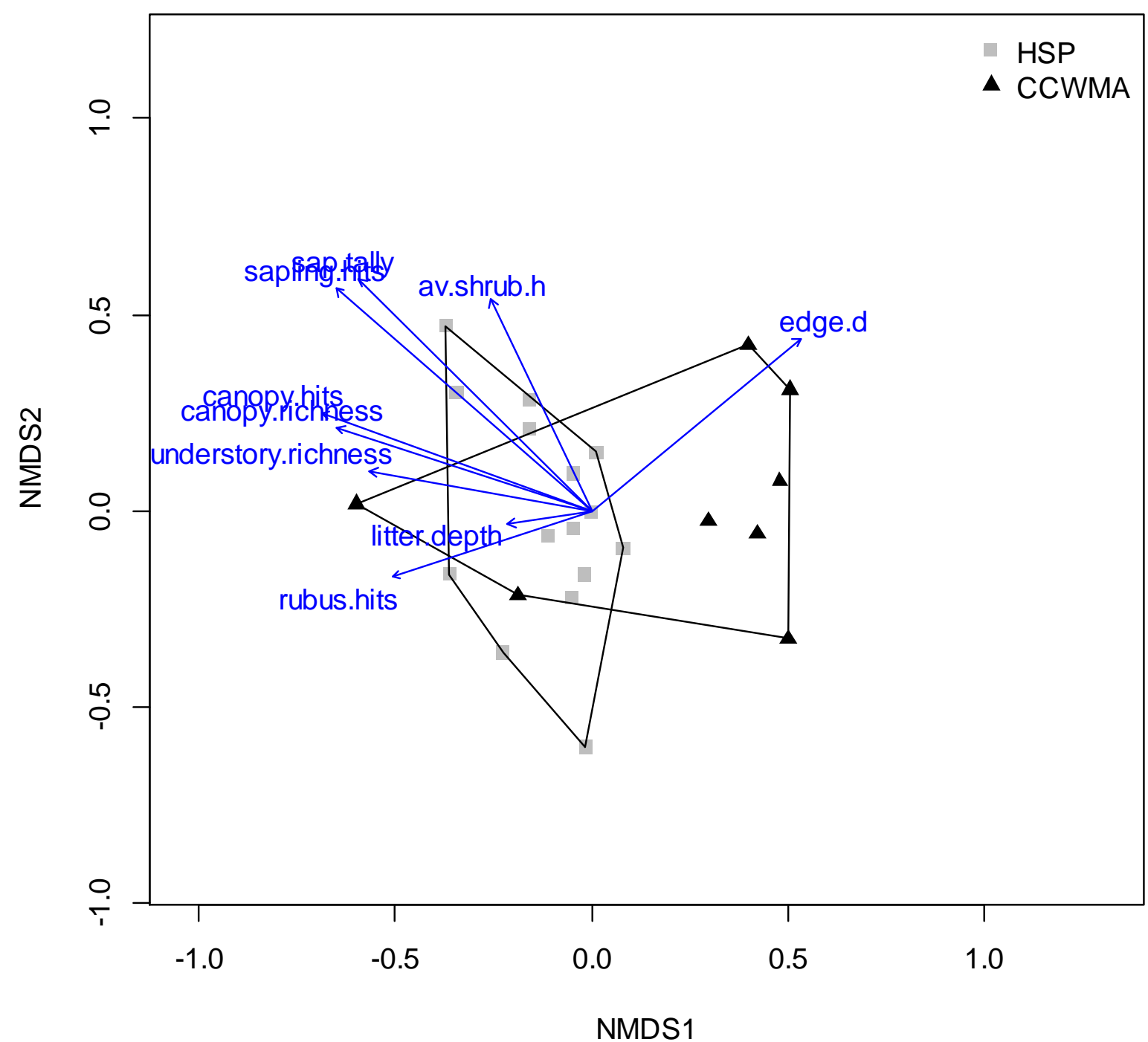

Fig. 6. The Nonmetric Multi-Dimensional Scaling ordination of avian communities at point counts for the two mined sites, correlated with surface gradients for the significantly differing vegetation variables at $\alpha=0.0029$. HSP (Hillman State Park) was not reclaimed, and CCWMA (Cross Creek Wildlife Management Area) was. 


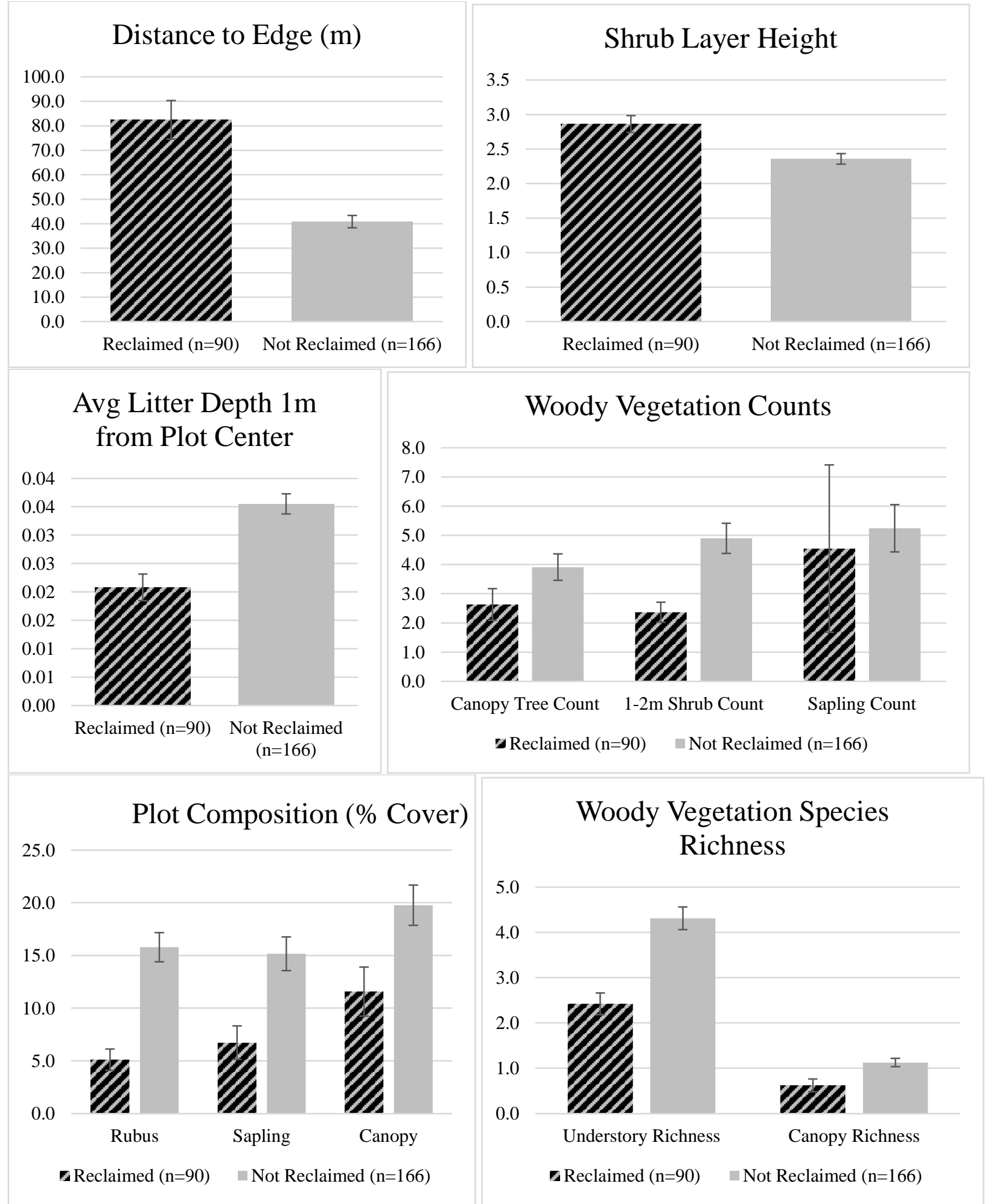

Fig. 7. Means and standard errors (error bars) for the eleven significantly different vegetation variables at $\alpha=0.0029$ between the two mined sites, one of which was reclaimed and the other was not. 
APPENDIX A

Table A1. Transformations used in ANOVAs for all variables in Blue-winged Warbler analyses.

\begin{tabular}{|c|c|c|c|}
\hline & $\begin{array}{c}\text { Territory } \\
\mathrm{V} \\
\text { Random }\end{array}$ & $\begin{array}{c}\text { Nests } \\
\mathrm{v} \\
\text { Territory } \\
\end{array}$ & $\begin{array}{c}\text { Successful } \\
\text { v } \\
\text { Failed } \\
\text { Nests } \\
\end{array}$ \\
\hline \multicolumn{4}{|l|}{ Nest-Only Vegetation } \\
\hline Nest Ht. to rim (m) & $\mathrm{n} / \mathrm{a}$ & $\mathrm{n} / \mathrm{a}$ & None \\
\hline Substrate Ht. (m) & $\mathrm{n} / \mathrm{a}$ & $\mathrm{n} / \mathrm{a}$ & None \\
\hline Shrub Ht. (m) & $\mathrm{n} / \mathrm{a}$ & $\mathrm{n} / \mathrm{a}$ & None \\
\hline Max Shrub Width (m) & $\mathrm{n} / \mathrm{a}$ & $\mathrm{n} / \mathrm{a}$ & None \\
\hline Width Perpendicular to Max (m) & $\mathrm{n} / \mathrm{a}$ & $\mathrm{n} / \mathrm{a}$ & None \\
\hline Distance - Nest to Shrub Stem (m) & $\mathrm{n} / \mathrm{a}$ & $\mathrm{n} / \mathrm{a}$ & $\operatorname{sqrt}(\mathrm{x})$ \\
\hline Distance - Nest to Nearest Branch (m) & $\mathrm{n} / \mathrm{a}$ & $\mathrm{n} / \mathrm{a}$ & $\operatorname{sqrt}(\mathrm{x})$ \\
\hline \# of Stems @ 10cm Height & $\mathrm{n} / \mathrm{a}$ & $\mathrm{n} / \mathrm{a}$ & None \\
\hline Avg \% Nest Concealment & $\mathrm{n} / \mathrm{a}$ & $\mathrm{n} / \mathrm{a}$ & None \\
\hline \multicolumn{4}{|l|}{ Ground Cover $(\%, 1 \mathrm{~m}$ from Plot Center) } \\
\hline Litter & $\mathrm{n} / \mathrm{a}$ & None & None \\
\hline Grass & $\mathrm{n} / \mathrm{a}$ & None & $\operatorname{sqrt}(\mathrm{x})$ \\
\hline Bare Ground & $\mathrm{n} / \mathrm{a}$ & None & None \\
\hline Forb & $\mathrm{n} / \mathrm{a}$ & $\operatorname{sqrt}(\mathrm{x})$ & None \\
\hline Woody & $\mathrm{n} / \mathrm{a}$ & $\operatorname{sqrt}(x)$ & $\operatorname{sqrt}(\mathrm{x})$ \\
\hline Vine & $\mathrm{n} / \mathrm{a}$ & $\log (x+1)$ & None \\
\hline Rubus & $\mathrm{n} / \mathrm{a}$ & $\log (x+1)$ & $\log (x+1)$ \\
\hline \multicolumn{4}{|l|}{ 5m Radius from Plot Center } \\
\hline $1-2 \mathrm{~m}$ Shrub Count & $\log (x+1)$ & $\log (x+1)$ & $\operatorname{sqrt}(\mathrm{x})$ \\
\hline 1-2m Shrub \% Exotic Species & $\operatorname{asin}(x)$ & None & None \\
\hline$>2 \mathrm{~m}$ Shrub Count & $\operatorname{sqrt}(\mathrm{x})$ & $\operatorname{sqrt}(\mathrm{x})$ & None \\
\hline$>2 \mathrm{~m}$ Shrub \% Exotic Species & None & None & None \\
\hline Sapling Count & $\log (\mathrm{x}+1)$ & $\operatorname{sqrt}(\mathrm{x})$ & None \\
\hline Understory Richness & None & None & None \\
\hline \multicolumn{4}{|l|}{ Plot Variables } \\
\hline$\overline{\% \text { Canopy Closure }}$ & $\operatorname{sqrt}(x)$ & $\operatorname{sqrt}(x)$ & None \\
\hline Snag Count & $\operatorname{sqrt}(x)$ & $\operatorname{sqrt}(x)$ & None \\
\hline Distance to Edge (m) & $\log (x+1)$ & $\log (x+1)$ & $\log (x+1)$ \\
\hline Avg Litter Depth $1 \mathrm{~m}$ from Plot Center & $\operatorname{sqrt}(\mathrm{x})$ & None & $\operatorname{sqrt}(\mathrm{x})$ \\
\hline Herbaceous Layer Height & None & None & None \\
\hline Shrub Layer Height & None & None & None \\
\hline Sapling Layer Height & None & None & None \\
\hline Avg Vertical Vegetation Density & None & None & None \\
\hline Canopy Tree Count & $\operatorname{sqrt}(\mathrm{x})$ & $\operatorname{sqrt}(\mathrm{x})$ & $\log (x+1)$ \\
\hline
\end{tabular}


Plot Composition (\% of plot containing cover type)

Grass

None None None

Forb

None

None None

Vine

$\log (\mathrm{x}+1) \quad \operatorname{sqrt}(\mathrm{x}) \quad$ None

Rubus

$\log (\mathrm{x}+1) \quad$ None None

Shrub

$\operatorname{sqrt}(\mathrm{x}) \quad$ None None

Sapling

$\log (\mathrm{x}+1) \quad$ None None

Canopy

$\operatorname{sqrt}(\mathrm{x})$

$\operatorname{sqrt}(\mathrm{x})$

None

Table A2. Average nesting period length for Blue-winged Warblers at our sites, used to calculate daily survival rates and probabilities of success with the Mayfield product method, and total exposure days per period per year.

\begin{tabular}{lccc}
\hline & Average Period & \multicolumn{2}{c}{ Exposure Days } \\
Nesting Stage & Length (days) & 2012 & 2013 \\
\hline Laying & 4.5 & 23 & 13 \\
Incubation & 11.3 & 62 & 46 \\
Nestling & 8.8 & 43 & 13 \\
Total & 24.6 & 128 & 72 \\
\hline
\end{tabular}

Table A3. Nesting cycle data for Blue-winged Warblers across all sites; eight nests in 2012 (four failed, four successful) and six nests in 2013 (four failed, two successful).

\begin{tabular}{|c|c|c|c|c|c|c|c|}
\hline & & \multicolumn{2}{|c|}{ Earliest } & \multicolumn{2}{|c|}{ Median Date } & \multicolumn{2}{|c|}{ Latest } \\
\hline & & 2012 & 2013 & 2012 & 2013 & 2012 & 2013 \\
\hline \multirow[t]{3}{*}{ 1st Egg Laid } & All Nests & 6-May & 12-May & 8-May & 20-May & 11-May & 31-May \\
\hline & Failed & 11-May & 16-May & 11-May & 20-May & 11-May & 31-May \\
\hline & Success & 6-May & 12-May & 8-May & 18-May & 10-May & 25-May \\
\hline \multirow[t]{3}{*}{ Clutch Complete } & All Nests & 11-May & 20-May & 14-May & 25-May & 16-May & 4-Jun \\
\hline & Failed & 16-May & 20-May & 16-May & 25-May & 16-May & 4-Jun \\
\hline & Success & 11-May & 16-May & 12-May & 22-May & 14-May & 28-May \\
\hline \multirow[t]{3}{*}{ Hatch Date } & All Nests & 23-May & 28-May & 25-May & 6-Jun & 27-May & 7-Jun \\
\hline & Failed & 27-May & 6-Jun & 27-May & 6-Jun & 27-May & 6-Jun \\
\hline & Success & 23-May & 28-May & 24-May & 2-Jun & 25-May & 7-Jun \\
\hline Fledge Date & Success & 1-Jun & 5-Jun & 2-Jun & 10-Jun & 3-Jun & 16-Jun \\
\hline
\end{tabular}


Table A4. The Structure loadings of the CANDISC function used to reduce and describe the north-south vegetative gradient at Cross Creek Wildlife Management Area. Structure loadings are the correlations of each variable to the resulting discriminant function.

\begin{tabular}{lr}
\hline Variable & Correlation \\
\hline edge.d & -0.53802 \\
av.sap.h & 0.476368 \\
shrub.tally.1.2 & -0.43627 \\
canopy.tally & 0.418799 \\
canopy.hits & 0.417902 \\
av.grass.forb.h & 0.404656 \\
litter.depth & -0.3555 \\
shrub.2.tally & -0.33265 \\
shrub.1.2.percent.exotic & -0.30667 \\
percent.canopy.closure & 0.296633 \\
litter.cover & -0.27053 \\
vine.hits & 0.227554 \\
forb.hits & 0.22447 \\
grass.hits & 0.206443 \\
sap.tally & -0.17794 \\
snag.count & 0.149947 \\
shrub.hits & -0.13683 \\
sapling.hits & 0.129 \\
rubus.hits & 0.116608 \\
woody.cover & -0.09906 \\
understory.richness & 0.086758 \\
shrub.2.percent.exotic & 0.086744 \\
grass.cover & 0.083625 \\
forb.cover & 0.082835 \\
av.vertical.density & -0.07161 \\
vine.cover & 0.053183 \\
av.shrub.h & 0.052393 \\
bare.cover & -0.04093 \\
rubus.cover & -0.01254 \\
\hline
\end{tabular}




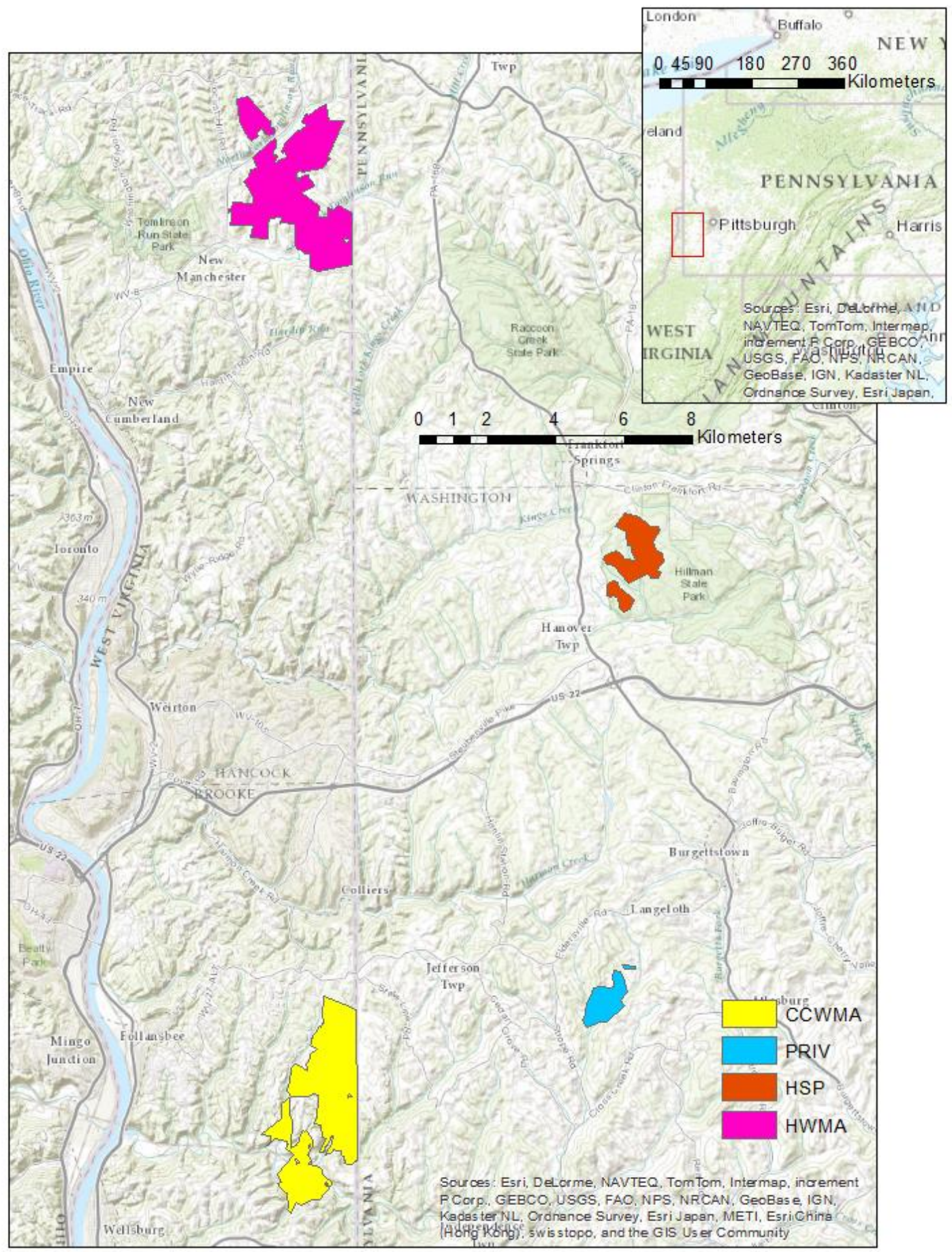

Figure A1. Study sites for both years. In 2012 research was only conducted on Hillman State Park (HSP) and private lands (PRIV). In 2013 research was only conducted on HSP, Hillcrest Wildlife Management Area, and Cross Creek Wildlife Management Area. CCWMA and HSP are former surface mines, HWMA and PRIV are shrublands which were never mined. 

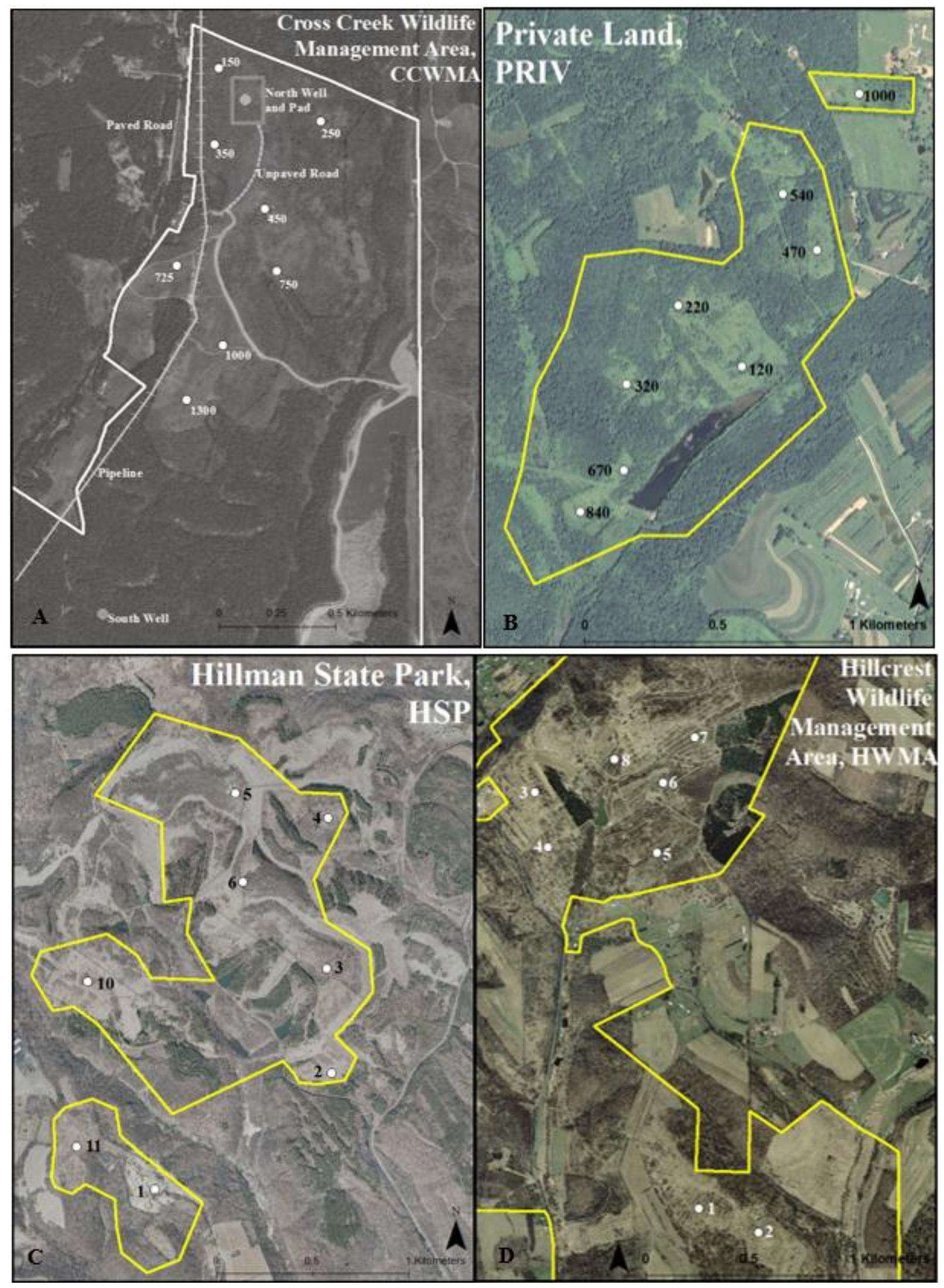
Figure A2. Site maps. (A) Cross Creek Wildlife Management Area (CCWMA) including both wells, the eight point count stations, and added approximations of infrastructure which has been added since the aerial was taken (2008); (B) Private Land (PRIV) including the eight point count stations (imagery from 2006); (C) Hillman State Park (HSP) including the eight point count stations (imagery from 2006); (D) Hillcrest Wildlife Management Area (HWMA) including the eight point count stations (imagery from 2005). 

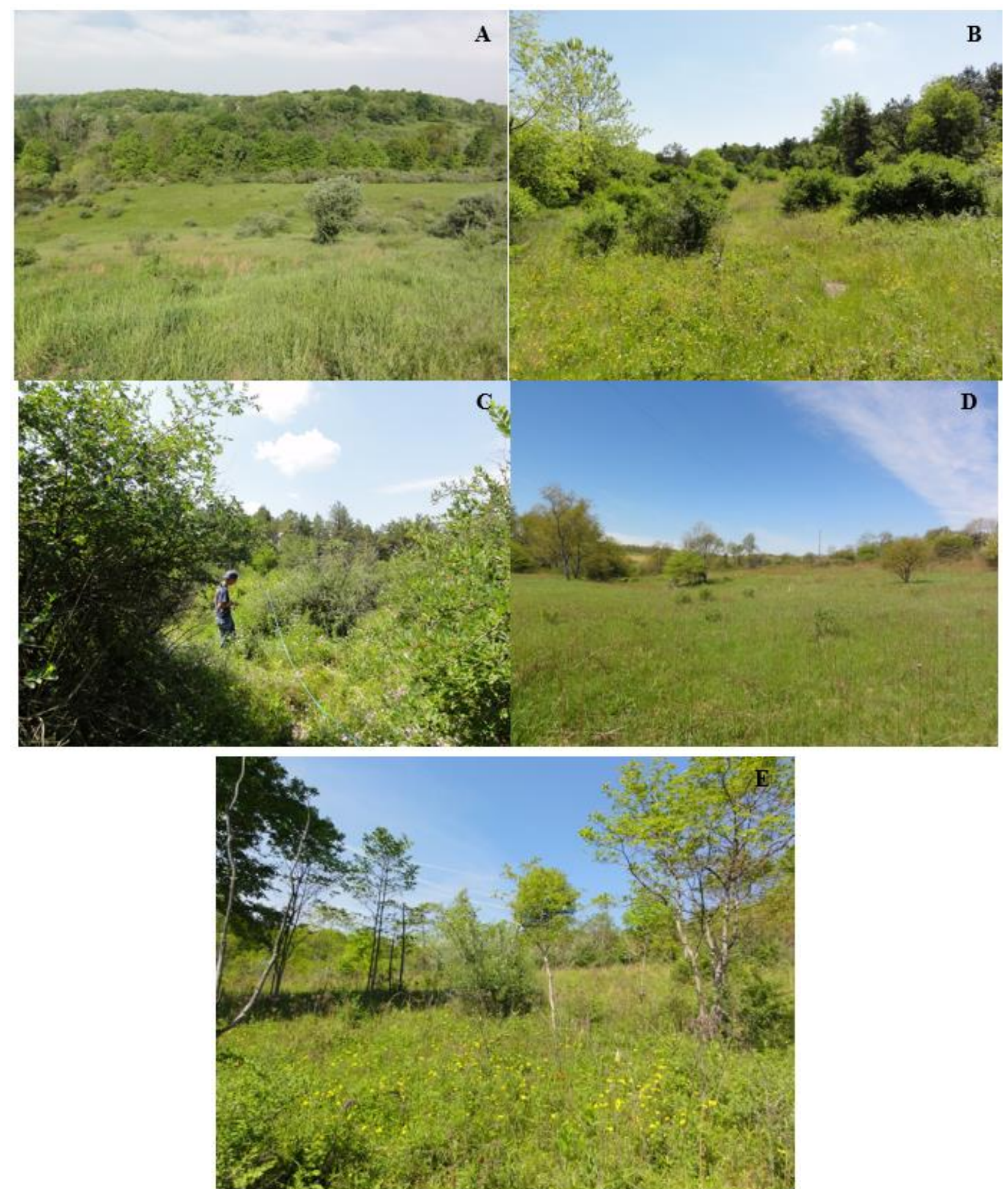

Figure A3. Site photographs. (A) Cross Creek Wildlife Management Area in early May 2013, (B) Hillman State Park in late May 2012, (C) Hillman State Park in late June 2013, (D) Hillcrest Wildlife Management Area in early May 2013, (E) Private land site in late May 2012. 
West Virginia, Climate Division 1, Temperature, April-May

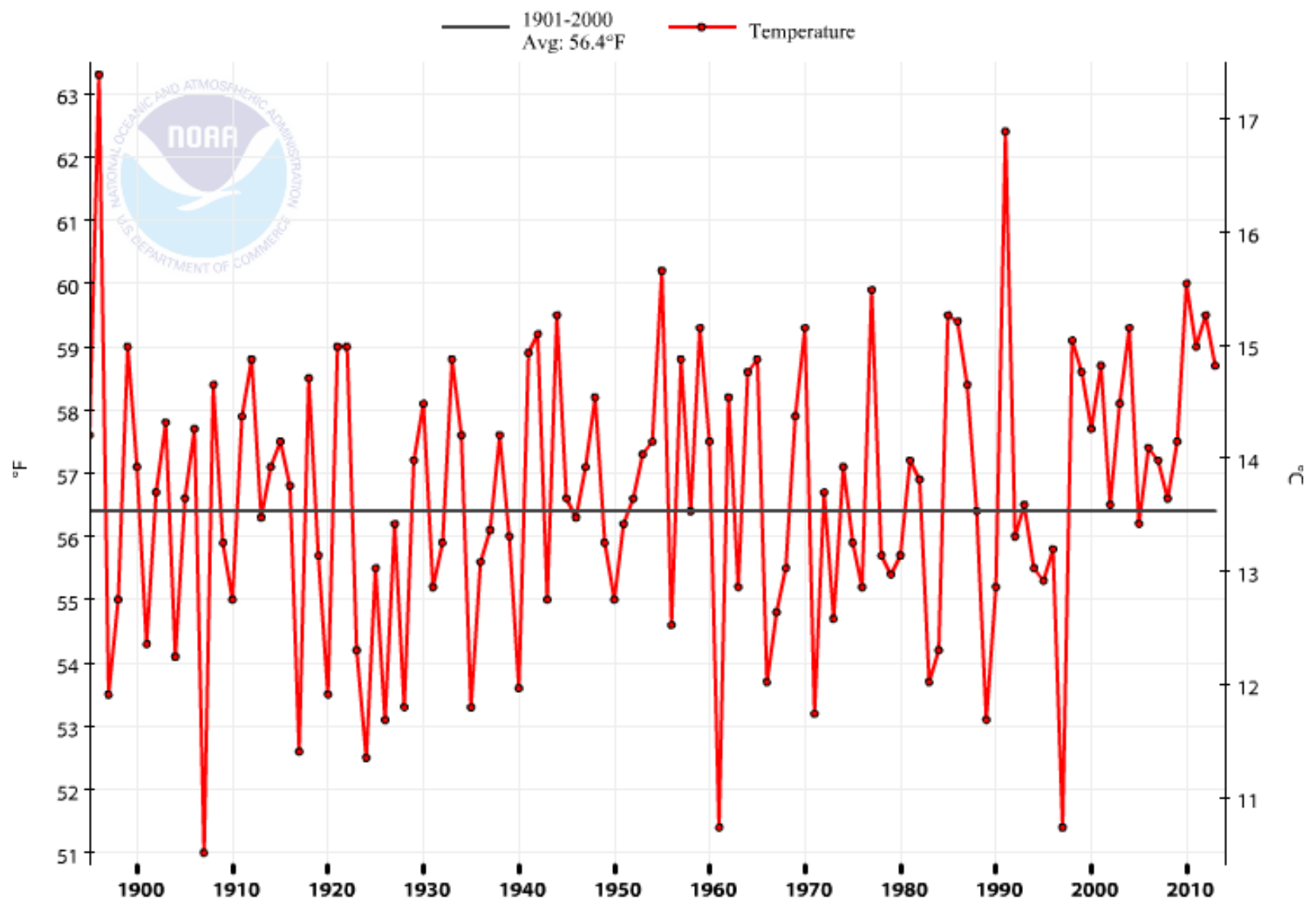

Figure A4. Mean temperatures for April and May in Northwestern WV from 1895-2013. Image is from the NOAA National Climatic Data Center, Asheville NC, web site at http://www.ncdc.noaa.gov/cag/time-series/us 


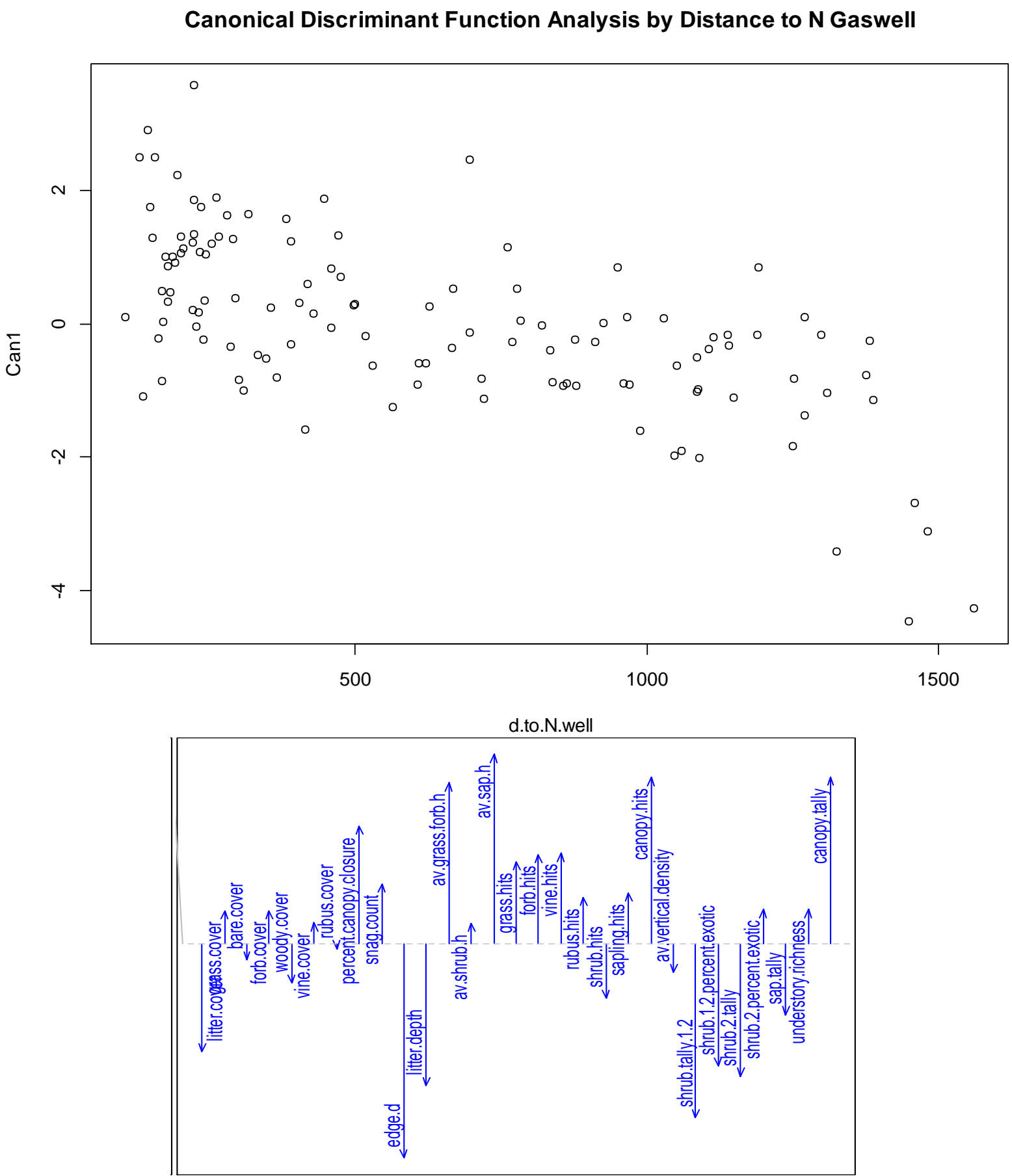

Figure A5. The scores (top) and structure of the discriminant function which re-expresses vegetative variables at Cross Creek wildlife Management Area based on distance to the northern gas well. Scores are the values that each vegetation plot is reassigned in the new function, and structure shows the relative importance of each variable in determining the function. 


\section{APPENDIX B}

Table B1. All species detected in point counts at all sites over both years.

\begin{tabular}{|c|c|c|c|c|c|c|c|}
\hline \multirow[b]{2}{*}{ Common Name } & \multirow[b]{2}{*}{$\underline{\text { Scientific Name }}$} & \multirow[b]{2}{*}{$\underline{\text { Alpha }}$} & \multicolumn{2}{|c|}{2012} & \multicolumn{3}{|c|}{2013} \\
\hline & & & HSP & PRIV & CCWMA & HSP & HWMA \\
\hline Acadian Flycatcher & Empidonax virescens & ACFL & $\mathrm{X}$ & $\mathrm{X}$ & & & \\
\hline American Crow & $\begin{array}{l}\text { Corvus } \\
\text { brachyrhynchos }\end{array}$ & AMCR & $\mathrm{X}$ & $\mathrm{X}$ & $\mathrm{X}$ & $\mathrm{X}$ & $\mathrm{X}$ \\
\hline American Goldfinch & Spinus tristis & AMGO & $\mathrm{X}$ & $\mathrm{X}$ & $\mathrm{X}$ & $\mathrm{X}$ & $\mathrm{X}$ \\
\hline American Redstart & Setophaga ruticilla & AMRE & $\mathrm{X}$ & $\mathrm{X}$ & & & \\
\hline American Robin & Turdus migratorius & AMRO & $\mathrm{X}$ & $X$ & $\mathrm{X}$ & $\mathrm{X}$ & $X$ \\
\hline American Woodcock & Scolopax minor & AMWO & & & & & $\mathrm{X}$ \\
\hline Baltimore Oriole & Icterus galbula & BAOR & $\mathrm{X}$ & $X$ & $\mathrm{X}$ & $\mathrm{X}$ & $\mathrm{X}$ \\
\hline Barn Swallow & Hirundo rustica & BASW & & & & & $\mathrm{X}$ \\
\hline Black-billed Cuckoo & $\begin{array}{l}\text { Coccyzus } \\
\text { erythropthalmus }\end{array}$ & $\mathrm{BBCU}$ & $\mathrm{X}$ & $\mathrm{X}$ & & $X$ & \\
\hline Bay-breasted Warbler & Setophaga castanea & BBWA & $\mathrm{X}$ & $\mathrm{X}$ & & & \\
\hline Black-capped Chickadee & Poecile atricapillus & $\mathrm{BCCH}$ & $X$ & $\mathrm{X}$ & & & $\mathrm{X}$ \\
\hline Blue-gray Gnatcatcher & Polioptila caerulea & BGGN & $\mathrm{X}$ & $\mathrm{X}$ & $\mathrm{X}$ & $\mathrm{X}$ & \\
\hline Brown-headed Cowbird & Molothrus ater & $\mathrm{BHCO}$ & $\mathrm{X}$ & $\mathrm{X}$ & $\mathrm{X}$ & $\mathrm{X}$ & $\mathrm{X}$ \\
\hline Blue Jay & Cyanocitta cristata & BLJA & $\mathrm{X}$ & $\mathrm{X}$ & $X$ & $X$ & $\mathrm{X}$ \\
\hline Blackpoll Warbler & Setophaga striata & BLPW & & $X$ & & & \\
\hline Brown Thrasher & Toxostoma rufum & BRTH & $X$ & $X$ & $X$ & $X$ & $X$ \\
\hline $\begin{array}{l}\text { Black-throated Green } \\
\text { Warbler }\end{array}$ & Setophaga virens & BTNW & $\mathrm{X}$ & $\mathrm{X}$ & & & \\
\hline Broad-winged Hawk & Buteo platypterus & BWHA & $X$ & & & & \\
\hline Blue-winged Warbler & $\begin{array}{l}\text { Vermivora } \\
\text { cyanoptera }\end{array}$ & BWWA & $\mathrm{X}$ & $X$ & $\mathrm{X}$ & $\mathrm{X}$ & $\mathrm{X}$ \\
\hline Carolina Chickadee & Poecile carolinensis & $\mathrm{CACH}$ & $X$ & $X$ & $X$ & $X$ & $X$ \\
\hline Canada Goose & Branta canadensis & $\mathrm{CAGO}$ & $X$ & $\mathrm{X}$ & $X$ & & \\
\hline Carolina Wren & $\begin{array}{l}\text { Thryothorus } \\
\text { ludovicianus }\end{array}$ & CARW & $X$ & $\mathrm{X}$ & $\mathrm{X}$ & & $\mathrm{X}$ \\
\hline Cedar Waxwing & Bombycilla cedrorum & CEDW & $\mathrm{X}$ & $X$ & $\mathrm{X}$ & $\mathrm{X}$ & $X$ \\
\hline Chipping Sparrow & Spizella passerina & CHSP & $\mathrm{X}$ & $\mathrm{X}$ & $\mathrm{X}$ & $\mathrm{X}$ & \\
\hline Chimney Swift & Chaetura pelagica & CHSW & & $X$ & $X$ & & \\
\hline Common Grackle & Quiscalus quiscula & COGR & & $\mathrm{X}$ & & & \\
\hline Common Yellowthroat & Geothlypis trichas & COYE & $X$ & $\mathrm{X}$ & $X$ & $X$ & $\mathrm{X}$ \\
\hline Chestnut-sided Warbler & $\begin{array}{l}\text { Setophaga } \\
\text { pensylvanica }\end{array}$ & CSWA & & $\mathrm{X}$ & & $\mathrm{X}$ & $\mathrm{X}$ \\
\hline Downy Woodpecker & Picoides pubescens & DOWO & $\mathrm{X}$ & $\mathrm{X}$ & & $\mathrm{X}$ & \\
\hline Eastern Kingbird & Tyrannus tyrannus & EAKI & & & $\mathrm{X}$ & & \\
\hline Eastern Meadowlark & Sturnella magna & EAME & & & $X$ & & \\
\hline Eastern Phoebe & Sayornis phoebe & EAPH & $\mathrm{X}$ & $\mathrm{X}$ & $\mathrm{X}$ & & \\
\hline Eastern Towhee & $\begin{array}{l}\text { Pipilo } \\
\text { erythrophthalmus }\end{array}$ & EATO & $\mathrm{X}$ & $\mathrm{X}$ & $X$ & $X$ & $\mathrm{X}$ \\
\hline Eastern Wood-Pewee & Contopus virens & EAWP & $\mathrm{X}$ & $\mathrm{X}$ & $\mathrm{X}$ & & \\
\hline European Starling & Sturnus vulgaris & EUST & & & & & $X$ \\
\hline Field Sparrow & Spizella pusilla & FISP & $\mathrm{X}$ & $\mathrm{X}$ & $\mathrm{X}$ & $X$ & $X$ \\
\hline Great Blue Heron & Ardea herodias & GBHE & & $\mathrm{X}$ & & $\mathrm{X}$ & \\
\hline Great Crested Flycatcher & Myiarchus crinitus & GCFL & & $X$ & $\mathrm{X}$ & & \\
\hline $\begin{array}{l}\text { Gray Catbird } \\
\text { Grasshopper Sparrow }\end{array}$ & $\begin{array}{l}\text { Dumetella } \\
\text { carolinensis } \\
\text { Ammodramus }\end{array}$ & $\begin{array}{l}\text { GRCA } \\
\text { GRSP }\end{array}$ & $X$ & $X$ & $\begin{array}{l}X \\
X\end{array}$ & $\mathrm{X}$ & $X$ \\
\hline
\end{tabular}


savannarum

\begin{tabular}{|c|c|c|c|c|c|c|c|}
\hline Hairy Woodpecker & Picoides villosus & HAWO & $X$ & $X$ & $X$ & $X$ & $\mathrm{X}$ \\
\hline Hooded Warbler & Setophaga citrina & HOWA & $\mathrm{X}$ & $\mathrm{X}$ & & & \\
\hline House Wren & Troglodytes aedon & HOWR & $X$ & $X$ & & & \\
\hline Indigo Bunting & Passerina cyanea & INBU & $\mathrm{X}$ & $\mathrm{X}$ & $X$ & $\mathrm{X}$ & $\mathrm{X}$ \\
\hline Kentucky Warbler & Geothlypis formosa & KEWA & & $\mathrm{X}$ & & & \\
\hline Killdeer & Charadrius vociferus & KILL & & $\mathrm{X}$ & & & $\mathrm{X}$ \\
\hline Mallard & Anas platyrhynchos & MALL & & $\mathrm{X}$ & & & \\
\hline Magnolia Warbler & Setophaga magnolia & MAWA & $\mathrm{X}$ & $X$ & & $X$ & \\
\hline Mourning Dove & Zenaida macroura & MODO & $X$ & $X$ & $X$ & $X$ & $\mathrm{X}$ \\
\hline Nashville Warbler & $\begin{array}{l}\text { Oreothlypis } \\
\text { ruficapilla }\end{array}$ & NAWA & & & & & $\mathrm{X}$ \\
\hline Northern Cardinal & Cardinalis cardinalis & NOCA & $X$ & $X$ & $X$ & $X$ & $\mathrm{X}$ \\
\hline Northern Flicker & Colaptes auratus & NOFL & $X$ & $\mathrm{X}$ & $\mathrm{X}$ & $\mathrm{X}$ & $\mathrm{X}$ \\
\hline Orchard Oriole & Icterus spurius & OROR & & & $\mathrm{X}$ & & \\
\hline Ovenbird & Seiurus aurocapillus & OVEN & $\mathrm{X}$ & $\mathrm{X}$ & & $\mathrm{X}$ & \\
\hline Pileated Woodpecker & Dryocopus pileatus & PIWO & $X$ & $X$ & & & \\
\hline Prairie Warbler & Setophaga discolor & PRAW & $X$ & $X$ & $X$ & $\mathrm{X}$ & $\mathrm{X}$ \\
\hline Rose-breasted Grosbeak & $\begin{array}{l}\text { Pheucticus } \\
\text { ludovicianus }\end{array}$ & RBGR & $\mathrm{X}$ & $X$ & & $\mathrm{X}$ & \\
\hline Red-breasted Nuthatch & Sitta canadensis & RBNU & $\mathrm{X}$ & $\mathrm{X}$ & & $\mathrm{X}$ & $\mathrm{X}$ \\
\hline Red-bellied Woodpecker & Melanerpes carolinus & RBWO & $X$ & $\mathrm{X}$ & $\mathrm{X}$ & $\mathrm{X}$ & $\mathrm{X}$ \\
\hline Ruby-crowned Kinglet & Regulus calendula & RCKI & $X$ & $X$ & $X$ & & \\
\hline Red-eyed Vireo & Vireo olivaceus & REVI & $\mathrm{X}$ & $\mathrm{X}$ & $\mathrm{X}$ & $\mathrm{X}$ & $\mathrm{X}$ \\
\hline Ring-necked Pheasant & Phasianus colchicus & RNPH & & & & $\mathrm{X}$ & $\mathrm{X}$ \\
\hline Red-shouldered Hawk & Buteo lineatus & RSHA & $\mathrm{X}$ & & & & \\
\hline Red-tailed Hawk & Buteo jamaicensis & RTHA & & $X$ & & & \\
\hline $\begin{array}{l}\text { Ruby-throated } \\
\text { Hummingbird }\end{array}$ & Archilochus colubris & RTHU & $\mathrm{X}$ & & & & \\
\hline Red-winged Blackbird & Agelaius phoeniceus & RWBL & $\mathrm{X}$ & $\mathrm{X}$ & $\mathrm{X}$ & $X$ & $\mathrm{X}$ \\
\hline Scarlet Tanager & Piranga olivacea & SCTA & $\mathrm{X}$ & $\mathrm{X}$ & $\mathrm{X}$ & $\mathrm{X}$ & \\
\hline Song Sparrow & Melospiza melodia & SOSP & $\mathrm{X}$ & $X$ & $\mathrm{X}$ & $\mathrm{X}$ & $\mathrm{X}$ \\
\hline Tennessee Warbler & Oreothlypis peregrina & TEWA & & & $X$ & $\mathrm{X}$ & \\
\hline Tree Swallow & Tachycineta bicolor & TRSW & $X$ & $X$ & $X$ & $X$ & $\mathrm{X}$ \\
\hline Tufted Titmouse & Baeolophus bicolor & TUTI & $\mathrm{X}$ & $\mathrm{X}$ & $X$ & $\mathrm{X}$ & $\mathrm{X}$ \\
\hline Turkey Vulture & Cathartes aura & TUVU & & $\mathrm{X}$ & & & \\
\hline White-breasted Nuthatch & Sitta carolinensis & WBNU & $\mathrm{X}$ & $\mathrm{X}$ & & & \\
\hline White-eyed Vireo & Vireo griseus & WEVI & $\mathrm{X}$ & $\mathrm{X}$ & $\mathrm{X}$ & $\mathrm{X}$ & $\mathrm{X}$ \\
\hline Willow Flycatcher & Empidonax traillii & WIFL & $X$ & $X$ & $X$ & $\mathrm{X}$ & $\mathrm{X}$ \\
\hline Wild Turkey & Meleagris gallopavo & WITU & $X$ & $X$ & & $\mathrm{X}$ & \\
\hline Wood Thrush & Hylocichla mustelina & WOTH & $X$ & $X$ & $\mathrm{X}$ & $X$ & \\
\hline Yellow-breasted Chat & Icteria virens & YBCH & $\mathrm{X}$ & $X$ & $X$ & $\mathrm{X}$ & $\mathrm{X}$ \\
\hline Yellow-billed Cuckoo & Coccyzus americanus & YBCU & & & & $\mathrm{X}$ & \\
\hline Yellow Warbler & Setophaga petechia & YWAR & $X$ & $X$ & $X$ & $\mathrm{X}$ & $\mathrm{X}$ \\
\hline
\end{tabular}


Table B2. Relative abundances (mean detections per point) of species from maximum point counts. All flyovers, raptors, waterbirds, transitory migrants, and detections $>75 \mathrm{~m}$ from the observer were removed. For species codes see Table B1.

\begin{tabular}{|c|c|c|c|c|c|c|c|c|c|c|}
\hline & \multicolumn{4}{|c|}{2012} & \multicolumn{6}{|c|}{2013} \\
\hline & \multicolumn{2}{|c|}{$\operatorname{HSP}(n=7)$} & \multicolumn{2}{|c|}{ PRIV $(\mathrm{n}=8)$} & \multicolumn{2}{|c|}{$\operatorname{CCWMA}(\mathrm{n}=8)$} & \multicolumn{2}{|c|}{$\operatorname{HSP}(n=8)$} & \multicolumn{2}{|c|}{ HWMA $(\mathrm{n}=8)$} \\
\hline & Mean & $\mathrm{SE}$ & Mean & $\mathrm{SE}$ & Mean & $\mathrm{SE}$ & Mean & SE & Mean & SE \\
\hline \multicolumn{11}{|c|}{ Early Successional } \\
\hline AMGO & 1.57 & 0.20 & 0.75 & 0.25 & 1.25 & 0.45 & 1.25 & 0.31 & 1.50 & 0.38 \\
\hline BRTH & 0.43 & 0.30 & 0.50 & 0.19 & 1.00 & 0.19 & 1.13 & 0.44 & 0.25 & 0.16 \\
\hline BWWA & 0.57 & 0.30 & 1.38 & 0.32 & 0.50 & 0.27 & 0.63 & 0.18 & 0.25 & 0.16 \\
\hline CEDW & 1.43 & 0.20 & 1.13 & 0.30 & 0.25 & 0.16 & 0.75 & 0.25 & 1.00 & 0.33 \\
\hline CHSP & 0.00 & 0.00 & 0.00 & 0.00 & 0.38 & 0.26 & 0.25 & 0.25 & 0.00 & 0.00 \\
\hline COYE & 2.86 & 0.26 & 3.38 & 0.26 & 1.25 & 0.31 & 2.88 & 0.30 & 3.38 & 0.56 \\
\hline CSWA & 0.00 & 0.00 & 0.00 & 0.00 & 0.00 & 0.00 & 0.13 & 0.13 & 0.13 & 0.13 \\
\hline EAME & 0.00 & 0.00 & 0.00 & 0.00 & 0.25 & 0.25 & 0.00 & 0.00 & 0.00 & 0.00 \\
\hline EATO & 3.14 & 0.51 & 3.88 & 0.23 & 2.38 & 0.26 & 3.25 & 0.41 & 1.88 & 0.30 \\
\hline FISP & 3.14 & 0.67 & 3.75 & 0.37 & 3.75 & 0.90 & 3.75 & 0.67 & 2.88 & 0.67 \\
\hline GRCA & 1.71 & 0.47 & 1.63 & 0.42 & 0.88 & 0.23 & 1.50 & 0.27 & 1.63 & 0.38 \\
\hline GRSP & 0.00 & 0.00 & 0.00 & 0.00 & 0.88 & 0.40 & 0.00 & 0.00 & 0.00 & 0.00 \\
\hline INBU & 1.43 & 0.20 & 1.63 & 0.38 & 2.00 & 0.63 & 2.13 & 0.55 & 1.50 & 0.33 \\
\hline MODO & 0.14 & 0.14 & 0.13 & 0.13 & 0.00 & 0.00 & 0.13 & 0.13 & 0.13 & 0.13 \\
\hline PRAW & 1.43 & 0.43 & 0.00 & 0.00 & 0.13 & 0.13 & 1.75 & 0.37 & 0.13 & 0.13 \\
\hline SOSP & 1.43 & 0.30 & 0.88 & 0.35 & 2.50 & 0.33 & 1.25 & 0.37 & 2.75 & 0.41 \\
\hline WEVI & 1.14 & 0.26 & 0.88 & 0.30 & 0.75 & 0.25 & 0.63 & 0.26 & 0.75 & 0.25 \\
\hline $\mathrm{YBCH}$ & 1.14 & 0.40 & 0.50 & 0.27 & 0.50 & 0.27 & 1.00 & 0.27 & 1.88 & 0.52 \\
\hline \multicolumn{11}{|l|}{ Generalist } \\
\hline AMCR & 0.43 & 0.20 & 0.63 & 0.26 & 0.25 & 0.16 & 0.13 & 0.13 & 0.75 & 0.37 \\
\hline AMRO & 2.00 & 0.31 & 1.63 & 0.32 & 1.25 & 0.16 & 2.00 & 0.27 & 1.00 & 0.33 \\
\hline BHCO & 0.86 & 0.26 & 1.13 & 0.23 & 0.75 & 0.25 & 0.75 & 0.37 & 0.75 & 0.16 \\
\hline BLJA & 0.86 & 0.26 & 1.00 & 0.27 & 0.13 & 0.13 & 1.50 & 0.27 & 0.38 & 0.26 \\
\hline CARW & 0.14 & 0.14 & 0.63 & 0.26 & 0.13 & 0.13 & 0.00 & 0.00 & 0.38 & 0.26 \\
\hline COGR & 0.00 & 0.00 & 0.13 & 0.13 & 0.00 & 0.00 & 0.00 & 0.00 & 0.00 & 0.00 \\
\hline EAKI & 0.00 & 0.00 & 0.00 & 0.00 & 0.38 & 0.26 & 0.00 & 0.00 & 0.00 & 0.00 \\
\hline EUST & 0.00 & 0.00 & 0.00 & 0.00 & 0.00 & 0.00 & 0.00 & 0.00 & 0.13 & 0.13 \\
\hline HOWR & 0.14 & 0.14 & 0.00 & 0.00 & 0.13 & 0.13 & 0.00 & 0.00 & 0.25 & 0.16 \\
\hline NOCA & 1.43 & 0.30 & 1.25 & 0.31 & 1.13 & 0.13 & 1.25 & 0.49 & 2.00 & 0.46 \\
\hline RWBL & 0.29 & 0.18 & 0.88 & 0.52 & 1.75 & 0.65 & 0.50 & 0.27 & 2.75 & 0.49 \\
\hline YWAR & 1.14 & 0.40 & 1.63 & 0.50 & 1.88 & 0.40 & 1.50 & 0.42 & 2.25 & 0.45 \\
\hline \multicolumn{11}{|c|}{ Forest (Interior or Edge) } \\
\hline AMRE & 0.00 & 0.00 & 0.25 & 0.16 & 0.00 & 0.00 & 0.00 & 0.00 & 0.00 & 0.00 \\
\hline BAOR & 0.14 & 0.14 & 0.50 & 0.19 & 0.13 & 0.13 & 0.13 & 0.13 & 0.25 & 0.25 \\
\hline $\mathrm{BBCU}$ & 0.00 & 0.00 & 0.13 & 0.13 & 0.00 & 0.00 & 0.13 & 0.13 & 0.00 & 0.00 \\
\hline
\end{tabular}




\begin{tabular}{lllllllllll} 
BGGN & 0.00 & 0.00 & 0.38 & 0.18 & 0.38 & 0.26 & 0.13 & 0.13 & 0.00 & 0.00 \\
BTNW & 0.00 & 0.00 & 0.13 & 0.13 & 0.00 & 0.00 & 0.00 & 0.00 & 0.00 & 0.00 \\
CACH & 0.57 & 0.30 & 0.63 & 0.38 & 0.25 & 0.16 & 0.63 & 0.32 & 0.50 & 0.27 \\
DOWO & 0.14 & 0.14 & 0.13 & 0.13 & 0.00 & 0.00 & 0.13 & 0.13 & 0.00 & 0.00 \\
EAWP & 0.00 & 0.00 & 0.00 & 0.00 & 0.13 & 0.13 & 0.00 & 0.00 & 0.00 & 0.00 \\
GCFL & 0.00 & 0.00 & 0.13 & 0.13 & 0.25 & 0.25 & 0.00 & 0.00 & 0.00 & 0.00 \\
HOWA & 0.29 & 0.29 & 0.25 & 0.16 & 0.00 & 0.00 & 0.25 & 0.25 & 0.00 & 0.00 \\
NOFL & 0.14 & 0.14 & 0.50 & 0.27 & 0.13 & 0.13 & 0.25 & 0.25 & 0.25 & 0.16 \\
OROR & 0.00 & 0.00 & 0.00 & 0.00 & 0.13 & 0.13 & 0.00 & 0.00 & 0.00 & 0.00 \\
OVEN & 0.29 & 0.18 & 0.50 & 0.27 & 0.00 & 0.00 & 0.38 & 0.26 & 0.00 & 0.00 \\
RBGR & 0.00 & 0.00 & 0.50 & 0.27 & 0.00 & 0.00 & 0.00 & 0.00 & 0.00 & 0.00 \\
RBNU & 0.14 & 0.14 & 0.13 & 0.13 & 0.00 & 0.00 & 0.00 & 0.00 & 0.13 & 0.13 \\
RBWO & 0.14 & 0.14 & 0.13 & 0.13 & 0.00 & 0.00 & 0.13 & 0.13 & 0.13 & 0.13 \\
RCKI & 0.00 & 0.00 & 0.13 & 0.13 & 0.13 & 0.13 & 0.00 & 0.00 & 0.00 & 0.00 \\
REVI & 0.57 & 0.30 & 0.38 & 0.18 & 0.13 & 0.13 & 0.25 & 0.16 & 0.13 & 0.13 \\
SCTA & 0.43 & 0.30 & 0.50 & 0.19 & 0.00 & 0.00 & 0.00 & 0.00 & 0.00 & 0.00 \\
TUTI & 0.00 & 0.00 & 0.13 & 0.13 & 0.50 & 0.27 & 0.25 & 0.16 & 0.00 & 0.00 \\
WBNU & 0.14 & 0.14 & 0.00 & 0.00 & 0.00 & 0.00 & 0.00 & 0.00 & 0.00 & 0.00 \\
WIFL & 0.14 & 0.14 & 0.13 & 0.13 & 1.38 & 0.53 & 0.13 & 0.13 & 0.63 & 0.26 \\
WOTH & 0.71 & 0.29 & 0.38 & 0.26 & 0.00 & 0.00 & 1.00 & 0.27 & 0.00 & 0.00 \\
YBCU & 0.00 & 0.00 & 0.00 & 0.00 & 0.00 & 0.00 & 0.13 & 0.13 & 0.00 & 0.00 \\
\hline
\end{tabular}

